\title{
BEYOND CULTURE: SUCCESS FACTORS FOR TRANSNATIONAL MULTIPARTY COLLABORATION
}

By

\section{James R. Hemsath}

Submitted in Partial Fulfillment of the Requirements

for the Degree of Doctor of Management

at the Weatherhead School of Management

Advisors:

Chris Laszlo, Ph.D.

Richard Boland, Jr., Ph.D.

Kathleen Buse, Ph.D.

Philip Cola, Ph.D.

CASE WESTERN RESERVE UNIVERSITY

April 2017 
(C) James R. Hemsath, 2017

All rights reserved. 


\section{DEDICATION}

This work is dedicated to those that have encouraged me, supported me, and told me to suck it up and get back to work.

First and foremost, this is dedicated to my best friend, love of my life, my wife Nancy. She supported me, provided me the space to work, poured me on the airplane late at night on Tuesdays and most importantly picked me up at the airport on Sunday.

To my children; Matthew, Adrienne and Joshua who cheered me on, read my papers and listened to my rants.

To Lori and Matt, the two best project managers I've ever worked with, who made sure I had time and managed work while I was gone and on more than one occasion were guinea pigs for things I had learned.

Finally, to Cohort 2017 who knew that my family would grow by 20 when I started this program. 


\section{ACKNOWLEDGMENTS}

To my subject matter advisor, Dr. Chris Laszlo-you kept putting new ideas in front of me an encouraged me to think bigger than I thought I could, but most importantly you believed in me and that made all the difference, when I grow up I want to be you. To Dr. Dick Boland and Dr. Bo Carlsson for the ongoing feedback, advice and guidance - always reading what I wrote and never laughing (in front of me). To the great research team, who pushed and prodded and gave the best feedback ever, there is no way I could have done the research this report describes without you. Dr. Kalle Lyytinen, Dr. Kathy Buse, Dr. Phil Cola, Dr. Yunmei Wang, Dr. Gene Pierce and Dr. Stephan Liozu. And most importantly, my thanks to Sue Nartker, Marilyn Chorman and Shelley Muchnicki - this program would not run without you; you are the best.

If you want to build a ship, don't drum up people to collect wood and don't assign them tasks and work, but rather teach them to long for the endless immensity of the sea. - Antoine de Saint-Exupery

Thank you all for teaching me to long for that sea. 


\section{TABLE OF CONTENTS}

\section{BEYOND CULTURE: SUCCESS FACTORS FOR TRANSNATIONAL}

MULTIPARTY COLLABORATION ……..................................................................... 1

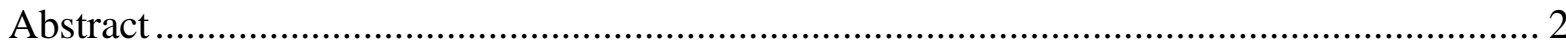

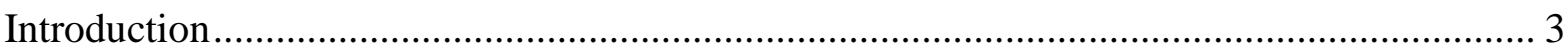

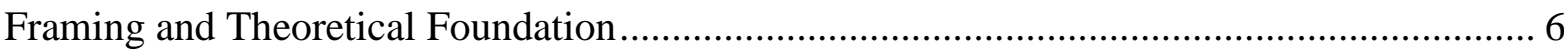

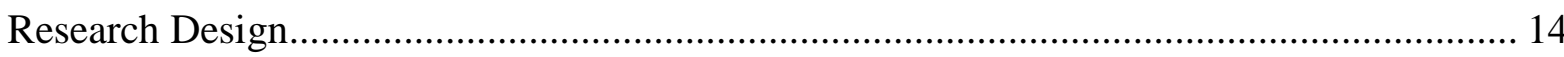

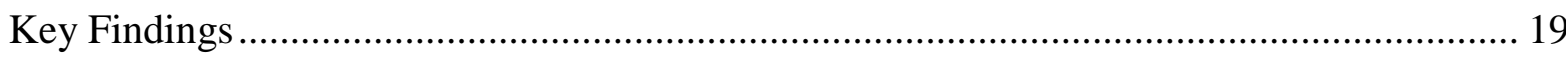

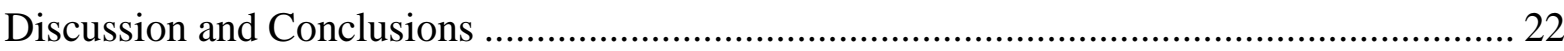

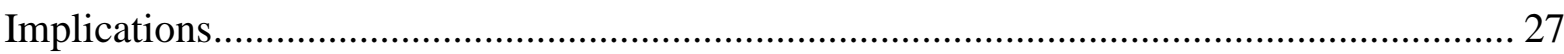

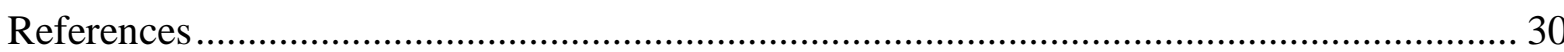

List of Figures

Figure 1: Theoretical Framing of Multiparty Transnational Collaboration....................... 7

Figure 2: Sequential Exploratory Mixed Method Approach .......................................... 16

Figure 3: Final Structural Equation Model ..................................................................... 20

Figure 4: Systems View of Multiparty Transnational Collaboration................................. 25

LOOKING BEYOND CULTURE: BUILDING SUCCESSFUL MULTIPARTY

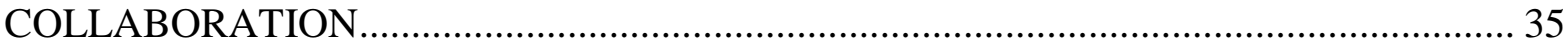

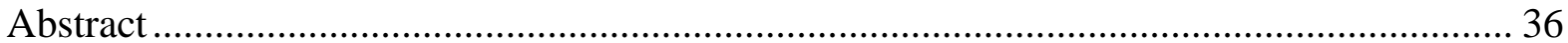

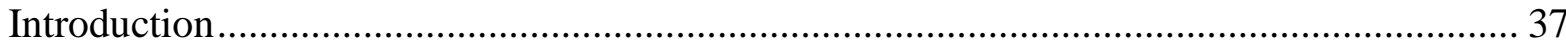

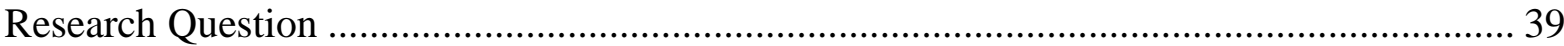

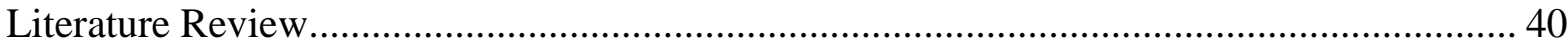

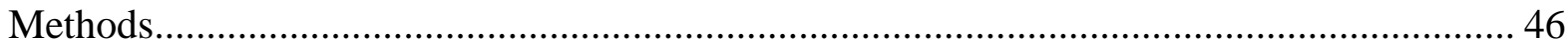

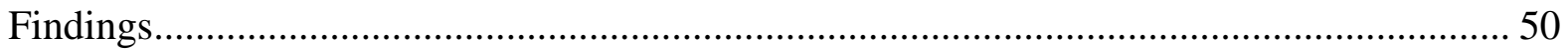

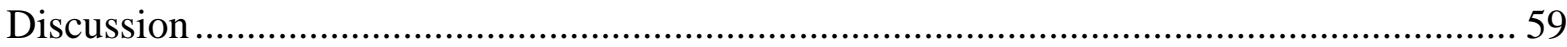

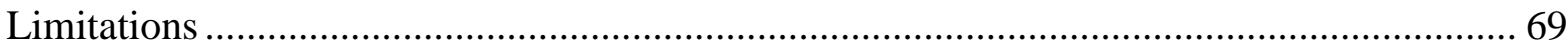

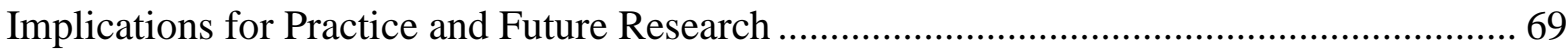

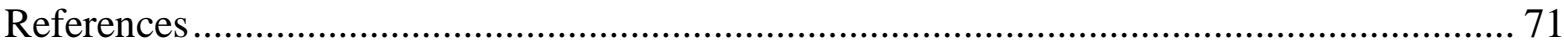

List of Tables

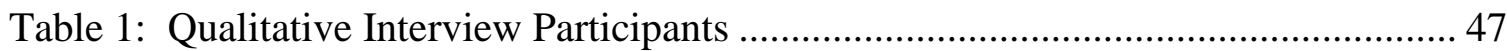

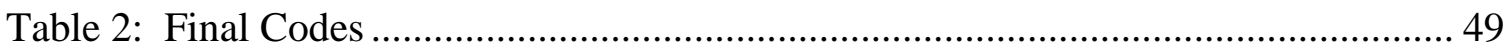

List of Figures

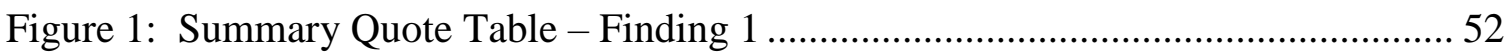




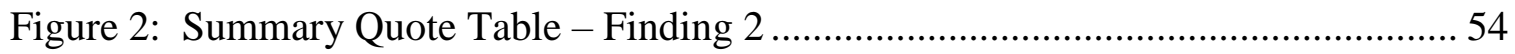

Figure 3: Summary Quote Table - Finding 3 ...................................................... 57

Figure 4: Summary Quote Table - Finding 4 ....................................................... 59

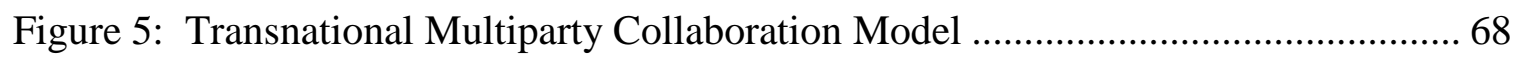

TRANSNATIONAL MULTIPARTY COLLABORATION: DETERMINING

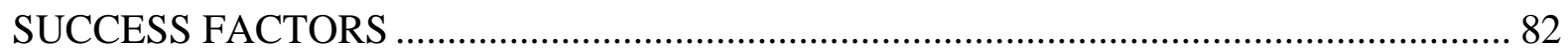

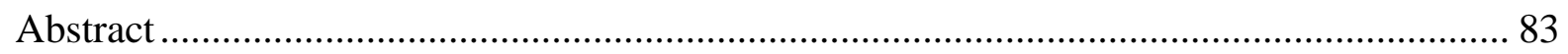

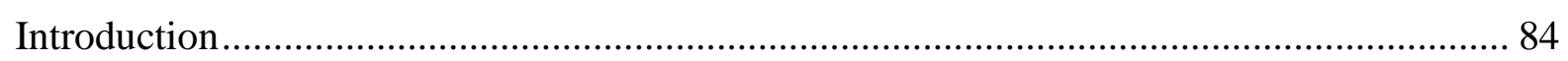

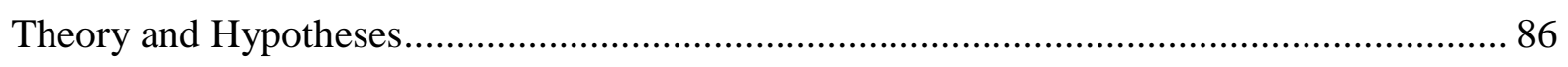

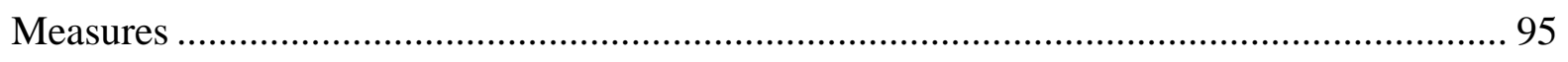

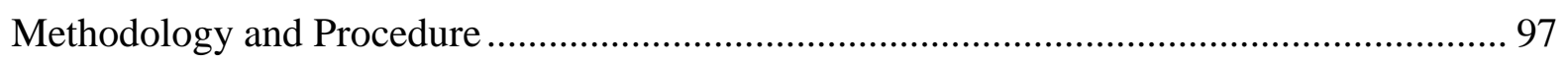

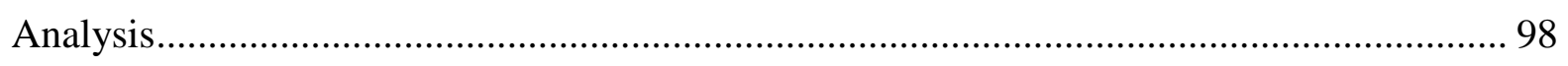

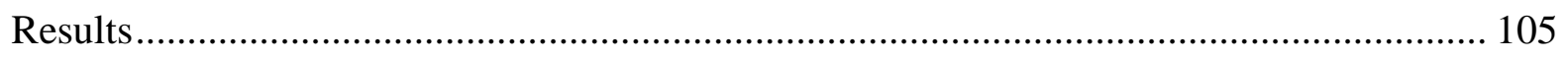

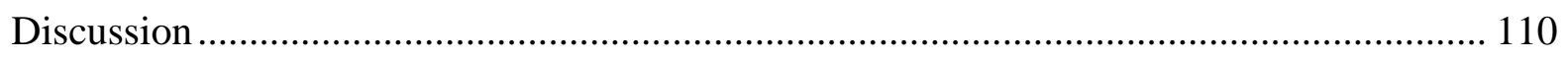

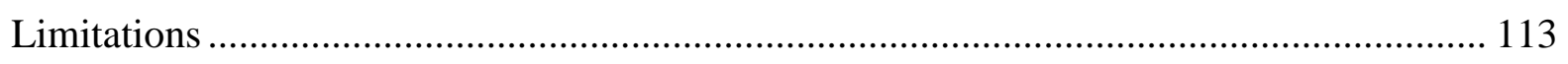

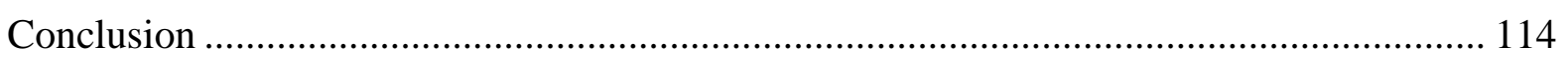

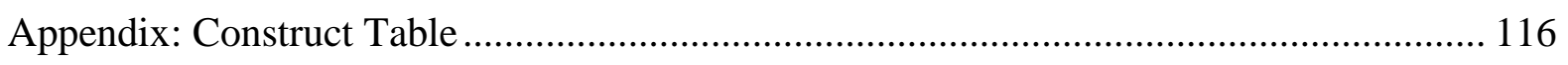

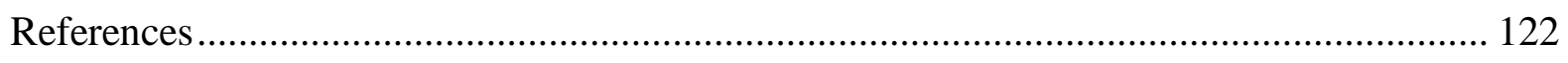

List of Tables

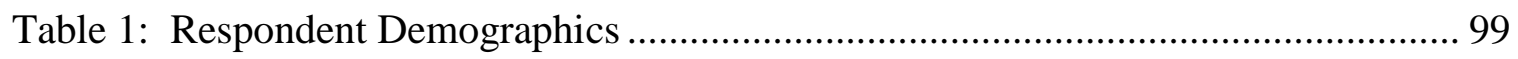

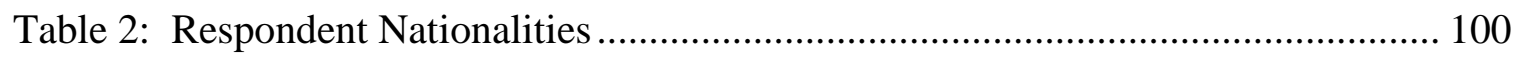

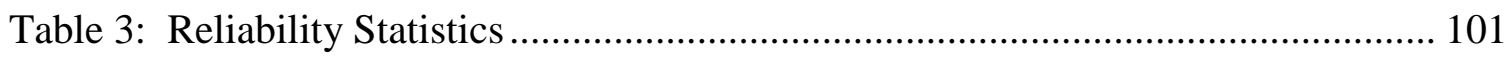

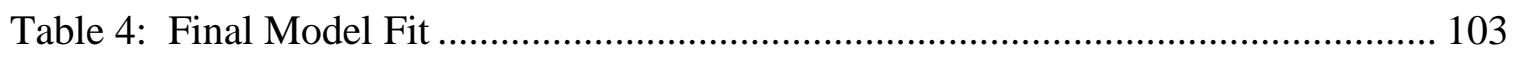

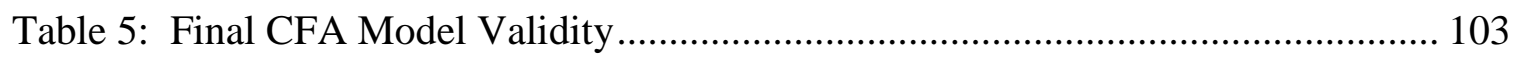

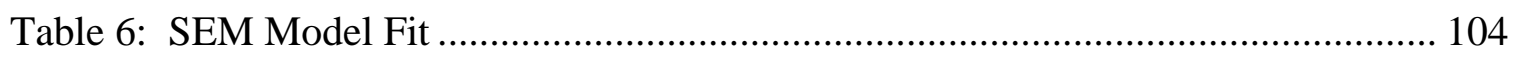

Table 7: Standardized Regression Weights and Associated P-Values ......................... 106

Table 8: Hypothesis Summary Table ........................................................................ 108

List of Figures

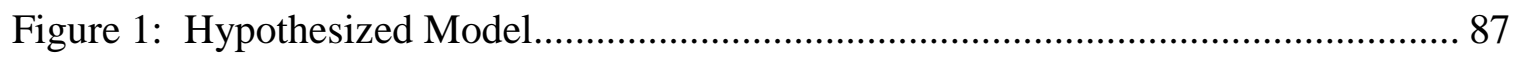

Figure 2: Final Structural Equation Model (SEM) ................................................ 106 


\title{
BEYOND CULTURE: SUCCESS FACTORS FOR TRANSNATIONAL MULTIPARTY COLLABORATION
}

\author{
By
}

\section{James R. Hemsath}

Submitted in Partial Fulfillment of the Requirements for the Integrative Paper in the Doctor of Management

at the Weatherhead School of Management

Advisors:

Chris Laszlo, Ph.D.

Richard Boland, Jr., Ph.D.

Kathleen Buse, Ph.D.

Philip Cola, Ph.D.

CASE WESTERN RESERVE UNIVERSITY

April 2017 


\title{
BEYOND CULTURE: SUCCESS FACTORS FOR TRANSNATIONAL MULTIPARTY COLLABORATION
}

\begin{abstract}
The complexities of global business require rapid and effective responses across borders. These demand an understanding of factors that influence success with transnational multiparty collaboration. Core issues for collaboration in such settings include: 1) understanding the role that culture and identity play in creating a fused individual and organizational identity; 2) development of strong connectedness between parties; and 3) creation of shared vision. This thesis reports on a mixed methods research study which involved the use of qualitative data gathered through interviews with business professional's experience on transnational multiparty projects and quantitative data gathered through surveys representing eleven national/cultural sectors. Our findings show: 1) as differences in culture can be a show-stopper, energy must be expended for active management and awareness of cultural differences; 2) collaborative environment is created through empathy and trust that acknowledges Identity (role and individual) and 3) the significance of an inclusive process of creating a shared vision. We apply a systems approach to understand the role of various components that interact in generating a collaborative space. We approach collaboration as an emergent process created when all three elements are present and interact.
\end{abstract}

Keywords: collaboration; multiparty; identity; culture; transnational; interconnectedness; empathy; trust; shared vision 


\section{INTRODUCTION}

There is a truism about working in Alaska published in1895 in the Alaskan Mining Journal-“The road is long, supplies are costly, seasons are short, fortune is fickle." This, in a nutshell, defines what is like to do business and perhaps, even more importantly, to construct infrastructures in the High North. The distance material and supplies travel is long, the location of these projects (especially natural resource projects) is far from population centers. The cost of these supplies is high both from a transportation perspective as well as a design perspective due to the harsh climate. The time to move products tends to be short (summer months only), and like any business the economics can change in a heartbeat, leaving the project heavily in debt. Climate change is opening up new shipping lanes while at the same time it has increased the severity of winter storms and generated erosion that threatens old communities (Alaska Sea Grant Marine Advisory Program, n.d.). The Arctic, endowed with a quarter of the world's oil and gas reserves (Bird et al., 2008) and the current ability to shorten the shipping distances by half (Greenert, 2014) from Europe to Asia and the United States, is poised to be the next significant global arena. To support this development, significant investments in infrastructure (Allianz Global Corporate \& Specialty SE, 2014) are necessary at a level that exceeds any one locale's or region's investment ability.

How can this development be accomplished? Diversifying risks will require groups from different regions and different countries to invest and participate in projects in conjunction with the indigenous peoples of the North. The problems being tackled are complex and simple cooperation will not be sufficient — true collaboration, where individuals and organizations build on the strengths of all parties will be the only way forward in these situations. Such multiparty collaborations need to consider both the technical complexities of 
the projects as well as the complex social and cultural issues brought to bear by the public and private authorities, technical experts, and social interest groups involved in the projects. This adds the challenge to manage cultural diversity, recognize cultural differences, and work effectively through cross-cultural conflicts - common challenges within cross-cultural teams (Congden, Matveev, \& Desplaces, 2009; Marquardt \& Horvath, 2014). In such situation: "Participation is not merely an instrument, but a complex system of structure and processes" (Bouwen \& Taillieu, 2004: 138). Understanding the motivations, drivers, intergroup characteristics, and inter-organizational dynamics of collaboration is thus critical in improving multiparty collaboration in diverse cultural settings (Prins, 2010).

In companies that operate globally, team performance often becomes vulnerable to cross-cultural effects (Congden et al., 2009; Matveev \& Nelson, 2004). Managing cultural diversity, recognizing cultural differences, and managing effectively cross-cultural conflicts have surfaced as frequent challenges for cross-cultural teams (Congden et al., 2009; Marquardt \& Horvath, 2014). However, the extant literature does not extensively discuss factors that influence the success of cross-cultural collaboration. A bulk of the discussion centers on innovation around technical issues or the creation of arenas where innovation can take place or what some term as "districts" (Katz \& Wagner, 2014) within the context of constant change. References to "transnational" in articles related to innovation focus on the needs of diverse teams to foster innovation rather than how to contribute to innovation across borders (Bouncken \& Winkler, 2010; Edmondson, 2012a).

What is not clearly understood in the pertinent literature is how the combination of transnational and cross-cultural projects are likely to complicate collaboration. The problem of practice here encompasses a broad mix of subjects including collaboration, the effect of 
multiple parties and working cross-borders as well as cultural effects. This combination of factors is highly complex in that it could be considered a wicked problem. One of the key features of a wicked problem is that there is no single "solution" to the problem. Collaboration, by its very nature - where individuals or organizations seek to find a way to build on the strengths of all parties - is possibly the only approach to follow in these situations. Therefore, in an effort to understand factors influencing collaborative success in diverse cultural settings involving multi-party collaboration we seek to explore the antecedents and consequences of such collaboration at an individual level.

Due to the complexity of the problem, we will follow a mixed methods approach. In particular, we explore factors which can curb or facilitate collaboration in projects that are made up of multiple parties (entities) each of which entering to project with specific motivation and where parties originate from multiple nationalities and cultures. The research goal is to identify and understand how a variety of factors such as culture, identity, interconnectedness, trust, empathy, shared vision facilitate collaboration in such settings. In particular, we address the following research questions (RQ):

RQ1: What factors explain successful transnational, cross-cultural multiparty collaboration?

RQ2: What role do culture, cultural intelligence, and identity and role identity play in facilitating multi-party collaboration in cross-border settings involving multiple cultures?

RQ3: What are the relationships between empathy, trust and shared vision as they influence collaboration? 
RQ4: How can these factors be combined into an impactful model of cross-cultural collaboration?

We integrated our research results related to these questions by triangulating both qualitative and quantitative data. We generally find that the relationships between shared vision and collaboration are more nuanced than expected and that role and individual identities influence shared vision and collaboration in distinct ways. Long ago the value of Arctic transportation was recognized as a way to shorten distances and cost of moving goods and services (Nansen, 1914). This research assumes that this old idea is finally coming to fruition if the North can act as a model of cooperation in the international trade arena (Nansen, 1923) and also push for the advancement of human knowledge (Emmerson, 2010). Collaboration, working across borders in transnational teams to provide a better life for the people of the North, is at the heart of this research.

\section{FRAMING AND THEORETICAL FOUNDATION}

The literature discusses some aspect of multiple parties' ability to collaborate (multiparty collaboration), how culture and cultural intelligence impact this ability, the role which individual and group identity play in this process. The literature also shows the importance of shared vision, empathy, interconnectedness, and trust as conditions for more effective multiparty collaboration. Figure 1 integrates these topics and anchors them in three theories: Intentional Change Theory, which defines how individuals and groups can effectively work together based on shared vision, interconnectedness, empathy and trust; Social Identity Theory which grounds our analysis of identity both at the individual, role and group level; and Cultural Intelligence Theory which helps us understand the role and impact of culture as people from different cultures collaborate. This section is organized by the key 
theoretical anchors, and then the facilitating factors of trust, empathy, interconnectedness and shared vision are discussed. Finally, we will review some of the key literature on collaboration and multiparty collaboration.

\section{FIGURE 1 \\ Theoretical Framing of Multiparty Transnational Collaboration}

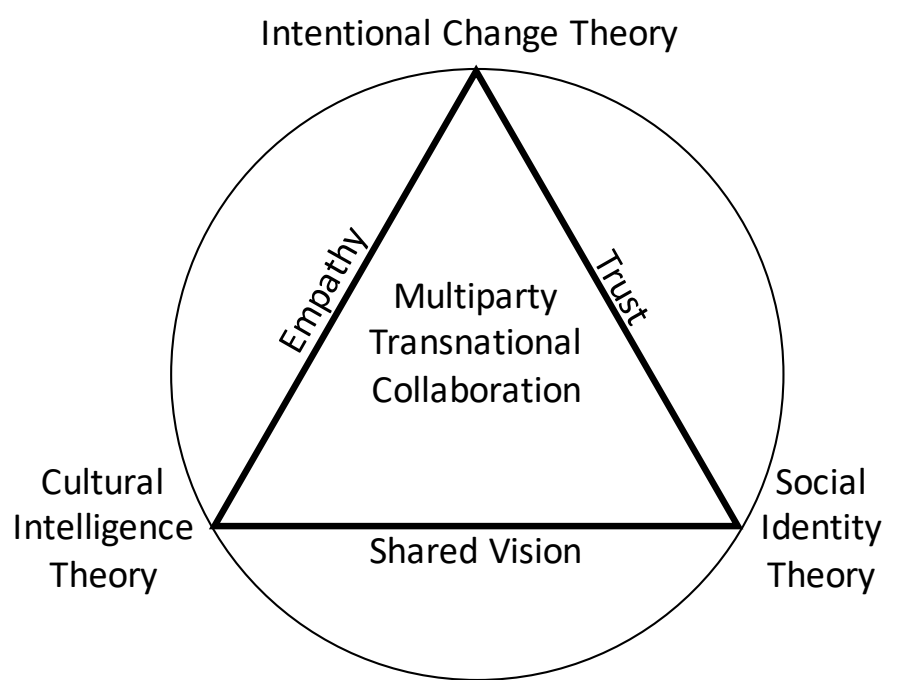

\section{Cultural Intelligence Theory}

Culture and cultural influences have been studied in a variety of settings; in discussions on collaboration across borders and cultures businesses need to be aware of aspects of culture and the influence it plays- either in monocultural or diverse cultural settings. The challenge in managing multicultural teams effectively is to recognize the underlying cultural causes of conflict and to intervene to get the team back on track (Brett, Behfar, \& Kern, 2006).

The theory of Cultural Intelligence (CQ) is comprised of an individual's capability to function and manage effectively in culturally diverse settings based on multiple facets including cognitive, motivational and behavioral features (Van Dyne et al., 2012)(Earley, 
2002). This theory posits that the greater an individual's CQ, the more likely they will be successful in developing relations with someone from a different culture. Cultural intelligence: an outsider's seemingly natural ability to interpret someone's unfamiliar and ambiguous gestures the way that person's compatriots would and is related to emotional intelligence, but it picks up where emotional intelligence leaves off (Earley \& Mosakowski, 2004). CQ has been used as a moderator in studies on transformational leadership (Bass, 1985) and organizational innovation (Elenkov \& Manev, 2009).

In any discussion on working in a cross-cultural environment the work of Hofstede is generally invoked (Chanlat, Davel, \& Dupuis, 2013; Lakshman, 2013; Ronen \& Shenkar, 2013) or references to Project Globe (Brewer \& Venaik, 2010; Brodbeck, Hanges, Dickson, Gupta, \& Dorfman, 2004; Hofstede, 2010). The intent of this work was to identify broad cultural dimensions (e.g., individualism vs. collectivism; power distance, uncertainty avoidance) that then was tied to national cultures. In knowing what the differences were between nationalities individuals or even organizations all would be better prepared to work in that environment. This work is based on large groups not individuals, "Cultures are not king-size individuals, they are wholes, and their internal logic cannot be understood in the terms used for the personality dynamics of individuals" (Hofstede, 2010: 1340). Hofstede's work tends toward the dyadic as well, looking that the differences between one culture and another. Finally, it is a static approach that does not fit the dynamic situation of a group or team coming together for the purposes of a special project all with differing roles and responsibilities. 


\section{Social Identity Theory (Individual and Role)}

Social Identity Theory refers to a person's knowledge that they belong to a certain social group that has significance and meaning to them. Principles of the theory include: 1) people work to achieve and maintain a positive social identity; 2) positive social identity is based on favorable comparisons made among groups to which a person belongs; and 3) if social identity is unsatisfactory, then people strive to leave their current groups for one more favorable (Tajfel \& Turner, 1979). Identity can be defined person or individual's perception of who they are and what they represent (self-identity) as well as those groups or organizations they might be associated with (role). It is important to separate the concept of culture, defined as a shared way of life of a group of socially interacting people, transmitted from one generation to the next via acculturation and socialization processes (Ronen \& Shenkar, 2013), from identity; the individual's perception of who they are and what they represent. Culture are those norms, beliefs (religions) that distinguish a group of people, typically around national boundaries and are generally fixed and represent how people communicate and work together. Identity can change and develop depending on the situation. We would also separate organization or team culture from this definition as well, while those cultures too are about communication and getting things done; they tend to be transient in nature and do not have the generations of tradition that have helped form those cultures. Chevrier (2003) refers to the ability to create a project culture, while identity is a better word; the sentiment of being able to build on the strengths of individual identities and create a meta-identity is valid: "If the leaders of international project teams cannot draw upon shared national cultures, they may resort to other international cultures such as professional or corporate cultures to federate participants" (Chevrier, 2003: 147). 
Transnational multiparty teams have two identities that they need to 'work' with. The first is the identity of the organization they represent and the second is their individual identity. Both of these identities need to be accommodated. The former is more defined in terms of mission and objectives, while the second is one that can be more easily built on and would be open to a form of alignment known as Identity Fusion. Identity fusion is an "unexplored form of alignment that entails a visceral feeling oneness with the group" (Swann, Jetten, Gómez, Whitehouse, \& Bastian, 2012). This feeling of oneness is associated with "increased permeability of the boundary between the personal and social self," which can lead to increased likelihood that "individual identity will influence group identity and vice versa" (Swann et al., 2012). This alignment or fusion is a goal to aspire to in multiparty transnational collaborations; however, there is danger in becoming too group centric where unanimity is expected (group think, Hayes, 1997: 136) and discension discouraged. This lack of discussion and openness could be detrimental to collaboration. This alignment is intended to create a strong identity, that may take precedence over individual identity, but not to supplant it. "Highly fused leaders may remain highly committed to the group while exercising their individual agency to steer the group in new directions" (Swann et al., 2012: 11)

\section{Intentional Change Theory}

Intentional change theory (ICT) posits that positive, energizing relationships are not only critical in supporting change, but they involve a sense of a group identity which builds up a shared vision for the group (Boyatzis \& Akrivou, 2006). "For many years practitioners and academics alike have argued that the creation of a vision, be it at an individual, team or organizational level, motivates people to action and inspires them to reach beyond their 
current state" (Boyatzis, Rochford, \& Taylor, 2015: 1). The context of our research into transnational multiparty collaboration is, in a very specific sense, about changing the ways projects are done in the Arctic. In a world of continuous and rapid change, the capacity to sense and actualize emergent realities, that are perceived as the most attractive and compelling alternatives of the future is considered the most critical source of creating a better future (Kaiser, Feldhusen, \& Fordinal, 2013), this statement best describes the motivation of a group creating a shared vision. ICT looks towards the ideal self - this ideal self, drives the personal vision which, in turn, drives sustainable, intentional change. Similarly, we believe collective, shared desired images of the future, shared hope, and shared sense of a group's identity and distinctiveness, in the same way, become the shared vision that drives sustainable, intentional change at these other levels of human and social organization (Boyatzis \& Akrivou, 2006).

In order to facilitate a shared vision between the different parties, some level of connectedness must take place some action of connecting with each other on a personal level creating a degree of "interconnectedness" where trust is established and a degree of becoming embedded in an organizational structure (Edmondson \& Nembhard, 2009). We suggest that to arrive at this level of connectedness is necessary to allow different parties need to understand each other's culture and acknowledge that as individuals they also have a role to play in representing the identities of their organizations. To arrive at this level of connectedness will require the development of a level of Empathy and Trust as components of the process called transnational multiparty collaboration. The ability of an individual to be able to empathize with another person's role identity or other structural constraints on their ability to participate in a certain will allow both parties to find alternate solutions a key 
aspect of collaboration. Empathy can be defined as the "reactions of one individual to the observed experiences of another" (Davis, 1983). Ruben (1976) defines cultural empathy as "the capacity to clearly project an interest in others, as well as to obtain and to reflect a reasonably complete and accurate sense of another's thoughts, feelings, and/or experiences." Trust is defined as the willingness of a party to be vulnerable to the actions of another party based on the expectation that the other will perform a particular action important to the person who must trust them, irrespective of the ability to monitor or control that other party (Mayer, Davis, \& Schoorman, 1995). It has been suggested that trust and shared vision are important "determinants" or properties necessary for relationships that facilitate value creation and resource exchange to take place (Li, 2004: 78). Supporting and trusting relationships are the fulcrum that allows the change to take place (Van Oosten, 2006). As the level of trust and empathy increase it creates and environment where relationships are built that "facilitate the movement through discovery that brings about purposeful change" (Boyatzis \& Akrivou, 2006). Shared vision, empathy and trust derivatives of Intentional Change Theory are what create the environment in which multiparty collaboration can take place.

\section{Multiparty Collaboration}

Multiparty Collaboration by its very definition involves a wide variety of public and private authorities, technical experts, and social interest groups all viewed as stakeholders in working towards a shared goals (Prins \& Bouwen, 2003). But bringing together these different parties does not necessarily require collaboration, just adequate negotiations where there will be winners and losers. From a transnational perspective, this is not sufficient you cannot have winners and losers in a transnational effort where the point of the effort was to 
bring these groups together, they cannot be forced, they will simply not participate. Collaboration is a process of two or more people or organizations work together to realize shared goals. Inherent in this process is that the whole is greater than the sum and it is this level of interaction that we seek. It is at the heart of our research as articulated in our research questions: What factors explain successful transnational, cross-cultural multiparty collaboration? What role do culture, cultural intelligence, and identity and role identity play in facilitating multi-party collaboration in cross-border settings involving multiple cultures? What are the relationships between empathy, trust and shared vision as they influence collaboration?

The theories described above, literally and figuratively (Fig 1) frame our research question on multiparty transnational collaboration. Consider the following as examples of our $\mathrm{RQ}(\mathrm{s})$. "Meaningful involvement (ICT) requires several conditions: (a) people should experience participation on an issue as feasible and realistic based on the task (shared vision), (b) the boundaries and the limits of the people's authority and decision-making scope should be clearly defined and mutually accepted (Social Identity Theory, Cultural Intelligence), (c) participation thrives only in a climate of openness and trust (connectedness, empathy, trust). Defined this way participation is not merely an instrument, but a complex system of structure and processes" (Bouwen \& Taillieu, 2004: 138).

Multiparty collaboration at this scale will not have a single optimal solution; it is a complex problem (ICT), where the dynamic of collaboration is important including elements of negotiation. Especially in looking at such processes as 3-D Negotiations (Lax \& Sebenius, 2003; Lax \& Sebenius, 2006) where the emphasis of the process is on creating joint value and focusing on scope and sequence of tasks rather than making deals across the table (ICT, 
SIT). In the arena of cross-border negotiations, the emphasis on collaboration should not be on working on cultural differences but rather on how people across regions can come to agreement specifically concerning decision-making and governance of the process $(C I T)$ (Sebenius, 2002).

\section{RESEARCH DESIGN}

The intent of the research program was to explore what constitutes successful projects when the members of the project "teams" came from different nationalities and cultures. Complicating this exploration, we wanted to have the conversation about what it was like to work with team members that do not share your organization's mission. Perhaps, most importantly, we wanted to find out how the different roles contribute to true collaboration (vs. cooperation) on a project. In order to understand and discern how such factors work together a sequential exploratory mixed method approach (QUAL $\rightarrow$ QUAN $\rightarrow$ QUAL) (Creswell \& Clark, 2011: 86-90) was adopted. The approach combines elements of qualitative and quantitative strands to 1) identify factors that facilitate collaboration across borders and with multiple parties; 2) provide quantitative and statistical verification of potential causal connection between these facilitating factors and collaboration levels and 3) test and develop a methodology for practitioners to be successful in such projects. Mixed methods research is sometimes considered the third way of research that is neither qualitative (grounded theory) nor quantitative (surveys, statistical analysis) but involves a blended approach "working primarily within the pragmatist paradigm and interested in both the narrative and numeric data and their analyses (Teddlie \& Tashakkori, 2009). Mixed Methods Analysis is thus well suited to a research project where the research question evolves from initial observations of the practice to theory informed more rigorous models. Mixed methods 
research offers a systematic integration of quantitative and qualitative methods within a single study for the purpose of obtaining a fuller and deeper understanding of the phenomenon (Johnson, Onwuegbuzie, \& Turner, 2007). Using a Mixed Methods allows us to explore the problem of practice and related questions in a sequential manner; first obtaining a broad brush understanding of the problem and its setting and then drilling deeper and deeper into cause-effect relationships.

The first phase of our research was a qualitative inquiry which used grounded theory approach to analyze the lived experience of individuals who currently work with multiple parties on cross-border projects. Based on our qualitative findings, our first point of integration was the development causal model that seeks to articulate factors that influence multiparty collaboration from the practitioner's perspective. The suggested a hypothesized model was identified and the relationships of the antecedents in facilitating collaborative success were tested. The hypothesized model was used to generate a series of survey questions to collect data from a larger population to determine what statistical correlation exist between identified factors and collaboration success. We also examined the possible mediating effect that Shared Vision would have on Collaboration and the moderating effects of Culture would have on Empathy and Trust. Our point of integration at the end of this phase was the examination of our hypotheses concerning multiparty transnational collaboration using a structural equation model (SEM). In order to a) validate the findings and the model and b) help develop a comprehensive approach that can be used in other projects, we recommend that a third phase be conducted in the future. We suggest that an Action Research technique would be appropriate, working with a group of business 
practitioners who are engaged in projects that take place across borders and cultures. This

will be further defined in the Discussion section.

Our overall research program is shown in Figure 2.

FIGURE 2

\section{Sequential Exploratory Mixed Method Approach}

\begin{tabular}{|c|c|c|c|}
\hline & Research Question & Method & Finding \\
\hline 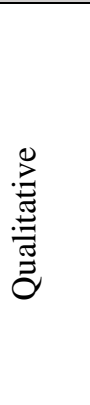 & $\begin{array}{l}\text { What factors help explain } \\
\text { successful transnational, cross- } \\
\text { cultural multiparty collaboration } \\
\text { (RQ1)? }\end{array}$ & $\begin{array}{l}\text { In-depth semi-structured } \\
\text { interviews with } 27 \\
\text { participants } \\
\text { Coding and thematic } \\
\text { analysis }\end{array}$ & $\begin{array}{l}\text { - Culture as a dissatisfier } \\
\text { - Identity plays larger role than } \\
\text { culture } \\
\text { - Interconnectedness between } \\
\text { parties will impact success } \\
\text { - Successful projects combine } \\
\text { shared vision, agreement on } \\
\text { common goals and an } \\
\text { appreciation of a greater } \\
\text { purpose }\end{array}$ \\
\hline : & $\begin{array}{l}\text { What role does culture, cultural } \\
\text { intelligence and identity play in } \\
\text { the facilitation of multiple parties } \\
\text { working across borders and } \\
\text { cultures (RQ2)? } \\
\text { What are the relationships } \\
\text { between connectedness, empathy, } \\
\text { trust and shared vision as they } \\
\text { relate to collaboration (RQ3)? }\end{array}$ & $\begin{array}{l}\text { Develop model \& } \\
\text { hypotheses } \\
\text { Instrument development } \\
\& \text { testing } \\
\text { Cross-sectional on-line } \\
\text { survey of } 287 \\
\text { participants } \\
\text { Representing } 11 \\
\text { national/culture sectors }\end{array}$ & $\begin{array}{l}\text { Balance differing perspectives } \\
\text { and approaches in creating a } \\
\text { shared vision in order-to allow } \\
\text { for the development of } \\
\text { collaborative solutions } \\
\text { - Allow all parties the opportunity } \\
\text { to develop trust in the relations } \\
\text { and develop a sense of empathy } \\
\text { for the differing roles that are } \\
\text { being played on the project } \\
\text { The success of a cross-border } \\
\text { project is both dependent on } \\
\text { understanding cultural needs } \\
\text { and perspectives in addition to } \\
\text { other actions }\end{array}$ \\
\hline 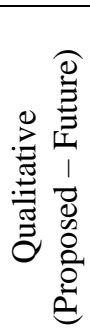 & $\begin{array}{l}\text { What are the relationships } \\
\text { between connectedness, empathy, } \\
\text { trust and shared vision as they } \\
\text { relate to collaboration (RQ3)? } \\
\text { How can these factors be } \\
\text { developed into a useful working } \\
\text { model (RQ4)? }\end{array}$ & $\begin{array}{l}\text { Participatory Action } \\
\text { Research } \\
50 \text { Participants } \\
\text { Future }\end{array}$ & - Not available at this time \\
\hline
\end{tabular}




\section{Phase 1 - QUALITATIVE}

In total, 27 interviews representing seven countries and five indigenous populations

from business, military, finance, NGO and trade organizations from the US, Canada, Finland, Norway, Iceland, Singapore, Denmark, and four Indigenous populations were collected. The project sample represented various age groups, backgrounds, and a variety of different projects located predominantly in Arctic countries as well as Singapore and participants were composed of 24 men and 4 women, age 35 to 65. Data was collected between March and September 2015. Semi-structured interviews were between 60 and 120 minutes, guided by an interview protocol with an occasional prompt for clarity, asking the following two questions:

1. Tell me about an experience you had where you were involved working across borders on a project that went well.

2. Tell me about an experience you had where you were involved working across borders on a project that had difficulties.

One interviewee asked to stop the interview part way through the process. The twenty-seven remaining interviews, totaling approximately 30 hours of conversation and 484 pages (single space) of transcripts, were analyzed. Approximately 850 open codes were identified, and then through the process of axial coding and selective coding, ten categories were developed.

"If qualitative research is to be judged by whether it produces valid knowledge, then we should properly ask highly critical question about any piece or research. And these questions should be no less probing and critical than we ask about any quantitative research study" (Silverman, 2014: 79). In Phase 1 (QUAL strand), interviewees were selected based on experience, national origin to assure that there was both experience as it related to working in cross-border situations and diversity in the sample. The findings were consistent 
across interviews and were consistent with management theory, which assures that the factors that will be integrated into the next phase have validity. To assure reliability in this qualitative phase, interviews were all conducted using the same script and using the same questions and the same and similar prompts. Coding of the transcripts used of the NVivo software which allowed the establishment of a code table providing consistency and reliability in the coding.

\section{Phase 2 - QUANTITATIVE}

Based on the findings from phase 1, we next examine the body of knowledge related to collaboration in a much more detailed. A hypothesized model was developed resulting in the identification of seven constructs influencing collaboration-Role Identity, Individual Identity, Cultural Intelligence, Empathy, and Trust were all used as independent variables while Shared Vision and Collaboration were used as Dependent Variables. A survey instrument was created for each construct with Liker-scales. Additional controls for Nationality, Age, Gender, Current Occupation (experience), Education and Sector (public, private, academic and NGO) were included. The sample population consisted of a cascading randomized sample of respondents with work experience in the Arctic. The sample was made up of the eight arctic nations. The survey was sent via email to approximately 2000 participants located in or working in the Arctic or working on Arctic projects. The survey was conducted between October and November 2016. The final sample consisted 300 participants that represented eleven national/cultural sectors - 63\% representing as Anglo, 12\% Nordic European and 7.5\% Indigenous. All data demonstrated statistical reliability and both convergent and divergent validity. 


\section{KEY FINDINGS}

\section{Qualitative}

Ten categories were developed which led to the following four key findings:

Finding 1: Differences in cultures need to be acknowledged, respected and managed but once they are accommodated they have no additional impact on collaboration and completion of the project/work.

Finding 2: Identity can cross borders and while dependent on culture plays a stronger role than national cultures.

Finding 3: The degree of connectedness or interconnectedness between parties will impact its success. Successful projects shared the attribute of connecting with the people and parties you were working with, the culture you are working in (and in part connecting with the identity of those parties).

Finding 4: Successful projects working across borders and with multiple parties combine the characteristics of sharing a vision of what is being done, agreement on a set of common goals and an appreciation of a greater purpose.

\section{Quantitative}

Statistical analysis resulting in the structural equation model shown in Figure 3

provide the following key findings.

1. In the development of a team or project vision or mission statement, it is important that it not used to submerge differing perspectives and approachesone needs to allow for the development of collaborative solutions.

2. Time must be spent to allow all parties the opportunity to develop trust and more importantly to develop a sense of empathy for the differing roles that are being played on the project.

3. The success of a cross-border project is not only dependent on understanding cultural needs and perspectives. It is important to do so, but the success of the project is dependent on other actions.

It is reasonable to assume that shared vision would act as an antecedent for collaboration; however, this was not born out in the data that was collected, and Figure 3 
represents Shared Vision as dependent variable. The $\mathrm{R}^{2}$, as shown in the model, represents the amount of variation that is explained by the independent variables; for Shared Vision $\mathrm{R}^{2}$ $=0.20$ and Collaboration $R^{2}=0.21$. Shared Vision being impacted by Group Identity,

Empathy and Trust while Collaboration is influenced by Individual Identity, Empathy and Trust.

FIGURE 3

Final Structural Equation Model

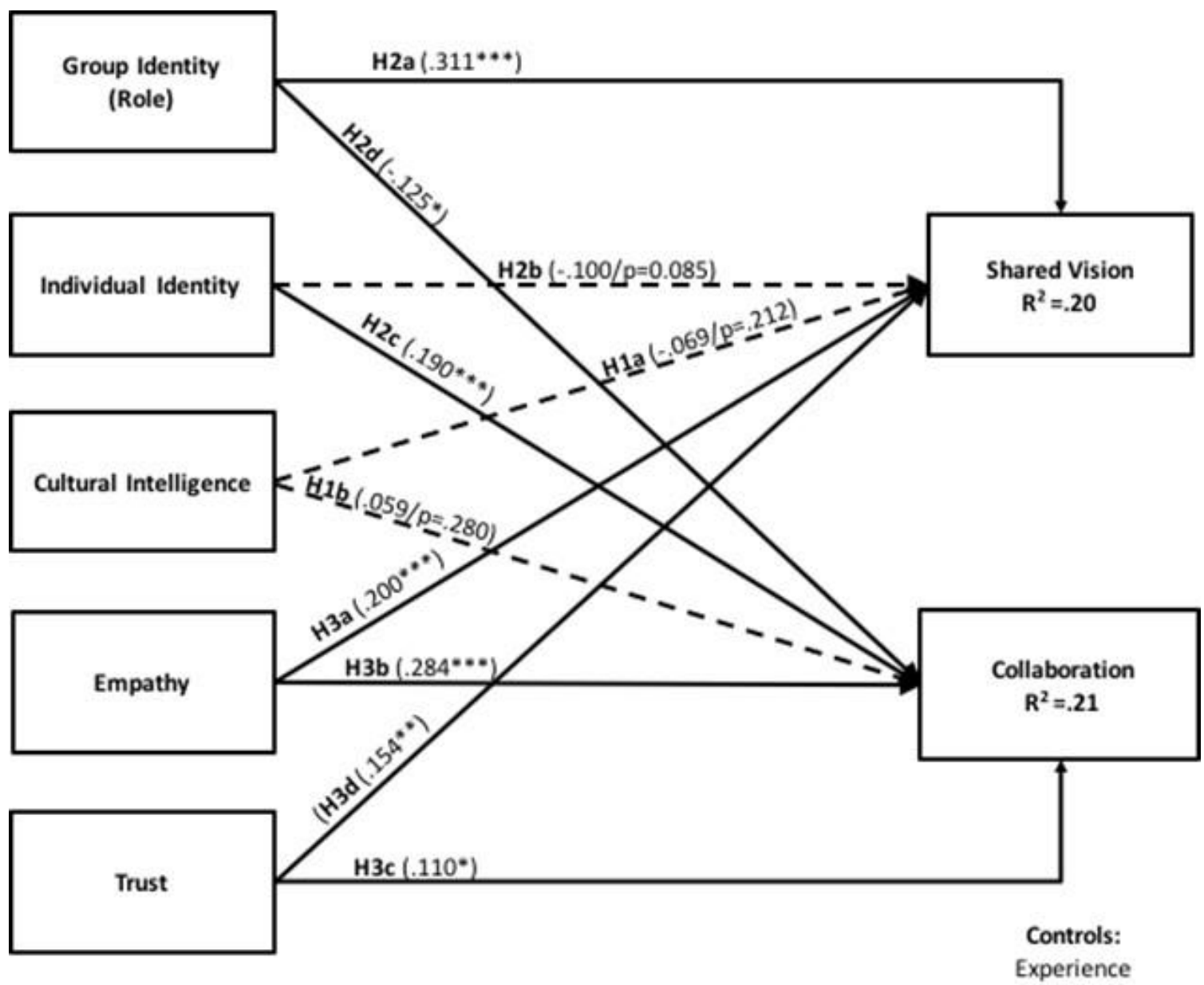




\section{Integrated Findings}

Our integrated findings were synthesized from the overlaps between qualitative and quantitative findings (summarized below) and their careful integration. As expected when researching transnational multiparty collaboration, the first finding relates to the role of culture and how to manage cultural difference. In our interviews with a variety of businesses and NGOs that worked across borders and with groups from different countries when pressed about how they managed cultural differences, the consensus was one managed the differences and moved on with one's work. The quantitative analysis utilizing a cultural intelligence scale showed that culture or rather the understanding of culture was not an antecedent to Shared Vision or Collaboration. Additional post hoc analysis showed that it acted neither as a moderator or a mediator confirming the qualitative finding.

Finding 1 - Cultural differences, uniqueness's and identity should be actively managed, but it is not the driving force behind multiparty transnational collaboration. Culture will play a preventive role if not acknowledged. Active awareness or consciousness of cultural differences within the overall system involving multiparty collaboration is key to success.

Identity was identified in many of the interviews as a playing a role in developing a shared vision. However, identity was much more than national affiliation. It included organizations and cultural or heritage components. Our quantitative analysis sought to distinguish between individual identity and role identity where the role identity was more closely related to shared vision and individual identity to collaboration.

Finding 2 - Identity both role and individual have a differential effect on the creation of shared vision and collaboration. Both must be consciously acknowledged, appreciated and balanced to have a successful collaborative project. 
Connectedness or interconnectedness was determined to play an important role in the experiences of our practitioners in our qualitative work. This was further explored by examining antecedents of interconnectedness, specifically empathy and trust.

Finding 3 - Trust and empathy play a significant role in creating a collaborative environment. Time must be allotted as well as opportunities for individuals and roles to create the trusting bonds necessary for these factors to develop.

It was expected that shared vision would, as it is indicated in Intentional Change Theory, identify an antecedent to collaboration for practitioners. Yet, statistical analysis indicates just the opposite. If we take these findings at face value, we are left with the following. Shared vision, as measured, was about the degree of unity and the very act of creating this unity may be the antithesis to collaboration.

Finding 4 - In order to allow the opportunity for collaboration to take place, care must be taken not to place too much emphasis on creating a shared and unified vision.

In examining the findings from both phases of research, it became apparent that multiparty collaboration is a complex problem, in the category of a wicked problems. Therefore, a system approach would be necessary.

Finding 5 - A systems approach focused on components that interact to generate a collaborative state is necessary for multi-party collaboration. Collaboration, overall, is an emergent process and requires a holistic and systemic way of approaching the task.

\section{DISCUSSION AND CONCLUSIONS}

Dealing with multinational parties across national boundaries, under uncertain conditions and timelines with multiple motivations are inherently complex with no specific optimal way forward. Taking a complexity perspective suggests that where prediction is problematic, anticipation offers useful adaptive information (Boisot \& McKelvey, 2010). We have been looking to identify necessary attributes that would allow a "collaboration to 
emerge" from the complex problem that is the root of our research question. Emergence refers to the relationship between the details of the system and the larger view (Bar-Yam, 2004: 27). This emergence is a key component of a complex system as explained by Ramalingam, Jones, Reba, and Young (2008: 20): “Many patterns and properties of a complex system emerge from the interrelations and interaction of component parts or elements of the system. These can be difficult to predict or understand by separately analyzing various 'causes' and 'effects,' or by looking just at the behavior of the system's component parts. They are known as emergent properties, and they form an important element in the defining concepts of complex systems."

The goal of this research was to identify those attributes that will allow parties to work in a complex environment and while understanding that they cannot predict, by addressing these attributes or component parts of the system will increase the likelihood that this emergence will take place. Integrating the results of the qualitative and quantitative studies have led to a system that encourages or facilitates the emergence of successful collaboration, diagramed in Figure 4. Culture or the understanding of cultures does not play a direct role in the collaborative effort, it is, however, essential when working with people, understanding identities and providing a base or a strength to build on. We would suggest that cultural factors be considered analogous to Herzberg's two-factor theory (Herzberg, Mausner, \& Snyderman, 1967) where you have "satisfiers" or "dissatisfiers," where culture occupies the dissatisfier role. As a dissatisfier, it does not contribute to collaboration, but if not managed it will impede all interactions. This was succinctly stated by an individual who worked in Norway, Africa and Egypt—“... as long as you respect the individual's culture, you can get the job done"; and more specifically "we need to look at the mindset and the 
character of the people that we deal with. It's very important to understand how they react, how they, approach work from a Western perspective but also from universal national perspective because each nationality has their own peculiarities" (Hemsath, 2015: 15).

Identity, Empathy and Trust, and Shared Vision are represented as interrelated functions. Identity, both individual and role, generally start this cycle; this relies on the individual approach to intercultural management, the teams work quality depends on its member's personal qualities_ _ openness, restraint, patience (Chevrier, 2013). However, what needs to be further understood is how to integrate better the role identity and individual identity. Our data analysis indicates that role identity associates with shared vision and individual identity associates with collaboration while empathy and trust associates with both. It does not serve any purpose of developing great connections with another on an individual level and then fall back on, "I'm sorry while I would like to do that, my organization will not" - additional research is needed on breaking down the "boundaries" of role identity and individual identity. It is critical to note that while we are thinking as individuals, the definition of role identity is key, it is more than prosocial relationships of teambuilding — each of the roles represent organizational entities, represented by individual(s) and it may be necessary to have defined commitments from organizations on the degree to which their representatives are empowered.

When examining the data for both shared vision and for collaboration, identity was a significant element in their development, and they both were impacted by empathy and trust. Not surprisingly empathy, trust, and identity work together in the development of shared vision and collaboration where the "central attribute is trustworthiness as the facilitator has not formal authority to establish collaboration" (Gray \& Wood, 1991). Empathy and trust 
bring that leverage to the table, but they are time dependent. Edmondson and Reynolds (2016) in looking to build meaningful cross-sector relationships suggest that teaming leaders build in social time to bring together to get to know one another.

Building an adaptive shared vision provides a foundation for collaboration that helps overcome the inevitable conflicts and misunderstandings that occur in cross-disciplinary work (Edmondson \& Reynolds, 2016). An individual's goodwill towards team members from other culture provides the backdrop for adjustments as well as continued trust in the individual; the relative malleability of the individual's behavior makes these adjustments possible (Chevrier, 2013: 215). As this process continues shared experiences are created, shared identities are developed (role and individual) and a shared mission comes into being, all creating the conditions where the team members move from cooperating to collaborating.

FIGURE 4

\section{Systems View of Multiparty Transnational Collaboration}

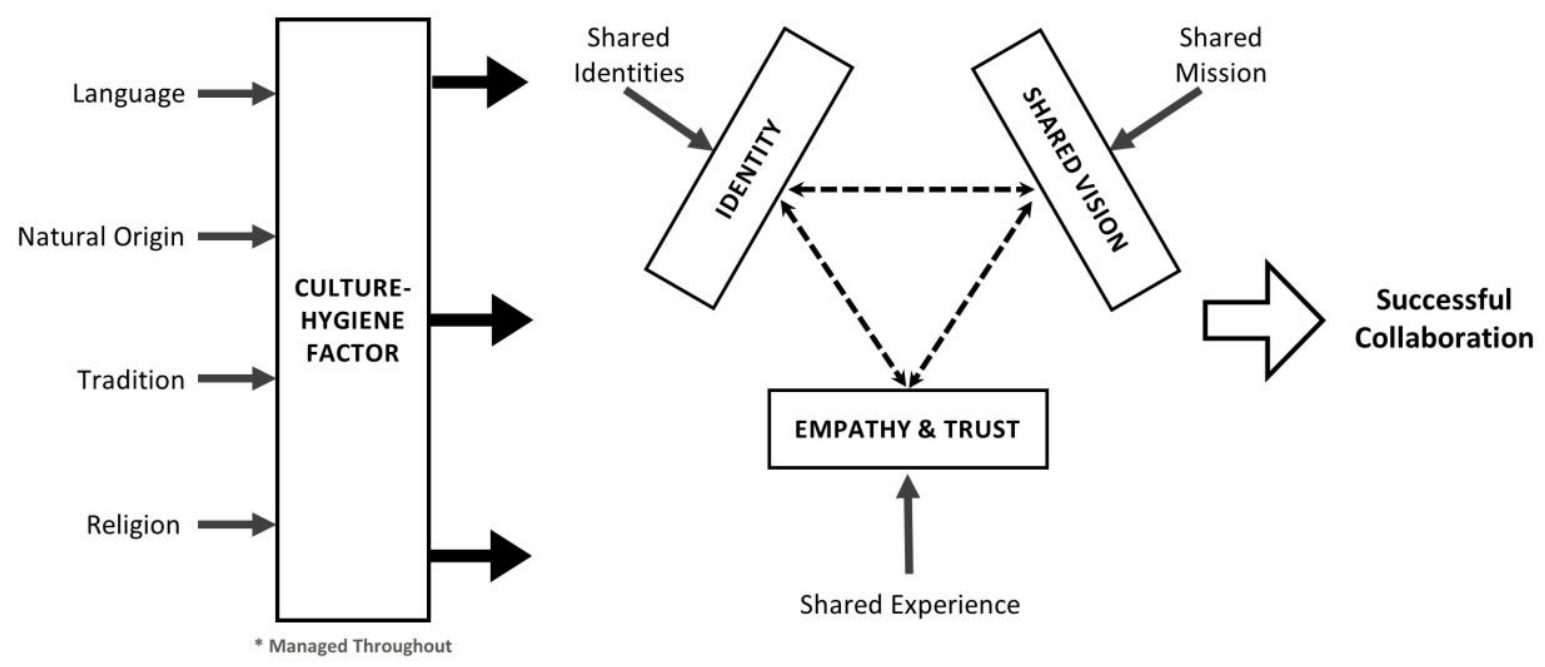

\section{Future Research}

Recent quantitative analysis indicated that shared vision and collaboration are distinct and while we can rationalize that distinction as a group dynamic issue demonstrating the 
need to balance the development of a shared vision with the tension that identity (role and individual) that can lead to collaborative solutions (Hemsath, 2017). Therefore, it is believed that measures used for collaboration and shared vision were not aligned. The collaboration survey instrument had a decidedly task focus while the shared vision was more on the how the individual views shared vision. This is an important distinction: the things that predict task collaboration are quite different from the things that predict shared vision (purpose), perhaps explain why role or social identity related to shared vision and individual identity related to the measure of task collaboration, with Trust and Empathy relating to both.

A third phase of research is recommended that would utilize a qualitative approach to develop actionable outcomes consistent with our pragmatic research goals. The first is to further explore the relationship between shared vision and collaboration processes. The quantitative findings were actually not in line with our qualitative findings and a third "data point" was necessary to help triangulate our inconsistent findings. Second, we wished to improve our understanding of the relationships between empathy and trust and how they influence the development of a fused identity and its relationship with shared vision.

Action research, according to Lewin (1946), is a research approach focused on working with groups where the research process is done in collaboration with those who have the most experience with the problem. "Action research aims to contribute both to the practical concerns of people in an immediate problematic situation and to the goals of social science by joint collaboration within a mutually acceptable ethical framework" (Rapoport, 1970: 499). Action Research is also a way to break down complex problems through Reflection-In-Action (Schön, 1983). An action-driven approach is focused on "designing a desirable future and inventing ways of bringing it about" (Ackoff, 1979: 189). Action 
Research (AR) generates grounded theory in action, and most importantly it is situational, that is, it seeks to understand how the relationships between people and events are a function of the context and situation (Susman \& Evered, 1978). Our problem of practice called just for this approach. We had determined what factors are potentially relevant through grounded theory and then used surveys to validate their impact. But we needed to take this one step further as to understand how these factors work together in practice. The AR approach is suggested to provide such holistic mechanisms. The population that we would collaborate with, as indicated in our problem of practice, would consisted of representatives from the Arctic Economic Council from each of the eight member states plus a representative from the six indigenous groups that make up the permanent participants of the Arctic Council, members of the Arctic Circle Infrastructure Task Force and the Arctic Coast Guard Forum.

\section{IMPLICATIONS}

\section{Theory /Practice/Other Domains}

"The limits of my language are the limits of my world." Wittgenstein (1999, original work published in 1922) - the Tractatus

Our research to date puts a different focus on working across borders. First, it suggests that culture must be treated as an ongoing management process to assure that cultural differences are being acknowledged (and in the case of collaboration, that differences are being built upon). A metaphor for this would be the Second Law of Thermodynamics and the property of entropy, which states in very basic terms without the application of energy a system will always deteriorate to a lower level of performance. The implications for the practitioner derived from our research would indicate that success in this area will be based on choosing the correct team members, not only do they need to be able to 
represent their party (Role) and have defined powers and responsibilities, but they should be chosen from those with high Cultural Intelligence (Ang et al., 2007). This implies that the selection of team members is critical and should be based on the following characteristics.

- Metacognitive CQ: Being conscious and aware of cultural knowledge that an individual would use when interacting with people from different cultures. There is an aspect of humility ingrained in this - knowing what you don't know.

- Cognitive CQ: Having the knowledge or ability to acquire knowledge on cultural values, religious beliefs as well as non-verbal expressions.

- Motivational CQ: To perform well in this environment, one has to be both enjoy working with other and different cultures and be both confident to socialize and deal with uncertainty in adjusting to a new culture.

- Behavioral CQ: An awareness, consciousness and willingness to change verbal and physical behaviors as the situation requires.

Shared Vision is often considered an antecedent to Collaboration, but what if shared vision was also an end state and the conditions that arrive out of shared vision- - hopefulness, success and a collective dream are the same conditions that arrive out of a successful collaboration. We believe that the iterative process of creating a shared vision amongst multiple parties is what creates a collaborative environment. The iteration building trust and empathy, building on the strengths of both identities, constantly revising the shared vision as shown in Figure 4 will result in a meta state where collaboration emerges.

What are the implications for the practitioner in this case? First, planning must include the time necessary for individuals to build bonds based on similarities, not differences, that will allow trust to grow. Second, it must be understood that transnational multiparty collaboration is both complex and a system. In addition to selection of team members that have a high cultural intelligence, there will be a need to select team members 
who have an understanding of systems that have an awareness of the larger picture and have a high regard for how all the components of the project are connected.

This research began within the context of development in the Arctic, where logistics and harsh climates create significant barriers to entry for new businesses and infrastructure. In order to spread the risk around it is likely that these kinds of projects will be executed using the tools, talents, and financing of multiple countries in the Arctic. But the Arctic and Alaska are simply a microcosm of the world. If large problems of drought, of energy poverty, of global warming are to be addressed, they will be addressed by multiple parties from around the world coming together, working together to solve the problem at hand. We feel the research described in this paper is relevant wherever groups come together from different cultures for the purpose of creating and executing a project. Empathy \& Trust, Identity, and Shared Vision reside at the core of creating a collaborative environment. The problems of the world are complex; and to paraphrase Einstein (attributed, 1946) we cannot solve our problems with the same level of thinking that created them. In order to solve these complex problems, we must change our way of thinking. When people work in a collaborative mode, building on the strengths of their differences, then we have moved to that next level of thinking.

Today, I call on the United Nations to turn its attention to the Far North to use our energy and our resources to harness big projects in the fight against poverty. The next decade, the next millennium, might be dedicated to the Arctic the Decade of the Arctic. In my part of the world, the peoples of the Arctic can communicate now without being blocked by curtains of iron or ice. Our "new frontier" is to work together to improve the living standards of our peoples; to fight both to preserve our values of old and welcome the new; to build a way of life that is truly sustainable Then the Arctic, no longer ignored, can participate in a world-wide effort to build peace for all people. Governor Walter J. Hickel (an address to the $47^{\text {th }}$ United Nations NGO Conference, September 1994) 


\section{REFERENCES}

Ackoff, R. L. 1979. Resurrecting the future of operational research. Journal of the Operational Research Society, 30(3): 189-199.

Alaska Sea Grant Marine Advisory Program. n.d. Sea level rise and storm surge: Available from https://seagrant.uaf.edu/map/climate/docs/sea-level.php.

Allianz Global Corporate \& Specialty SE. 2014. Allianz Safety and Shipping Review: 26.

Ang, S., Van Dyne, L., Koh, C., Ng, K. Y., Templer, K. J., Tay, C., \& Chandrasekar, N. A. 2007. Cultural intelligence: Its measurement and effects on cultural judgment and decision making, cultural adaptation and task performance. Management and Organization Review, 3(3): 335-371.

Bar-Yam, Y. 2004. Making things work: Solving complex problems in a complex world. London: Knowledge Industry.

Bass, B. M. 1985. Leadership and performance beyond expectations. Free Press; Collier Macmillan.

Bird, K. J., Charpentier, R. R., Gautier, D. L., Houseknecht, D. W., Klett, T. R., Pitman, J. K., Moore, T. E., Schenk, C. J., Tennyson, M. E., \& Wandrey, C. R. 2008. CircumArctic resource appraisal: Estimates of undiscovered oil and gas north of the Arctic Circle: United States Geological Survey (USGS).

Boisot, M., \& McKelvey, B. 2010. Integrating modernist and postmodernist perspectives on organizations: A complexity science bridge. Academy of Management Review, 35(3): 415-433.

Bouncken, R. B., \& Winkler, V. A. 2010. National and cultural diversity in transnational innovation teams. Technology Analysis \& Strategic Managment, 22(2): 133-151.

Bouwen, R., \& Taillieu, T. 2004. Multi-party collaboration as social learning for interdependence: Developing relational knowing for sustainable natural resource management. Journal of Community \& Applied Social Psychology, 14(3): 137-153.

Boyatzis, R. E., \& Akrivou, K. 2006. The ideal self as the driver of intentional change. Journal of Management Development, 25(7): 624-642.

Boyatzis, R. E., Rochford, K., \& Taylor, S. N. 2015. The role of the positive emotional attractor in vision and shared vision: Toward effective leadership, relationships, and engagement. Frontiers in Psychology, 6: 670.

Brett, J., Behfar, K., \& Kern, M. C. 2006. Managing multicultural teams. Harvard Business Review, 84(11): 85-97. 
Brewer, P., \& Venaik, S. 2010. GLOBE practices and values: A case of diminishing marginal utility? Journal of International Business Studies, 41(8): 1316-1324.

Brodbeck, F. C., Hanges, P. J., Dickson, M. W., Gupta, V., \& Dorfman, P. W. 2004. Comparative influence of industry and societal culture on organizational cultural practices. In R. J. House, P. J. Hanges, M. Javidan, P. Dorfman, \& V. Gupta (Eds.), Leadership, culture, and organizations: The GLOBE study of 62 societies: 654-668. Thousand Oaks, CA: Sage Publications, Inc.

Chanlat, J.-F., Davel, E., \& Dupuis, J.-P. (Eds.). 2013. Cross-cultural management: Culture and management across the world. New York, NY: Routledge.

Chevrier, S. 2003. Cross-cultural management in multinational project groups. Journal of World Business, 38(2): 141-149.

Chevrier, S. 2013. Managing multicultural teams. In J.-F. Chanlat, E. Davel, \& J.-P. Dupuis (Eds.), Cross-cultural management: culture and management across the world: 203-223. New York, NY: Routledge.

Congden, S. W., Matveev, A. V., \& Desplaces, D. E. 2009. Cross-cultural communication and multicultural team performance: A German and American comparison. Journal of Comparative International Management, 12(2): 73-89.

Davis, M. H. 1983. Measuring individual differences in empathy: Evidence for a multidimensional approach. Journal of Personality and Social Psychology, 44(1): 113-126.

Edmondson, A., \& Reynolds, S. S. 2016. Building the future: Big teaming for audacious innovation. Oakland, CA: Berrett-Koehler Publishers.

Edmondson, A. C. 2012. Teaming: How organizations learn, innovate, and compete in the knowledge economy. San Francisco, CA: Jossey-Bass.

Edmondson, A. C., \& Nembhard, I. M. 2009. Product development and learning in project teams: the challenges are the benefits*. Journal of Product Innovation Management, 26(2): 123-138.

Elenkov, D. S., \& Manev, I. M. 2009. Senior expatriate leadership's effects on innovation and the role of cultural intelligence. Journal of World Business, 44(4): 357-369.

Emmerson, C. 2010. The Future History of the Arctic. New York, NY: Public Affairs.

Gray, B., \& Wood, D. J. 1991. Collaborative Alliances: Moving from Practice to Theory. Journal of Appiced Behavioral Science, 27(1): 3-32.

Greenert, J. W. 2014. The United States Navy Arctic Roadmap for 2014 to 2030: Office of the Chief of Naval Operations. Washington DC, Dtic Document. 
Hayes, N. 1997. Successful team management. Thomson Learning.

Hemsath, J. R. 2015. Looking beyond culture: Building successful multiparty collaboration. Unpublished Qualitative Research Report. Case Western Reserve University, Cleveland, $\mathrm{OH}$.

Hemsath, J. R. 2017. Transnational multiparty collaboration: Determining success factors Unpublished Quantitative Research Report, Doctor of Management, Case Western Reserve Univeristy, Cleveland, $\mathrm{OH}$.

Herzberg, F., Mausner, B., \& Snyderman, B. 1967. The motivation to work (2 ed.). New York, NY: Wiley.

Hofstede, G. 2010. The GLOBE debate: Back to relevance. Journal of International Business Studies, 41(8): 1339-1346.

Johnson, R. B., Onwuegbuzie, A. J., \& Turner, L. A. 2007. Toward a definition of mixed methods research. Journal of Mixed Methods Research, 1(2): 112-133.

Kaiser, A., Feldhusen, B., \& Fordinal, B. 2013. Vision development as a knowledge creating process Paper presented at the 2013 46th Hawaii International Conference on System Sciences (HICSS). 3593-3602.

Katz, B., \& Wagner, J. 2014. The rise of innovation districts: A new geography of innovation in america. Brookings Institution.

Lakshman, C. 2013. Biculturalism and attributional complexity: Cross-cultural leadership effectiveness. Journal of International Business Studies, 44(9): 922-940.

Lax, D. A., \& Sebenius, J. K. 2003. 3-D negotiation: Playing the whole game. Harvard Business Review, 81(11).

Lax, D. A., \& Sebenius, J. K. 2006. 3D Negotiation. Boston, MA: Harvard Buisness School Press.

Lewin, K. 1946. Action research and minority problems. Journal of Social Issues, 2(4): 3446.

Marquardt, M. J., \& Horvath, L. 2014. Global teams: How top multinationals span boundaries and cultures with high-speed teamwork. Nicholas Brealey Publishing.

Matveev, A. V., \& Nelson, P. E. 2004. Cross cultural communication competence and multicultural team performance perceptions of American and Russian managers. International Journal of Cross Cultural Management, 4(2): 253-270.

Mayer, R. C., Davis, J. H., \& Schoorman, F. D. 1995. An integrative model of organizational trust. Academy of Management Review, 20(3): 709-734. 
Nansen, F. 1914. Through Siberia, the land of the future. London: Cambridge University Press.

Nansen, F. 1923. Russia and peace. London: Routledge.

Prins, S. 2010. From competition to collaboration: Critical challenges and dynamics in multiparty collaboration. Journal of Appiced Behavioral Science, 46(3): 281-312.

Prins, S., \& Bouwen, R. 2003. Distributed leadership in multiparty collaboration: Opportunities and challenges for leadership in the space-in-between organizations, Holland.

Ramalingam, B., Jones, H., Reba, T., \& Young, J. 2008. Exploring the science of complexity: Ideas and implications for development and humanitarian efforts (2nd ed.). London: Overseas Development Institute

Rapoport, R. N. 1970. Three dilemmas in action research: with special reference to the Tavistock experience. Human Relations, 23(6): 499-513.

Ronen, S., \& Shenkar, O. 2013. Mapping world cultures: Cluster formation, sources and implications. Journal of International Business Studies, 44(9): 867-897.

Ruben, B. D. 1976. Assessing communication competency for intercultural adaptation. Group \& Organization Management, 1(3): 334-354.

Schön, D. A. 1983. The reflective practitioner: How professionals think in action. New York, NY: Basic Books.

Sebenius, J. K. 2002. Hidden challenge of cross-border negotiations. Harvard Business Review, 80(3): 76-85.

Silverman, D. 2014. Interpreting qualitative data (5th ed.). Thousand Oaks, CA: Sage Publications, Inc.

Susman, G. I., \& Evered, R. D. 1978. An assessment of the scientific merits of action research. Administrative Science Quarterly, 23(4): 582-603.

Swann, J., William B, Jetten, J., Gómez, A., Whitehouse, H., \& Bastian, B. 2012. When group membership gets personal: A theory of identity fusion. Psychological Review, 119(3): 441.

Tajfel, H., \& Turner, J. C. 1979. An integrative theory of intergroup conflict. In W. G. Austin, \& S. Worchel (Eds.), The social psychology of intergroup relations: 33-47. Monterey, CA: Brooks-Cole. 
Teddlie, C., \& Tashakkori, A. 2009. Foundations of mixed methods research: Integrating quantitative and qualitative approaches in the social and behavioral sciences.

Thousand Oaks, CA: Sage Publications, Inc.

Van Dyne, L., Ang, S., Ng, K. Y., Rockstuhl, T., Tan, M. L., \& Koh, C. 2012. Subdimensions of the four factor model of cultural intelligence: Expanding the conceptualization and measurement of cultural intelligence. Social and Personality Psychology Compass, 6(4): 295-313.

Van Oosten, E. B. 2006. Intentional change theory at the organizational level: a case study. Journal of Management Development, 25(7): 707-717.

Wittgenstein, L. 1999. Tractatus Logico-Philosophicus (C. Ogden, Trans.). Dover Publications, Inc. Original work published in 1922. 


\title{
LOOKING BEYOND CULTURE: BUILDING SUCCESSFUL MULTIPARTY COLLABORATION
}

\author{
By \\ James R. Hemsath \\ Case Western Reserve University \\ Submitted in Partial Fulfillment of the Requirements of the Conceptual Paper in the \\ Doctor of Management Program \\ at the Weatherhead School of Management
}

Advisors:

Chris Laszlo, Ph.D.

Richard J. Boland, Ph.D.

Eugene A. Pierce, D.M.

\section{CASE WESTERN RESERVE UNIVERSITY}

December 2015 


\title{
LOOKING BEYOND CULTURE: BUILDING SUCCESSFUL MULTIPARTY COLLABORATION
}

\begin{abstract}
The complexities of global business and the need for rapid, effective responses to problems that cross borders and span cultures demand an understanding of why transnational multiparty collaborations have failed and why they have succeeded. At the core of this work is 1) understanding the role that culture and identity play in creating a meta-identity built on the strengths of individual and organization identities and the sameness those identities represent; 2) the development of strong connectedness between the parties; and 3) the creation of a shared vision of what is trying to be achieved. Ultimately, the strength of the meta-identity surpasses the strengths of individual identities without the loss of same to transition to a place where collaborative success can occur. This paper analyzes qualitative data through grounded theory techniques and respondents reported their experience on successful transnational multiparty endeavors and unsuccessful experiences. This paper summarizes the findings from twenty-seven interviews conducted with professionals in a variety of businesses encompassing the government, profit, and non-profit sectors representing six nations and four indigenous populations for the purpose of understanding the behavior of transnational, multiparty collaboration. Key implications from this study include the need for the understanding and awareness that the management of distinct cultures should be considered the management of a hygiene factor that can only dissatisfy and that the emphasis and effort be spent building on the strengths of individual identities, development of strong interconnectedness and the creation of a shared vision.
\end{abstract}

Keywords: collaboration; multiparty; identity; culture; transnational; interconnectedness; shared vision 


\section{INTRODUCTION}

"The story of the ozone treaty reflects new reality: nations must work together in the face of global threats, because if some major actors do not participate the efforts of others will be vitiated" (Benedick, 1991: 331). The Montreal Protocol on Substances that Deplete the Ozone Layer-agreed to in 1987, put into effect in 1989 and currently ratified in 197 nations (Benedick, 1991; Luken \& Grof, 2006; Sunstein, 2006) —is considered the best example of the most successful international treaties in recent times. Not only was it a success in aligning a variety of parties, it was a success in terms of reducing ozone depleting substances in the atmosphere (Estrada, Perron, \& Martínez-López, 2013; Montzka et al., 1999). Contrasting this; the Kyoto Protocol on Climate Change - agreed to in 1997 and put into effect in 2005-expired December 30, 2012 and is considered a failure both in terms of bringing parties together and failing to meet the objectives of the treaty (Brandt \& Svendsen, 2002; Kellow, 2010; Subbarao \& Lloyd, 2011; Sunstein, 2006).

The resulting complexity of global business and the need for rapid, effective responses to opportunities and challenges have put pressure on hierarchical organizational forms. Attempting to redesign organizations to cope with such pressure challenges, the usefulness of hierarchy as the primary mechanism of control and coordination, prompting calls for collaborative organization designs (Adler, 2001; Fjeldstad, Snow, Miles, \& Lettl, 2012). In this time of globalization, with problems that cross borders and span cultures, it is important to understand why transnational multiparty collaborations have failed and why they have succeeded. Multiparty collaboration must consider both technical complexities of the collaboration as well as the social issues that will require collaboration of a wide variety of public and private authorities, technical experts, and social interest groups, all as interested 
stakeholders (Prins \& Bouwen, 2003). "Participation is not merely an instrument, but a complex system of structure and processes" (Bouwen \& Taillieu, 2004: 138). Understanding the motivations, drivers, intergroup characteristics, and interorganizational dynamics is critical towards understanding multiparty collaboration (Prins, 2010). What is not clearly understood in the literature is how the combination of transnational and cross-cultural projects would complicate collaboration.

In companies that work to expand globally, team performance becomes vulnerable to cross-cultural interaction problems (Congden et al., 2009; Matveev \& Nelson, 2004). Managing cultural diversity, cultural differences, and cross-cultural conflicts have surfaced as frequent challenges for cross-cultural teams (Congden et al., 2009; Marquardt \& Horvath, 2014). However, the literature does not discuss cross-cultural collaboration. In review of literature related to collaboration and innovation across borders, much of the discussion centers on innovation of technical issues or the creation of areas where innovation could take place i.e. districts (Katz \& Wagner, 2014) within the context of constant change. References to "transnational" in articles related to innovation are focused on the need of a diverse team to foster innovation rather than innovation across borders (Bouncken \& Winkler, 2010; Edmondson, 2012a). The literature on innovation or collaboration, as it relates to systems, was again limited to the creations of product or entrepreneurship (Bergek, Jacobsson, Carlsson, Lindmark, \& Rickne, 2008; Carlsson, Jacobsson, Holmén, \& Rickne, 2002). The literature is silent on areas related to innovation and transnational collaboration regarding infrastructure and/or associated economic development. 


\section{RESEARCH QUESTION}

In order to address the above problem of practice, the following research question is proposed: What explains transnational/cross-cultural multiparty collaboration performance? And specifically, what is the experience of participating in a successful versus less successful transnational multiparty collaboration?

Multiparty collaboration is an organizational strategy to develop sustainable solutions for societal and environmental meta-problems that require multidisciplinary and multiorganizational involvement (Gray, 1989; Huxham, 1996; Huxham \& Vangen, 2005; Prins, 2010). Multiparty collaboration is defined as “... a process through which parties who see different aspects of a problem can constructively explore their differences and search for solutions" (Gray, 1989; Prins, 2010: 282).

The understanding of the relationship between cross-cultural (transnational) communication competence and multicultural team performance is insufficiently developed (Congden et al., 2009; Hofner Saphiere, 1996; Wiseman \& Shuter, 1994). Furthermore, past research finds the relationship between ethno-cultural (cross-cultural) diversity and performance to be highly complex and not well understood (Congden et al., 2009; Ng \& Tung, 1998). Combined analyses of multicultural team performance, cross-cultural communication competence, and national culture orientation have not been adequately explained in the performance of multicultural (transnational) teams. What is not clearly understood in the literature is how the combination of transnational and cross-cultural projects would complicate collaboration. It is our hope that this research will allow us to better understand how regions work together across borders and across cultures to develop 
collaborative solutions towards the development of infrastructure and economic development.

\section{LITERATURE REVIEW}

The following review will examine the most current and seminal literature related to collaboration, teaming, transnational constructs and culture related to our research focus of better understanding how multi-party collaborations work.

\section{Context}

With a quarter of the world's oil and gas reserves (Bird, et al, 2008) and the ability to shorten the shipping distances by half (Greenert, 2014) from Europe to Asia and the United States, the Arctic is poised to be the next significant global development arena. To support this development, significant investments in infrastructure (Allianz Global Corporate \& Specialty SE, 2014) will be necessary in amounts that may exceed any one locale or region's ability to provide. In 2014, the extent of Arctic sea ice was the sixth smallest on record, continuing a trend of decreasing sea ice that began in 2002 (Emmerson \& Lahn, 2012; Lindsey, 2013; NSIDC, 2014; United States Coast Guard, 2013). The resulting increase in open water has increased the interest in new shorter global transit sea routes, including the Northern Sea Route, Northwest Passage, Transpolar and Bering Straits (Arctic Council Arctic Marine Shipping Assessment (AMSA), 2009; Greenert, 2014; United States Coast Guard, 2013). This has resulted in significant increases in vessel traffic in the region-as much as ten-fold between 2010 and 2012 and thirty-fold projected increase on the Northern Sea Route by 2020 (Humpert, 2014; Kraska \& Baker, 2014).

Perhaps in the modern era, no one was a better spokesman for the Arctic than Fridtjof Nansen, Arctic Explorer and recipient of the 1922 Nobel Peace Prize. In 1914, just as Europe 
was entering World War I, he wrote about the potential of a trade route from the Arctic Kara Sea to Western Europe identifying early on the value of Arctic transportation as way to shorten distances and costs of moving goods and services. In the 1920s, he wrote from his view of the North about an international economic point of view that the North could act as a model of cooperation as it provided a push for the advancement of human knowledge (Emmerson, 2010). That aspect of collaboration, working across borders in transnational teams in order to provide a better life for the people of the North, is at the heart of this research.

\section{Multiparty Collaboration}

To address the technical complexity of working in the Arctic as well as the social issues mentioned above will require the collaboration of a wide variety of public and private authorities, technical experts, and social interest groups all as interested stakeholders (Prins \& Bouwen, 2003). "Meaningful involvement requires several conditions: (a) people should experience participation on an issue as feasible and realistic based on the task, (b) the boundaries and the limits of the people's authority and decision-making scope should be clearly defined and mutually accepted, (c) participation thrives only in a climate of openness and trust. Defined this way participation is not merely an instrument, but a complex system of structure and processes" (Bouwen \& Taillieu, 2004: 138). Understanding the motivations, drivers, intergroup characteristics and interorganizational dynamics lead to the need for stakeholder analysis. Silvia Prins (2010) also identifies four main challenges-Context and starting conditions, Task and collaborative aims, Organization of the process, and Collaborative relationships. What is not obvious in the literature is how the combination of transnational and cross-cultural projects would complicate collaboration. Multiparty 
collaboration at this scale will not have any given optimal solution; as a complex problem or wicked problem, the dynamic will be important. With this in mind, there may be areas to explore in the discipline of negotiation. Especially in looking at the process known as 3-D Negotiation (Lax \& Sebenius, 2003; Lax \& Sebenius, 2006) where the emphasis is on creating value and focusing on scope and sequence rather than across the table negotiations. In the area of cross-border negotiations, the emphasis as in collaboration should not be on cultural differences but rather on the how people in different regions come to agreement specifically in decision-making and governance (Sebenius, 2002). One other aspect that should also be considered and will also influence teaming is the multiple identities of individuals. Work has been done on this multiple identity behavior, via an intrapersonal identity network that provides a way to investigate patterns of relationships among multiple identities as it relates to organizational dynamics (Ramarajan, 2014). Positive Organizational Scholarship (POS) provides another viewpoint towards multiparty collaboration and the behavior of an organization with its emphasis on "goodness", paying attention to the enablers, the motivations and outcomes of positive phenomena; the study of nonlinear positive dynamics (positive spirals) and flourishing organizations (Cameron \& Caza, 2004; Cameron, Dutton, \& Quinn, 2003; Dutton \& Sonenshein, 2007).

Examining literature as it relates to business models has potential, although they tend to look at new product introduction (Amit \& Zott, 2010). For example, research in crowd sourcing, as it relates to innovation, identifies four ways that crowd sourcing innovation can take place: Contests, Collaborative Communities, Complementors and Labor markets (Boudreau \& Lakhani, 2013; Maccormack, Murray, \& Wagner, 2013). In a review of literature related to collaboration and innovation across borders, much of the discussion 
centers on innovation of technical issues (Bendis \& Byler, 2009; Bergek et al., 2008; Chebbi, Yahiaoui, Thrassou, \& Vrontis, 2013) or the creation of areas where innovation could take place i.e. districts (Coe \& Bunnell, 2003; Katz \& Wagner, 2014). References to "transnational" in articles related to innovation are focused on the need of a diverse team to foster innovation rather than innovation across borders (Bouncken \& Winkler, 2010; Edmondson, 2012b). The literature on innovation or collaboration as it relates to systems, was again limited to the creations of product or entrepreneurship (Bergek et al., 2008; Carlsson et al., 2002; Martinez de Velasco Aguirre, 2012). Open Innovation (Chesbrough, 2006) is also a new trend in innovation where the locus of innovation is shifted from individual entities to a broader and more shared approach. While the emphasis for open innovation tends toward software, there may be a metaphorical approach between Open Innovation and competition that may have application for finding a way forward on transnational projects.

In their article, “The Architecture of Collaboration", Fjeldstad, et al. discuss the ability of organizational actors to dynamically form collaborative relationships with four implications for research that should be considered going forward. First is the role of incentives and values in large-scale multiparty collaboration. Second is the nature of control in actor-oriented organization designs. Control is the determination of goals and the allocation of resources to pursue them. Third are the processes of transformation form hierarchical to actor-oriented organizations designs. And fourth is the issue of value creation and value appropriation in actor-oriented designs (Fjeldstad et al., 2012). 


\section{Culture}

Hofstede's cultural dimensions theory is a framework for cross-cultural (transnational) communication, developed by Geert Hofstede. Culture has been referred to as "software of the mind", how each person carries within themselves patterns of thinking, of acting, of deciding based on what they have learned throughout their lifetime. Culture is a collective phenomenon as it is typically shared with those that live in the same social environment (Hofstede, 1997a). This work has been studied in a variety of settings and at this time, is not a path that this project will take as a research area. But in all dealings of collaboration, teaming and innovation, because they are working within social groups, one must be aware of aspects of culture and the influence it plays. Hofstede has defined four cultural dimensions (Hofstede, 2001) that have been paraphrased by Sebenius-Distribution of Power, Tolerance for Uncertainty, Individualism vs. Collectivism and Harmony vs. Assertiveness (Sebenius, 2002). The Globe (Global Leadership and Organizational Behavior Economics) Study continues and expands on Hofestede's four dimensions to nine dimensions: Power Distance; Uncertainty Avoidance; Humane Orientation; Collectivism (Institutional); Collectivism (In-Group); Assertiveness; Gender Egalitarianism; Future Orientation; and Performance Orientation (Chhokar, et al, 2007). These factors need to be addressed in any model or approach to transnational and cross-cultural collaboration and teaming. The challenge in managing multicultural teams effectively is to recognize underlying cultural causes of conflict and to intervene to get the team back on track (Brett et al., 2006). 


\section{Sensemaking}

Sensemaking involves the ongoing retrospective development of plausible images that rationalize what people are doing. First, sensemaking occurs when a flow of organizational circumstances is turned into words and salient categories. Second, organizing itself is embodied in written and spoken texts. Third, reading, writing, conversing, and editing are crucial actions that serve as the media through which the invisible hand of institutions shapes conduct (Gioia, Thomas, Clark, \& Chittipeddi, 1994; Weick, Sutcliffe, \& Obstfeld, 2005). Weick identifies seven properties or distinguishing characteristics that set sensemaking apart from other processes (Weick, 1995).

- Grounded in identity construction sensemaking refers to the need to have a sense of identity which would also include being part of a team. Identity will be an important part of a transnational cross-cultural multiparty collaborative effort.

- Retrospective - provides a frame of reference based on past lived experience.

- Enactive of sensible environments - people enact their environment as they create the narratives or stories that define what they expect to happen.

- Social-sensemaking is a social activity, as what a person does is as part of the group and shared experiences.

- Ongoing - individuals are in the middle of a project; the situation is changing and ongoing, being modified by the feedback that the individual receives.

- Focused on and by extracted cues - this refers to the ability of individuals to extract cues to determine what is important and relevant to their situation.

- Driven by plausibility rather than accuracy - "In an equivocal, postmodern world, infused with the politics of interpretation and conflicting interests and inhabited by people with multiple shifting identities, an obsession with accuracy seems fruitless and not much practical help.

In a paper on corporate social responsibilities, sensemaking was used to assist in the construct of a business case for stakeholder engagement at both the local and international level (Schouten \& Remmé, 2006). 


\section{METHODS}

\section{Methodology}

This research was designed to learn and probe for explanations of transnational multiparty collaboration performance. This study employed grounded theory through a semistructured interview methodology. Grounded theory is the discovery of theory from data systematically obtained from social research (Glaser \& Strauss, 2009). Fieldwork was done to collect data that came from the lived experiences of human subject matter. Generating a theory from data means that most concepts not only come from the data, but are systematically worked out in relation to the data during the course of the research (Glaser \& Strauss, 2009). In grounded theory, there is constant comparative analysis in order to gain understanding. Coding was used to identify key themes and knowledge of the subject matter. The theories and concepts developed will help contribute to both the practitioner and academic communities.

In total, 27 interviews representing seven countries and five indigenous populations from business, military, finance, NGO and trade organizations from the US, Canada, Finland, Norway, Iceland, Singapore, Denmark, and four Indigenous populations were collected. The project sample represented various age groups, backgrounds, and a variety of different projects located predominantly in Arctic countries as well as Singapore and participants were composed of 24 men and 4 women, age 35 to 65 (see Table 1). 
TABLE 1

Qualitative Interview Participants

\begin{tabular}{|c|c|c|c|}
\hline Respondent & Nationality & Gender/Age & Business \\
\hline Subject: 1-B & Indigenous - Iñupiaq & F / 50's & Business/Corporate \\
\hline Subject: 1-C & USA & M / 60’s & Transportation \\
\hline Subject: $2-\mathrm{A}$ & Indigenous - Iñupiaq & $\mathrm{F} / 30$ 's & Business/Corporate \\
\hline Subject: 2-B & USA & M / 40’s & Business - Logistics \\
\hline Subject: $3-\mathrm{A}$ & Iceland & M / 40’s & Economist/NGO \\
\hline Subject: 3-B & Iceland & M / 30’s & Trade Organization \\
\hline Subject: $4-\mathrm{A}$ & Norway & M / 50’s & Trade Organization \\
\hline Subject: 4-B & Norway & M / 30’s & Trade Organization \\
\hline Subject: 5-A & Denmark & M / 40’s & Trade Organization \\
\hline Subject: 5-B & Denmark & M / 50’s & Trade Organization \\
\hline Subject: 6-A & Indigenous - Gwich'in & M / 60’s & Business/Corporation \\
\hline Subject: 6-B & USA & $\mathrm{F} / 50$ 's & University \\
\hline Subject: 7-A & Norway & $\mathrm{F} / 40$ 's & University \\
\hline Subject: 7-B & USA & M / 50’s & NGO \\
\hline Subject: 8 -A & Canada & M / 50’s & Government \\
\hline Subject: 8-B & Canada & M / 60’s & NGO \\
\hline Subject: 9-A & Singapore & M / 60’s & Business - Shipping \\
\hline Subject: 9-B & Singapore & M / 40’s & Business - Finance \\
\hline Subject: $10-\mathrm{A}$ & USA & M / 60’s & Business - Oil \\
\hline Subject: $10-B$ & USA & M / 50’s & Business - Finance \\
\hline Subject: $11-A$ & USA & M / 60’s & University \\
\hline Subject: 11-B & Indigenous - Yup'ik & M / 40’s & Business - Finance \\
\hline Subject: $12-A$ & Canada & M / 60’s & NGO \\
\hline Subject: $12-B$ & Finland & M / 50’s & Business - Shipping \\
\hline Subject: $13-\mathrm{A}$ & Indigenous - Sámi Sweden & M / 50’s & NGO \\
\hline Subject: 13-B & USA & M / 40’s & University \\
\hline Subject: 14-A & Norway & M / 30’s & Business - Oil \\
\hline Subject: 14-B & Norway & M / 30's & Military \\
\hline
\end{tabular}

\section{Data Collection}

In 2014, the Arctic Council (a high level intergovernmental forum promoting cooperation, coordination and interaction among the Arctic nations) established a circumpolar business forum - the Arctic Economic Council with the mandate to foster business development in the Arctic. This body is made up of business representatives from the eight Arctic nations and six indigenous populations of the Arctic. Interviews were conducted with members of this group and additional representatives they suggested. Data was collected between March and September 2015. Semi-structured interviews were between 
60 and 120 minutes, guided by an interview protocol with occasional prompt for clarity, asking the following two questions:

1. Tell me about an experience you had where you were involved working across borders on a project that went well.

2. Tell me about an experience you had where you were involved working across borders on a project that had difficulties.

Interviews were conducted face-to-face and/or over the telephone or Skype (audio and video). Interviews were recorded and later transcribed for analysis. Participants were all informed of the precautions that were taken to protect their privacy. All either signed a release form agreeing to participate in the interview and consenting to audio recording or verbally acknowledged consent when interviews were conducted via Skype or telephonically.

\section{Data Analysis}

The data analysis commenced with the first interview and continued throughout the data collection period utilizing an extensive, multi-process coding procedure. Throughout the process, the researcher remained open to emergent ideas and themes from the data and repeatedly moved from the data to the literature to ensure a clear understanding of the concepts. The analysis started with an initial or open coding process of the interview transcripts and then moved into axial coding (collapsing codes) from which findings were proposed. Open coding is defined as the "analytic process through which concepts are identified and their properties and dimensions are discovered in data" (Strauss \& Corbin, 1998). Open codes are descriptive: they identify, name, and categorize phenomena found in the text (Myers, 2013). Axial coding is defined, as "the process of relating categories to their subcategories, termed 'axial' because coding occurs around the axis of a category, linking categories at the level of properties and dimensions" (Strauss \& Corbin, 1998). Axial coding 
relates categories to subcategories, specifies the properties and dimensions of a category, and reassembles the data to give coherence to the emerging analysis (Charmaz, 2006). Selective coding is the process by which all categories are unified around a "core" category, and categories that need further explication are filled-in with descriptive detail (Corbin \& Strauss, 1990). The final set of codes will then enable the identification of key findings.

Approximately 858 codes were identified and collapsed into thirty naturally occurring combinations. These combinations were created from in vivo codes or simple categories such as education. Review of interview comments these 30 combinations are further condensed into seventeen categories. These codes were subsequently combined into 10 relevant categories as shown in Table 2.

\section{TABLE 2 \\ Final Codes}

These codes were used for successful and less successful projects

\begin{tabular}{|c|c|c|}
\hline Axial Code & Selective Code & Description \\
\hline Culture & $\begin{array}{l}\text { Culture (Local Support + } \\
\text { Columbus Effect) }\end{array}$ & $\begin{array}{l}\text { Patterns of thinking, of acting, of deciding based } \\
\text { on where they are from }\end{array}$ \\
\hline Identity & Identity (Local Support) & $\begin{array}{l}\text { Individual's conception of who they most } \\
\text { identify or affiliate with (group, country) }\end{array}$ \\
\hline Interconnectedness & Interconnectedness & $\begin{array}{l}\text { The degree that people understand and connect to } \\
\text { one another }\end{array}$ \\
\hline Greater Purpose & $\begin{array}{l}\text { Greater Purpose (Common } \\
\text { Approach + Shared Vision) }\end{array}$ & $\begin{array}{l}\text { Combination of shared vision and approach to } \\
\text { project }\end{array}$ \\
\hline Patience & Patience & $\begin{array}{l}\text { Investing the time to develop understanding and } \\
\text { relations }\end{array}$ \\
\hline Columbus Effect & & $\begin{array}{l}\text { An outside nation/culture coming into a region an } \\
\text { taking over for the "native" population }\end{array}$ \\
\hline Common Approach & & $\begin{array}{l}\text { Approach taken to solving a problem, executing } \\
\text { a project where all are in agreement }\end{array}$ \\
\hline Shared Vision & & $\begin{array}{l}\text { A shared vision (mental model) or understanding } \\
\text { of the final outcome }\end{array}$ \\
\hline Local Support & & $\begin{array}{l}\text { Use of local assistance to maneuver the project } \\
\text { around local traditions and customs }\end{array}$ \\
\hline Collaboration & & Working together to achieve shared goals \\
\hline
\end{tabular}




\section{FINDINGS}

From April 2015 through the end of August 2015, twenty-nine interviews were conducted with professionals in a variety of businesses encompassing the government, profit and non-profit sectors representing six nations and four indigenous populations for the purpose of understanding the behavior of transnational, multiparty collaboration. Of the twenty-nine interviews, two interviews were not used at the request of the interviewees, the twenty-seven remaining interviews, totaling approximately 30 hours of conversation and 484 pages (single space) of transcripts, were analyzed. Approximately 850 open codes were identified and then through the process of axial coding and selective coding, ten categories were developed which have led to the following five findings promulgated as follows.

Finding 1: Differences in cultures need to be acknowledged, respected and managed but once they are accommodated they have no additional impact on collaboration and completion of the project/work.

The process of acknowledging and managing culture was identified in 24 out of 27 interviews. After completing the interviews, it was observed the culture was only mentioned specifically in a few interviews, terms such as respect, traditions and discipline were used were used to describe factors relating to different cultures and how to address those cultures. For example, "as long as you respect the individual's culture, you can get the job done.” And from a different part of the world, demonstrated in the following quote from one of the interviews taken in Southeast Asia: "You need to manage it and to be courteous and to be respectful to religion. It is very important." At the center of understanding and working with different cultures is respect, regardless of the country if you respect an individual's culture, you will be able to work through cultural issues. One individual who had worked in both the Middle East and the Arctic reported: "In some ways, it's not so much different I had direct 
contact and very small issues to resolve in Syria. It was always done with respect. In Alaska, the issues were much more difficult, higher stakes, but we still always approached the program with respect, the people that we were in there with, with respect and their needs." Without an appreciation of cultural differences, one cannot move to other phases of collaborative effort. " ...About $60-70 \%$ of negotiations end up in the ditch, and that is mostly because there is a lack of understanding between the parties ... so most cases where the process doesn't work well is due to the fact that the parties don't understand each other. They don't speak the same languages; they don't understand each other's background. They don't see the cultural differences (emphasis added)." Another outfall of a lack of respect resulting in a lack of understanding of culture is a loss of trust in the other party, "There's just this sense of we don't really trust you. I don't know if it's a native trait or an Alaskan trait or what the trait is but I generally am very wary and it takes a long time for me to develop relationships both in Alaska and my own friends and in business.” This is an example of what one interviewee described as the "Columbus Effect" that it is "... natural, it's so easy to think that we have the truth and we are going to tell other cultures about the truths or what's right for them."

Complementing this are those factors related to local support (10 of 27 interviews) where it was emphasized that having local support to help one understand those aspects of "local culture" that could impede work. In the words of one Norwegian executive, "Some companies are good and have a lot of knowledge about many locations, but certainly no companies have all the best people with the knowledge about all the places in the world, and recognizing that that local understanding is a key requisite for success..." 
Culture is the key entry point in working with parties from different countries and cultures as well as working in different countries and cultures: "I find that cultures that are perceived to be very similar are almost more difficult to enter than cultures that are perceived very different. When a company like ours ... if we're going to start up a business in Mozambique, we spend a lot of time understanding how this works ... the culture, the politics, the history, economics, all of that ... whereas some of our most challenging projects have been in places like Canada or Ireland, because it's so similar, is the quote that have many have used. We don't need to spend that much time. It's an OECD country. It's just over there, and we speak English, so it's not a problem."

"Then you realize that actually the cultural gaps are much bigger than they appear on the surface. I think it's a mistake that we've done in the past, and I think other companies have done so as well, is assuming you understand a culture that seems on the surface to be very similar, but really isn't." Figure 1, summarizes a number of quotes from the interviews related to Finding 1.

\section{FIGURE 1}

\section{Summary Quote Table - Finding 1}

Finding 1: Differences in cultures need to be acknowledges, respected and managed but once accommodated they have no additional impact on collaboration

\begin{tabular}{l|l|}
$\begin{array}{l}\text { “... as long as you respect the individual's culture, } \\
\text { you can get the job done." }\end{array}$ & $\begin{array}{l}\text { "You need to manage it and to be courteous and to be } \\
\text { respectful to religion. }\end{array}$ \\
$\begin{array}{l}\text { "... issues to resolve in Syria. It was always done } \\
\text { with respect. In Alaska, the issues were more } \\
\text { difficult, higher stakes, but we always approached } \\
\text { the program with respect, the people that we were } \\
\text { in there with, with respect..." }\end{array}$ & $\begin{array}{l}\text { if it's a native trait ... but I generally am very wary } \\
\text { and it takes a long time for me to develop } \\
\text { relationships." }\end{array}$ \\
$\begin{array}{l}\text { "it's so easy to think that we have the truth and we } \\
\text { are going to tell other cultures about the truths or } \\
\text { what's right for them." }\end{array}$ & $\begin{array}{l}\text { "... where the process doesn't work well the parties } \\
\text { don't understand each other. They don't speak the } \\
\text { same languages; they don't understand each other's } \\
\text { background. They don't see the cultural differences." }\end{array}$ \\
$\begin{array}{l}\text { I think it's a mistake that we've done in the past, and } \\
\begin{array}{l}\text { I think other companies have done so as well, is } \\
\text { assuming you understand a culture that seems on } \\
\text { the surface to be very similar, but really isn't." }\end{array}\end{array}$ & $\begin{array}{l}\text { "... local understanding is a key requisite for } \\
\text { success..." }\end{array}$ \\
\hline
\end{tabular}




\section{Finding 2: Identity can cross borders and while dependent on culture plays a stronger role than national cultures.}

In 26 of 27 interviews identity was reported as a necessity in working across borders and cultures. Figure 2, below summarizes a number of key quotes from these interviews. While culture needs to be acknowledged and managed, understanding an individual's identity was key in successful projects. Often identity is transnational in its own right. The Executive Director of an NGO representing Sami Reindeer Herders made this statement that paints a picture of someone working across borders that talked to maintaining their identity even in working in two cultures: "I can pass the borders between those parties without getting lost myself." This strength identity is specifically relevant to the various Arctic indigenous populations that cross borders as a matter of identity. In the course of the interviews, a Native Alaskan commented that on her first trip to Yellowknife (in the Northwest Territory of Canada), that the "little girls outside could have been her". In the Arctic countries, the indigenous population has become a strong power group, especially in Alaska through the Alaska Native Claims Settlement Act and the creation of Native Corporation and in Canada with First Peoples rights and the establishment of an indigenous state-Nunavut. The Arctic Council has established six representative indigenous groups as permanent participants with the same voting status as the eight Arctic Nations and in the recently formed Arctic Economic Council (AEC) a similar structure was put in place. In interviews with members of the AEC, it was commented that the indigenous groups tended to vote as a block in order to offset the Nordic nations' influence.

Identities can be built on existing identities to create a group identity, a Singapore manager working on oil and gas projects noted, "My team comprised of British, Danish, 
Australians, South Africans ... we need to look at the mindset and the character of the people that we deal with. It's very important to understand how they react, how they, approach work from a Western perspective but also from universal national perspective because each nationality has their own peculiarities." Merging corporate identities can be problematic as well, "when you try to merge two company cultures, and then in addition, maybe two national cultures ... in our case, Norwegians and Canadians, in addition to a number of other personalities ... these elements turn into frustrations". While culture is mentioned, what is being described is the merger of corporate identities.

Identities need to be maintained, not replaced or dismissed. One respondent used the expression "Columbus Effect" to describe an outside party coming in and determining what needs to be done: "we're European we have all the answers" who you are and what you do (identity) is not important. And from a representative of an indigenous group “... an interaction, especially with Westerners, is you're the semi-literate or illiterate native and I'm the guy with the degree."

\section{FIGURE 2}

\section{Summary Quote Table - Finding 2}

Finding 2: Identity can cross borders and while dependent on culture plays a stronger role than national cultures.

\begin{tabular}{l|l|}
$\begin{array}{l}\text { "I can pass the borders between those parties without } \\
\text { getting lost myself". }\end{array}$ & $\begin{array}{l}\text { "we're European we have all the answers" who } \\
\text { you are and what you do (identity) is not } \\
\text { important. }\end{array}$ \\
\hline $\begin{array}{l}\text { look at the mindset and the character of the people that } \\
\text { we deal with. It's very important to understand how } \\
\text { they react, how they, approach work from a Western } \\
\text { perspective but also from universal national } \\
\text { perspective because each nationality has their own } \\
\text { peculiarities." }\end{array}$ & $\begin{array}{l}\text { when in addition, maybe two national cultures ... } \\
\text { then elements turn into frustrations" } \\
\text { these eleme }\end{array}$ \\
\hline
\end{tabular}


Finding 3: The degree of connectedness or interconnectedness between parties will impact its success. Successful projects shared the attribute of connecting with the people and parties you were working with, the culture you are working in (and in part connecting with the identity of those parties).

Twenty-five respondents (out of 27) referenced connectedness as in essential component of success in working with multiple parties in a transnational arena. This was a broad view of the way things work and can be work specific: "There are people that I really enjoy working with and would be happy to work on just about anything with and then there are other people with whom I've had enough experience that I just don't care what the topic is, I'm not really that interested in spending much time working with them." To taking the time to connect by taking an interest in their culture and who they are "So I try intensively if I'm going into a country to understand the culture. It turns out that it's kind of cool that Iceland's Chief of staff is the major translator of the Icelandic Sagas in English. So understanding those connections and so forth helps a lot. That can be food, it can be words, it can be names, it can be languages. I think that's very important because it's more than just having something to have small talk about. It's something to understand what's important to them." In other words, it is a way to connect. Connectedness is a critical component of being able to "work in the margins" that is working outside the hierarchy to get things done. "My interests, or my issues, or my agenda aren't being served by this;' it forces you almost into the margins of the meeting for informal levels of dialogue. It's a unique process in that a lot of what really happens doesn't happen at the main table. It happens in the lunchrooms or in the coffee breaks. It happens through these informal congregations of, let's say, a Russian official, and indigenous person, a non-Arctic state representative, and someone of influence from the State Department." 
Creating relationships is at the core of developing a sense of connectedness. In one interview, a senior manager at an investment fund spoke of the importance to him of working to develop relations with potential investors from another a country: "Having them meet people in the company, going over there, coming back here, all that interaction over the course of period of time builds these connections between each other that are very important..." It is also a resource that can be highly leveraged, in the case of a large multinational corporation; relations they developed in one project were able to be used elsewhere, "Inuits and their knowledge about ice. They know more about ice than anyone else, perhaps, and taking that knowledge and that experience on the east coast of Canada."

But connectedness is more than connections - it is development of a relationship that builds on the strengths and needs of all the parties: “... it was more a sense of a partner. In fact, at one point during that program, we actually rescued and helped towed in a whale that had been taken. When the seas got rough and the boats were unable to perform, we send a boat out and helped to do that. It was a very cooperative atmosphere." This sense of connectedness takes time and it is important to plan for this time. "We're not going to drill for ten years, but we would like to engage with you. We want to talk about our plans. We want to listen to your concerns and see if there are things we can do to meet at a common ground. You can't always do that, but for us, it's extremely important to have that dialogue and continue that dialogue". Figure 3, summarizes a number of quotes from the interviews related to Finding 3. 


\section{FIGURE 3}

\section{Summary Quote Table - Finding 3}

\begin{tabular}{|c|c|}
\hline $\begin{array}{l}\text { "There are people that I really enjoy working with and } \\
\text { would be happy to work on just about anything with } \\
\text { and then there are other people with whom I've had } \\
\text { enough experience that I just don't care what the topic } \\
\text { is, I'm not really that interested in spending much time } \\
\text { working with them." }\end{array}$ & $\begin{array}{l}\text { So I try intensively if I'm going into a country to } \\
\text { understand the culture. It turns out that it's kind of } \\
\text { cool that Iceland's Chief of staff is the major } \\
\text { translator of the Icelandic Sagas in English. }\end{array}$ \\
\hline to "work in the margins" & $\begin{array}{l}\text { My interests, or my issues, or my agenda aren't } \\
\text { being served by this }\end{array}$ \\
\hline $\begin{array}{l}\text { "Inuits and their knowledge about ice. They know } \\
\text { more about ice than anyone else, perhaps, and taking } \\
\text { that knowledge and that experience on the east coast of } \\
\text { Canada". }\end{array}$ & $\begin{array}{l}\text { "having them meet people in the company, going } \\
\text { over there, coming back here, all that interaction } \\
\text { over the course of period of time builds these } \\
\text { connections between each other that are very } \\
\text { important...". }\end{array}$ \\
\hline $\begin{array}{l}\text { "... it was more a sense of a partner. In fact, at one } \\
\text { point during that program, we actually rescued and } \\
\text { helped towed in a whale that had been taken. When the } \\
\text { seas got rough and the boats were unable to perform, } \\
\text { we send a boat out and helped to do that. It was a very } \\
\text { cooperative atmosphere". }\end{array}$ & $\begin{array}{l}\text { We're not going to drill for ten years, but we would } \\
\text { like to engage with you. We want to talk about our } \\
\text { plans. We want to listen to your concerns and see } \\
\text { if there are things we can do to meet at a common } \\
\text { ground." You can't always do that, but for us, it's } \\
\text { extremely important to have that dialogue and } \\
\text { continue that dialogue }\end{array}$ \\
\hline
\end{tabular}

\section{Finding 4: Successful projects working across borders and with multiple parties combine the characteristics of sharing a vision of what is being done, agreement on a set of common goals and an appreciation of a greater purpose.}

The ability for a multiparty group to succeed working across borders is dependent on

the level that they are able to have a shared vision in what they are attempting to accomplish

with common goals and an understanding that there is a greater purpose in what they are

doing. Twenty-six respondents identified that it was necessary to have a greater purpose in

mind when working across borders and cultures included in this were components of shared

vision and common purpose. Figure 4, below summarizes a number of key quotes from

these interviews. This combination is necessary to align interests and identities and is

captured in the remarks of a respondent, who had worked in the offshore arctic region

recalled "a small number of very focused people, who understood the mission with great 
clarity, and complications associated with working in such a pristine environment, as well as working very close to villagers and people who depended on the sea for their survival." And, "in many cases we saw the challenges, the opportunity, we saw it with enough clarity that we could translate that into what we needed to do every day, and built our culture around that, which meant necessarily breaking down barriers, because they were in our way." This culture or identity is a key starting point in developing a shared vision as shared in how an indigenous created a business plan. "The vision was, together grow the company make not only our town a better place but to make the Yukon a better place.” This aspect of greater purpose and strong identity is important at the global level as well as recounted about early discussions related to the impacts on the Arctic indigenous people of Persistent Organic Pollutants (POPs): "what the aboriginal coalition brought to those global negotiations ... was an unassailable high moral ground and political authority in the first session of negotiations, and that lasted throughout the next year and a half to two years in the global negotiations."

The aspect of greater purpose and common goals is also related back to connectedness: "We see that there are commonalities also in the way of working and the types of challenges you face, which enables both our Canadian colleagues and our Norwegian colleagues to work together to reach a common goal, and having a similar outlook ... and it might sound a bit simple, but just the fact that it's cold and it rains a lot, tends to bring people together, and just sort of, 'Oh, it's raining again. Well, it rains back home as well.' Then you can laugh about those types of things, but it is something that brings people together, in addition to the more structured parts of projects." Finally, to summarize bringing people together over a common vision, the president of an indigenous corporation stated, "We have shareholders that we represent so we can't favor one shareholder base in a 
village over the others. We can help try to make things happen there but I guess paramount

behind things that we do we have to try to ensure that we do what's best for all the

shareholders. Including our at-large shareholders."

\section{FIGURE 4 \\ Summary Quote Table - Finding 4}

\begin{tabular}{|c|c|}
\hline \multicolumn{2}{|c|}{$\begin{array}{l}\text { Finding 4: Successful projects working across borders and with multiple parties combine the characteristics } \\
\text { of sharing a vision of what is being done, agreement on a set of common goals and an appreciation of a } \\
\text { greater purpose. }\end{array}$} \\
\hline $\begin{array}{l}\text { "a small number of very focused people, who } \\
\text { understood the mission with great clarity, and } \\
\text { complications associated with working in such a } \\
\text { pristine environment, as well as working very close to } \\
\text { villagers and people who depended on the sea for their } \\
\text { survival." }\end{array}$ & $\begin{array}{l}\text { "in many cases we saw the challenges, the } \\
\text { opportunity, we saw it with enough clarity that we } \\
\text { could translate that into what we needed to do } \\
\text { every day, and built our culture around that, which } \\
\text { meant necessarily breaking down barriers, because } \\
\text { they were in our way." }\end{array}$ \\
\hline $\begin{array}{l}\text { "The vision was, together grow the company make not } \\
\text { only our town a better place but to make the Yukon a } \\
\text { better place." }\end{array}$ & $\begin{array}{l}\text { "what the aboriginal coalition brought to those } \\
\text { global negotiations... was an unassailable high } \\
\text { moral ground and political authority ...." }\end{array}$ \\
\hline $\begin{array}{l}\text { work together to reach a common goal, and having a } \\
\text { similar outlook ... and it might sound a bit simple, but } \\
\text { just the fact that it's cold and it rains a lot, tends to } \\
\text { bring people together, and just sort of, "Oh, it's raining } \\
\text { again. Well, it rains back home as well." }\end{array}$ & $\begin{array}{l}\text { "We have shareholders that we represent so we } \\
\text { can't favor one shareholder base in a village over } \\
\text { the others. We can help try to make things happen } \\
\text { there but I guess paramount behind things that we } \\
\text { do we have to try to ensure that we do what's best } \\
\text { for all the shareholders." }\end{array}$ \\
\hline
\end{tabular}

In summary, the research suggests that these four findings may provide explanation and possibly influence in multiparty collaboration that work across borders and cultures. It is the absence of these findings that explains where projects were not as successful as envisioned. These findings have caused us to rethink our understanding of cultural factors as it relates to doing business across borders. The following sections will examine a new conceptual model derived from these findings that may have implications for understanding and implementing transnational multiparty collaboration.

\section{DISCUSSION}

The motivation to engage in this research was to understand transnational multiparty collaboration. The expectation was that there would be significant discussion on the role of 
culture, especially in light of the work that has been done by Hofstede, Trompenaars, Project Globe, and others where culture is defined in specific ways of communicating, authority and managing conflict. The approach to working across cultures is mapped in specific categories of "dos and do nots". Hofestede had identified five distinct cultural attributes that were then expanded by Project Globe to nine (Uncertainty Avoidance, Power Distance, Societal Collectivism, In-Group Collectivism, Gender Egalitarianism, Assertiveness, Future Orientation, Performance Orientation and Humane Orientation (House, Hanges, Javidan, Dorfman, \& Gupta, 2004). In order to implement this approach, Meyer proposes mapping eight management styles (Communicating, Evaluating, Persuading, Leading, Deciding, Trusting, Disagreeing and Scheduling) and those factors are linked back to similar descriptors mentioned above (Meyer, 2014). This work has had broad application and references including cross-border negotiations (Meyer, 2015; Sebenius, 2002), global software outsourcing (Krishna, Sahay and Walsham, 2004), transnational mergers (Ahern, Daminelli, \& Fracassi, 2012; Reus, 2012), project management (Chevrier, 2003; Ochieng \& Price, 2009; Zwikael, Shimizu, \& Globerson, 2005), design (Schadewitz, 2009) and as a means to understand "prosocial behaviors of donating to charities, volunteering and helping strangers" (Luria, Cnaan, \& Boehm, 2014).

And yet these structures did not stand out in any of the interviews. There were no discussions of processes, structure or "mapping" of key cultural components. Rather, terms such as respect, traditions and discipline were used were used to describe factors relating to different cultures and how to address those cultures. A much more relaxed approach to problems as they came along was more the norm. "As long as you respect the individual's culture, you can get the job done" seemed to encapsulate Finding 1: Differences in cultures 
needs to be acknowledged, respected and managed but once that is accommodated it has no additional impact on collaboration and completion of the project/work. What would explain this difference in expectations? First, the world is a more global place than even a decade ago, in addition to living at time where it is not unusual to know someone that has their origins from a country than yours, social media, 24/7 news programs, cable TV travel programs all provide exposure to different culture. Second, the majority of the studies listed above, for the most part, have at their core the scenario where an American would be moving to work in a foreign division of an organization or working with a team in another country. The population that the field research was conducted with and interviews taken were individuals that routinely worked with different countries or cultures and this was business as usual and their organizations reflected that business as normal attitude when working internationally. "The lack of institutional management of cross-cultural differences means that the leader explicitly or implicitly relies on tolerance and self-control to surmount differences" (Chevrier, 2003: 145). Finally, it is important to point out that individuals interviewed did not suggest that culture differences could be ignored; it was a factor that needed to be acknowledged and managed on an ongoing basis, but project success factors laid somewhere else. The management of culture did not assure success on multiparty efforts that crossed borders, nor did it lead to the emergence of any collaborative effort.

It is this last point that suggests that there is a different way to account for cultural distinctions that the cultural "factors" (as described above) should be considered in a different manner than previously done. That the identification and management of these distinctions are not vehicles to successful projects, the acknowledgement of the nine cultural attributes of Project Globe, will not guarantee that a team or a group will work together. 
However, one can state that if you do not accommodate cultural differences you will not succeed. We would suggest that cultural factors be considered analogous to "hygiene" factors where they would act as "dissatisfiers" if not addressed. Herzberg's two-factor theory (Herzberg et al., 1967) identifies two distinct sets of factors for job satisfaction and job performance in organizations. The first set identified as "satisfiers" or "motivators", results in satisfaction when adequately fulfilled. The other set, identified as "dissatisfiers" or "hygiene factors", causes dissatisfaction when not met, but if met are never motivators. Motivators tend to be intrinsic and are controlled by the individual or part of the job content. Hygiene factors are extrinsic in nature in that they involve those things surrounding the job but are not directly involved in the work itself. The most common example used in this discussion is salary or money; money can only be a dissatisfier and never a motivator. In a like way, acknowledging and understanding other cultures on your team will not be a motivator for those team members, assuring that religious requirements (prayer time for example), or dietary requirements will not be a motivator for someone, if not acknowledged there could be resentment, but acknowledged does not provide motivation. What is noteworthy in this discussion in that "stories about dissatisfaction involved bad company policies, but stories about satisfaction did not involve good company policies, they involved achievement" (Sachau, 2007: 379).

With the understanding that culture on its own can only be a dissatisfier, what then promotes the working together of multiple parties that come from different places and cultures? What defines the "tipping point" or emergence point for collaborative success? Figure 5 articulates a model, a construct that has as its engine three components of identity, interconnectedness and shared vision. All three components (as defined as Findings 2, 3 and 
4) are strongly interrelated and build on each other until collaborative success emerges. The discussion below defines through literature and experience what those three constructs are and how they interrelate.

Strongly related to culture is identity. Identity can be defined person or individual's perception of who they are and what they represent (self-identity) as well as those groups or organizations they might be associated with. Identity can be cultural, national, organizational or professional. While associated and potentially derived from culture, it is broader in its development and most importantly it can evolve, change or be built on, but like culture, identity is something that is not given up lightly, this feeling is particularly strong in indigenous populations. Sylvie Chevrier in her article Cross-cultural management in multinational project groups refers to the ability to create a project culture, while identity is a better word; the sentiment of being able to build on the strengths of individual identities and create a meta-identity is valid. "If the leaders of international project teams cannot draw upon shared national cultures, they may resort to other international cultures such as professional or corporate cultures to federate participants" (Chevrier, 2003: 147).

During the course of the interviews, all were asked about their background and education, with the exception of the Americans, and all introduced themselves by their national identity-Norwegian, Singaporean, Finnish, Canadian, etc. Interviewee’s representing indigenous groups introduced themselves by tribe. And the Americans introduced themselves by profession, degree or university. Walker Connor (1993) argues that "statesmen and scholars" tend to underestimate the "capacity" that "non-rational well springs of ethnonationalism" have on "influencing group behaviour". He then goes on to emphasize that these identities appeal to "kinship" and "blood". The interviews reflect this theme as 
well. When asked to describe how the interviewee's worked across borders, they sometimes described that working relations, in ethnonational terms-“Northern Europeans" have different work ethics from "Southern Europeans"- was code for Norway vs. Italy and that it was important to understand that and accommodate that in their planning. In one conversation with an Icelander, he described that Norwegians liked to have meetings in Iceland as it gave them a chance to visit a country where language and habit were more akin to early, original Norwegians and they had a chance to learn this history. While Connor's premise is still true, in the 20 years since this article was written, the world has become flatter there is more of a tendency to see "The Nation as Imagined Community" (Anderson, 1991). Our research also spoke of regional ethnonational descriptions such as Nordic, North American, Northern, and even Arctic as ways to describe identities that needed to be accommodated in transnational activities.

Social Identity refers to a person's knowledge that they belong to a certain social group that has significance and meaning to them. Theoretical principles of the theory include: 1) people work to achieve and maintain a positive social identity; 2) positive social identity is based on favorable comparisons made among groups to which a person belongs; and 3) if social identity is unsatisfactory, then people strive to leave their current groups for one more favorable (Tajfel \& Turner, 1979). Data suggests that transnationally individuals will identify with a group that may not simply be driven by borders. Arctic indigenous groupsmembership cross borders and often individuals from Norway, Sweden, Denmark or Finland—refer to themselves as Nordic (Iceland as well).

Transnational multiparty teams have two identities that they have to work with. The first is the identity of the organization they represent and the second is their individual 
identity. Both of these identities need to be accommodated. The former is more defined in terms of mission and objectives, while the second is one that can be more easily built on and would be open to a form of alignment known as Identity Fusion. Identity fusion is a relatively "unexplored form of alignment that entails a visceral feeling oneness with the group". This feeling of oneness is associated with "increased permeability of the boundary between the personal and social self", which can lead to increased likelihood that "individual identity will influence group identity and vice versa" (Swann et al., 2012). This alignment would be extremely powerful in multiparty transnational collaborations as discussed in looking at the four principles of identity fusion. The first is "Agentic-personal-self" where when an individual "fuses" with a group they do not give up their self-identity, but rather they take on the group identity. This increases the probability for collaboration within the team. Second is "Identity Synergy", where the group identity is greater than the sum of the individual identity. Third is "Relational Ties", those with highly fused identities recognize the same in the other group members strengthening the relational ties they have (the interconnectedness) making the group stronger. The last principle is "Irrevocability"; this is different from other teams where individuals remain tied to the group as long as the reason for the group fits their needs, because of the strong relational ties that were created. This creates a strong identity, that while it may supercede or take precedence over individual identity it does supplant it. The theory behind fused identity is one where influence flows in both direction to the group and to the individual, that personal self remains viable at the same time as the group identity. "Highly fused leaders may remain highly committed to the group while exercising their individual agency to steer the group in new directions" (Swann et al., 2012: 11). 
This concept of fused identity has at its core relational ties, where identities are recognized in others creating stronger bonds between group members — on both an individual basis and on organization basis. In our field research, this attribute was categorized as "interconnectedness" that action of connecting with each other on personal level creating a degree of interconnectedness where trust is established and a degree of becoming embedded in an organizational structures (Edmondson \& Nembhard, 2009). This happens over time and it was often referred to in the context of getting things done. The expression "in the margin of the meeting" was used to represent that it wasn't an organizational process that accomplished things rather it was the relationships. In his book, Relational being: Beyond self and community, Kenneth Gergen (2009) writes that all good emerges not from individual minds but from the relational process and that it is out of collaborative action that the individual mind comes into existence. "Conversations are invited for example, about times in which relations have been productive, from these conversations are drawn positive images of what is possible, and during this process a form of relationship emerges in which all are engaged in productive coordination" (Gergen, 2007: 376). He was referring to the process of Appreciative Inquiry, as it relates to developing relations and a sense of interconnectedness. Supporting and trusting relationships are the fulcrum that allows change to take place (Van Oosten, 2006). In the Intentional Change Theory, relationships actually facilitate the movement through each discovery that brings about purposeful change (Boyatzis \& Akrivou, 2006).

If a single word best captures the meaning of spirituality and the vital role it plays in people's lives, that word is interconnectedness. Those associated with organizations they perceived as "more spiritual" also saw their organizations as "more profitable" (Mitroff \& 
Denton, 1999). Spirituality should not be confused with religion, but should be considered the emotions that are at the core of an individual's belief system, something that an individual or group can rally around. In one of the interviews, President John F. Kennedy's speech at Rice University was mentioned, it was in that speech that President Kennedy articulated the vision that the United States would send a man to the moon and return him safely to earth, not because it was easy, but because it was difficult. A case can be made, especially after his assassination, that this goal articulated a spiritual connection between Americans at that time that allowed them to achieve great things, a focus that has not been achieved since.

The intentional change theory (ICT) establishes that positive, energizing relationships are not only critical in supporting change but a sense of group identity is an important element in the construct of shared vision (Boyatzis \& Akrivou, 2006). Which brings us to the final component of our model, which we are calling Greater Purpose, an aggregator of not just those aspects of a greater purpose or an aspect of spirituality as discussed above, but shared vision as well. "For many years practitioners and academics alike have argued that the creation of a vision, be it at an individual, team or organizational level, motivates people to action and inspires them to reach beyond their current state" (Boyatzis et al., 2015: 1). In order to create a shared vision (or personal vision), the individual or team must be in a Positive Emotional Attractor (PEA) mode. In this mode, neurologically the individual or team is in a creative and open mind, literally putting them in a frame of mind where collaboration can take place. The action of divining a greater purpose would put the team in this PEA state providing the opportunity for successful collaboration. In a world of continuous and rapid change, the capacity to sense and actualize emergent realities, that is 
perceiving the most attractive and compelling version of the future at the very moment it emerges and acting on it instantly and appropriately is considered the most critical source of future competitive environment (Kaiser et al., 2013).

Figure 5 represents a construct to explain collaborative success for transnational multiparty teams. First, the aspect of a cultural hygiene factor both emphasizes that culture must be managed for the long term in order to avoid dissatisfaction. Second, the interaction between identity, interconnectedness and greater purpose and shared vision is ongoing, each attribute building on the other attributes, a virtuous cycle, until a "meta-identity" emerges, building on shared experiences, strengths and sameness, that is of sufficient strength that the team identity is stronger than the individual's identity without incurring a sacrifice of those identities.

\section{FIGURE 5}

\section{Transnational Multiparty Collaboration Model}

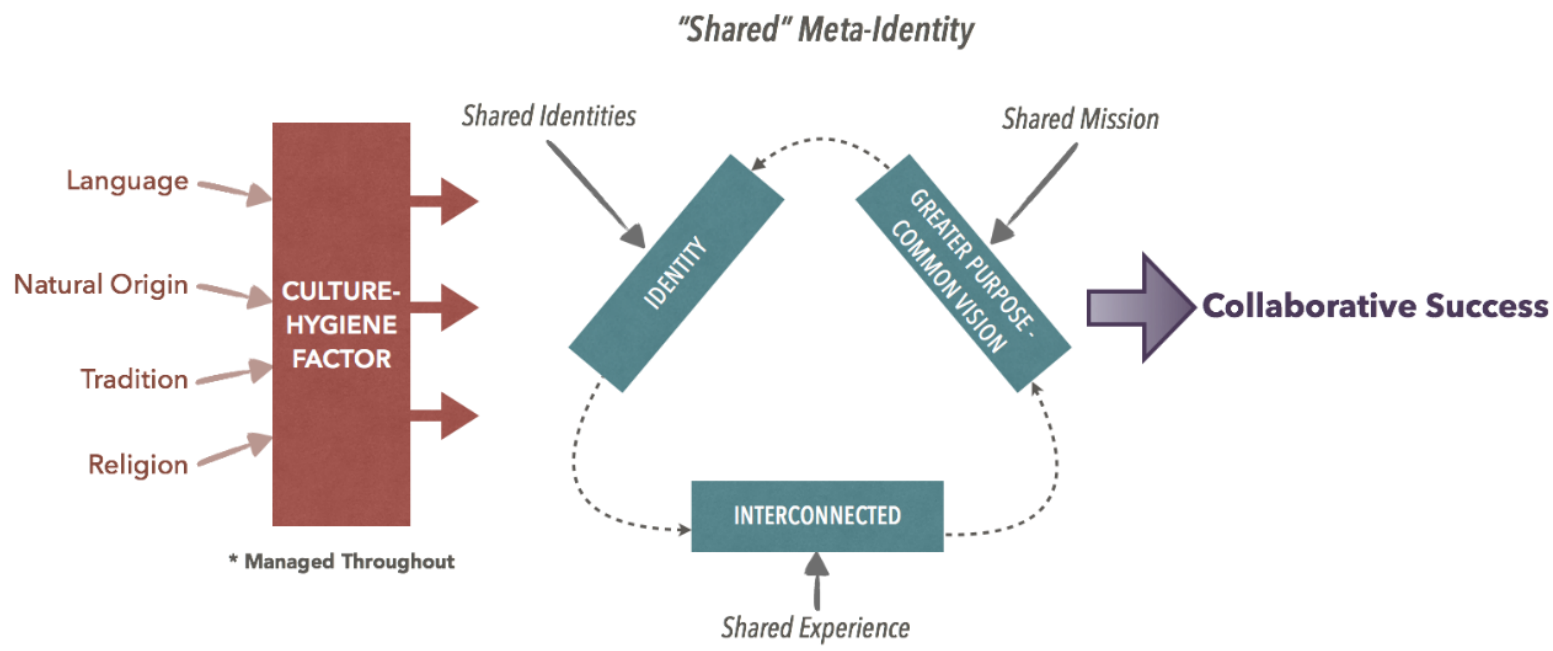

It is at this point, we believe, that the conditions are right to encourage a positive collaboration. It is believed that this transition or emergence is what explains the success of projects or work in this environment and creates an environment where the team and the 
individuals can truly flourish where "individuals who are full of vitality, for whom the "spirit within" is awakened, who are deeply in touch with their own purpose, and who feel connected to others" (Laszlo et al., 2014).

\section{LIMITATIONS}

Potential limitations of this study are as follows:

- The sample size of 27 may be small as it relates to the breadth of conclusions.

- There were limited responses that dealt with collaboration specifically, adding two additional questions may have helped elicit additional information:

1. How would you define successful collaboration?

2. We have talked about your individual experiences. Are there any organizational requirements that you have experienced that has led to cross border collaboration?

- The grounded theory approach serves as the strength of this study as well as its limitation (Mehan, 1979). It is well documented that there is the risk of disparity between the discourse of subjects in an interview and their actual actions as well as the struggle to keep the researcher's assumptions and potential biases at bay (Silverman, 1993).

\section{IMPLICATIONS FOR PRACTICE AND FUTURE RESEARCH}

This study has implications for practitioners even at this early stage. The concept that the role of a culture, as defined by national norms, is a hygiene factor is important. Specifically, culture must be acknowledged and managed continually if it is to avoid being a dissatisfier. However, it will never be a satisfier or motivator on transnational collaborative efforts. For that to occur, effort and time must be spent to allow for team/project identities to be developed on the strengths of individual identities. It is important to protect those identities in order to avoid the problems of a "Columbus effect" that would void efforts to create a larger identity. Additionally, attention and time must be given to allow for 
relationships to develop leading to an interconnectedness of the team. Finally, having shared

purpose and common visions as they relate to the project goals is critical to set the environment for success and collaboration.

However, this work also suggests the following areas for future research:

- It is envisioned that a continuum - Competition -> Cooperation -> Collaboration - exists where the degree of interconnectedness and shared vision (increase) drives the degree to which collaboration can take place. Look to see if this phenomenon is occurring and how to measure it.

- Better understand the degree to which the cultural hygiene factor has on collaboration

- Better understand the relationship of shared/vision/common goals/greater purpose with shared humanity.

- Sensemaking is grounded in identity construction referring to the need to have a sense of identity that would also include being part of a team. Sensemaking is also a social activity, as what a person does is as part of the group and shared experiences. Examining the role of sensemaking could play in the Identity Interconnectedness - Greater Purpose virtuous cycle could contribute to understanding this effect.

- A system is defined as a collection of elements that interact over time to form a unified whole and operate towards a common purpose, again there are aspects of a system in the framework for transnational multiparty collaboration. Behavior is determined by the interaction between the positive reinforcement and diffusion causal loops. In creating this model, the notion of a motivation threshold (mental model) that would assist in the definition of how much reinforcement and support from either experts or management to assure an innovative approach can succeed. Again, another area where further research can be conducted.

The results of this research have revised our understanding of how multiparty teams execute their work across borders - specifically; the aspect of culture as a hygiene factor and the power identity plays in developing a meta-identity. It is our hope and belief that this work can make a difference in the development of infrastructure projects not only in the Arctic, but wherever cross-border, cross-cultural work is being done. 


\section{REFERENCES}

Ackoff, R. L. 1979. Resurrecting the future of operational research. Journal of the Operational Research Society, 30(3): 189-199.

Adler, P. S. 2001. Market, hierarchy, and trust: The knowledge economy and the future of capitalism. Organization Science, 12(2): 215-234.

Ahern, K. R., Daminelli, D., \& Fracassi, C. 2012. Lost in translation? The effect of cultural values on mergers around the world. Journal of Financial Economics, 117(1): 165189.

Alaska Sea Grant Marine Advisory Program. n.d. Sea level rise and storm surge: Available from https://seagrant.uaf.edu/map/climate/docs/sea-level.php.

Allianz Global Corporate \& Specialty SE. 2014. Allianz Safety and Shipping Review: 26.

Amit, R. H., \& Zott, C. 2010. Business model innovation: Creating value in times of change. Barcelona, Spain: IESE Business School - University of Navarra.

Ang, S., \& Van Dyne, L. 2008. Conceptualization of cultural intelligence: Definition, distinctiveness, and nomological network. In S. Ang, \& L. Van Dyne (Eds.), Handbook of cultural intelligence: Theory, measurement, and applications: 3-15. New York: M.E. Sharpe.

Ang, S., Van Dyne, L., Koh, C., Ng, K. Y., Templer, K. J., Tay, C., \& Chandrasekar, N. A. 2007. Cultural intelligence: Its measurement and effects on cultural judgment and decision making, cultural adaptation and task performance. Management and Organization Review, 3(3): 335-371.

Arctic Council Arctic Marine Shipping Assessment (AMSA). 2009. Arctic marine shipping assessment: Arctic Council, April 2009, www.pame.is.

Bar-Yam, Y. 2004. Making things work: Solving complex problems in a complex world. London: Knowledge Industry.

Bass, B. M. 1985. Leadership and performance beyond expectations. Free Press; Collier Macmillan.

Bendis, R., \& Byler, E. 2009. Creating a national innovation framework: Building a publicprivate support system to encourage innovation, Science Progress. Washington: Center for American Progress.

Benedick, R. E. 1991. Ozone diplomacy. Cambridge: Harvard University Press. 
Bergek, A., Jacobsson, S., Carlsson, B., Lindmark, S., \& Rickne, A. 2008. Analyzing the functional dynamics of technological innovation systems: A scheme of analysis. Research Policy, 37(3): 407-429.

Bird, K. J., Charpentier, R. R., Gautier, D. L., Houseknecht, D. W., Klett, T. R., Pitman, J. K., Moore, T. E., Schenk, C. J., Tennyson, M. E., \& Wandrey, C. R. 2008. CircumArctic resource appraisal: Estimates of undiscovered oil and gas north of the Arctic Circle: United States Geological Survey (USGS).

Boisot, M., \& McKelvey, B. 2010. Integrating modernist and postmodernist perspectives on organizations: A complexity science bridge. Academy of Management Review, 35(3): 415-433.

Boudreau, K. J., \& Lakhani, K. R. 2013. Using the crowd as an innovation partner. Harvard Business Review, 91(4): 61-69.

Bouncken, R. B., \& Winkler, V. A. 2010. National and cultural diversity in transnational innovation teams. Technology Analysis \& Strategic Managment, 22(2): 133-151.

Bouwen, R., \& Taillieu, T. 2004. Multi-party collaboration as social learning for interdependence: Developing relational knowing for sustainable natural resource management. Journal of Community \& Applied Social Psychology, 14(3): 137-153.

Boyatzis, R. E., \& Akrivou, K. 2006. The ideal self as the driver of intentional change. Journal of Management Development, 25(7): 624-642.

Boyatzis, R. E., Rochford, K., \& Taylor, S. N. 2015. The role of the positive emotional attractor in vision and shared vision: Toward effective leadership, relationships, and engagement. Frontiers in Psychology, 6: 670.

Brandt, U. S., \& Svendsen, G. T. 2002. Hot air in Kyoto, cold air in The Hague - the failure of global climate negotiations. Energy Policy, 30(13): 1191-1199.

Brett, J., Behfar, K., \& Kern, M. C. 2006. Managing multicultural teams. Harvard Business Review, 84(11): 85-97.

Brewer, P., \& Venaik, S. 2010. GLOBE practices and values: A case of diminishing marginal utility? Journal of International Business Studies, 41(8): 1316-1324.

Brodbeck, F. C., Hanges, P. J., Dickson, M. W., Gupta, V., \& Dorfman, P. W. 2004. Comparative influence of industry and societal culture on organizational cultural practices. In R. J. House, P. J. Hanges, M. Javidan, P. Dorfman, \& V. Gupta (Eds.), Leadership, culture, and organizations: The GLOBE study of 62 societies: 654-668. Thousand Oaks, CA: Sage Publications, Inc.

Cameron, K. S., \& Caza, A. 2004. Contributions to the discipline of positive organizational scholarship. American Behavioral Scientist, 47(6): 731-739. 
Cameron, K. S., Dutton, J. E., \& Quinn, R. E. (Eds.). 2003. Positive organizational scholarship: Foundations of a new discipline. San Francisco, CA: Berrett-Koehler Publishers, Inc.

Carlsson, B., Jacobsson, S., Holmén, M., \& Rickne, A. 2002. Innovation systems: analytical and methodological issues. Research Policy, 31(2): 233-245.

Chanlat, J.-F., Davel, E., \& Dupuis, J.-P. (Eds.). 2013. Cross-cultural management: Culture and management across the world. New York, NY: Routledge.

Charmaz, K. 2006. Constructing grounded theory: A practical guide through qualitative research. London: SagePublications Ltd.

Chebbi, H., Yahiaoui, D., Thrassou, A., \& Vrontis, D. 2013. The exploration activity's added value into the innovation process. Global Business and Economics Review, 15(2-3): 265-278.

Cheek, J. M., Smith, S., \& Tropp, L. R. 2002. Relational identity orientation: A fourth scale for the AIQ Paper presented at the meeting of the Society for Personality and Social Psychology, Savannah, GA.

Chesbrough, H. 2006. Open business models: How to thrive in the new innovation landscape. Boston, MA: Harvard Business School Press.

Chevrier, S. 2003. Cross-cultural management in multinational project groups. Journal of World Business, 38(2): 141-149.

Chevrier, S. 2013. Managing multicultural teams. In J.-F. Chanlat, E. Davel, \& J.-P. Dupuis (Eds.), Cross-cultural management: culture and management across the world: 203-223. New York, NY: Routledge.

Coe, N. M., \& Bunnell, T. G. 2003. 'Spatializing' knowledge communities: towards a conceptualization of transnational innovation networks. Global Networks, 3(4): 437456.

Colquitt, J. A., Scott, B. A., \& LePine, J. A. 2007. Trust, trustworthiness, and trust propensity: A meta-analytic test of their unique relationships with risk taking and job performance. Journal of Applied Psychology, 92(4): 909-927.

Congden, S. W., Matveev, A. V., \& Desplaces, D. E. 2009. Cross-cultural communication and multicultural team performance: A German and American comparison. Journal of Comparative International Management, 12(2): 73-89.

Connor, W. 1993. Beyond reason: The nature of the ethnonational bond. Ethnic and Racial Studies, 16(3): 373-389. 
Corbin, J., \& Strauss, A. 1990. Basics of qualitative research (Vol. 15). Newbury Park, CA: Sage.

Davis, M. H. 1983. Measuring individual differences in empathy: Evidence for a multidimensional approach. Journal of Personality and Social Psychology, 44(1): $113-126$.

Dutton, J. E., \& Sonenshein, S. 2007. Positive organizational scholarship. In S. Lopez, \& A. Beauchamps (Eds.), Encylopedia of Postive Psychology. Oxford: Blackwell Publishing.

Edmondson, A., \& Reynolds, S. S. 2016. Building the future: Big teaming for audacious innovation. Oakland, CA: Berrett-Koehler Publishers.

Edmondson, A. C. 2012a. Teaming: How organizations learn, innovate, and compete in the knowledge economy. San Francisco, CA: Jossey-Bass.

Edmondson, A. C. 2012b. Teamwork on the fly. Harvard Business Review, 90(4): 72-80.

Edmondson, A. C., \& Nembhard, I. M. 2009. Product development and learning in project teams: the challenges are the benefits*. Journal of Product Innovation Management, 26(2): 123-138.

Elenkov, D. S., \& Manev, I. M. 2009. Senior expatriate leadership's effects on innovation and the role of cultural intelligence. Journal of World Business, 44(4): 357-369.

Emmerson, C. 2010. The Future History of the Arctic. New York, NY: Public Affairs.

Emmerson, C., \& Lahn, G. 2012. Arctic opening: Opportunity and risk in the High North. London: Chatham House.

Estrada, F., Perron, P., \& Martínez-López, B. 2013. Statistically derived contributions of diverse human influences to twentieth-century temperature changes. Nature Geoscience, 6(12): 1050-1055.

Fjeldstad, Ø. D., Snow, C. C., Miles, R. E., \& Lettl, C. 2012. The architecture of collaboration. Strategic Management Journal, 33(6): 734-750.

Fornell, C., \& Larcker, D. F. 1981. Evaluating structural equation models with unobservable variables and measurement error. Journal of Marketing Research, 18(1): 39-50.

Garcia-Morales, V. J., Llorens-Montes, F. J., \& Verdú-Jover, A. J. 2006. Antecedents and consequences of organizational innovation and organizational learning in entrepreneurship. Industrial Management \& Data Systems, 106(1): 21-42.

Gergen, K. J. 2007. Relativism, religion, and relational being. Common Knowledge, 13(2): 362-378. 
Gergen, K. J. 2009. Relational being: Beyond self and community. New York, NY: Oxford University Press.

Gioia, D. A., Thomas, J. B., Clark, S. M., \& Chittipeddi, K. 1994. Symbolism and strategic change in academia: The dynamics of sensemaking and influence. Organization Science, 5(3): 363-383.

Glaser, B. G., \& Strauss, A. L. 2009. The discovery of grounded theory: Strategies for qualitative research. New Brunswick, NJ: Aldine Transaction.

Gray, B. 1989. Collaborating: Finding common ground for multiparty problems. San Francisco, CA: Jossey-Bass.

Gray, B., \& Wood, D. J. 1991. Collaborative Alliances: Moving from Practice to Theory. Journal of Appiced Behavioral Science, 27(1): 3-32.

Greenert, J. W. 2014. The United States Navy Arctic Roadmap for 2014 to 2030: Office of the Chief of Naval Operations. Washington DC, Dtic Document.

Gutiérrez Gutiérrez, L. J., Lloréns-Montes, F. J., \& Bustinza Sánchez, Ó. F. 2009. Six sigma: From a goal-theoretic perspective to shared-vision development. International Journal of Operations \& Production Management, 29(2): 151-169.

Hair, J. F., Black, W. C., Babin, B. J., \& Anderson, R. E. 2010. Multivariate data analysis (7th ed.). Upper Saddle River, NJ: Pearson Prentice Hall

Hall, K. L., Stokols, D., Moser, R. P., Taylor, B. K., Thornquist, M. D., Nebeling, L. C., Ehret, C. C., Barnett, M. J., McTiernan, A., \& Berger, N. A. 2008. The collaboration readiness of transdisciplinary research teams and centers: Findings from the National Cancer Institute's TREC year-one evaluation study. American Journal of Preventive Medicine, 35(2): S161-S172.

Hayes, N. 1997. Successful team management. Thomson Learning.

Hemsath, J. R. 2015. Looking beyond culture: Building successful multiparty collaboration. Unpublished Qualitative Research Report. Case Western Reserve University, Cleveland, $\mathrm{OH}$.

Hemsath, J. R. 2017. Transnational multiparty collaboration: Determining success factors Unpublished Quantitative Research Report, Doctor of Management, Case Western Reserve Univeristy, Cleveland, $\mathrm{OH}$.

Herzberg, F., Mausner, B., \& Snyderman, B. 1967. The motivation to work (2 ed.). New York, NY: Wiley.

Hofner Saphiere, D. M. 1996. Productive behaviors of global business teams. International Journal of Intercultural Relations, 20(2): 227-259. 
Hofstede, G. 1997a. Culture and organizations: Software of the mind. New York: McGrawHill.

Hofstede, G. 1997b. Cultures and organzations: Software of the mind. New York, NY: McGraw-Hill.

Hofstede, G. 2001. Culture consequence. Thousand Oaks, CA: Sage.

Hofstede, G. 2010. The GLOBE debate: Back to relevance. Journal of International Business Studies, 41(8): 1339-1346.

House, R., Javidan, M., Hanges, P., \& Dorfman, P. 2002. Understanding cultures and implicit leadership theories across the globe: an introduction to project GLOBE. Journal of World Business, 37(1): 3-10.

House, R. J., Hanges, P. J., Javidan, M., Dorfman, P. W., \& Gupta, V. 2004. Culture, leadership, and organizations: The GLOBE study of 62 societies. Sage publications.

Hu, L. t., \& Bentler, P. M. 1999. Cutoff criteria for fit indexes in covariance structure analysis: Conventional criteria versus new alternatives. Structural Equation Modeling: A Multidisciplinary Journal, 6(1): 1-55.

Humpert, M. 2014. Arctic shipping: an analysis of the 2013 Northern Sea Route season: The Arctic Institute Center for Circumpolar Security Studies.

Huxham, C. 1996. Creating collaborative advantage. Sage.

Huxham, C., \& Vangen, S. 2005. Managing to collaborate. Abingdon: Routledge.

Jarvis, C. B., MacKenzie, S. B., \& Podsakoff, P. M. 2003. A critical review of construct indicators and measurement model misspecification in marketing and consumer research. Journal of Consumer Research, 30(2): 199-218.

Johnson, R. B., Onwuegbuzie, A. J., \& Turner, L. A. 2007. Toward a definition of mixed methods research. Journal of Mixed Methods Research, 1(2): 112-133.

Kaiser, A., Feldhusen, B., \& Fordinal, B. 2013. Vision development as a knowledge creating process Paper presented at the 2013 46th Hawaii International Conference on System Sciences (HICSS). 3593-3602.

Katz, B., \& Wagner, J. 2014. The rise of innovation districts: A new geography of innovation in america. Brookings Institution.

Kellow, A. 2010. Is the Asia-Pacific Partnership a viable alternative to Kyoto? Wiley Interdisciplinary Reviews: Climate Change, 1(1): 10-15. 
Kraska, J., \& Baker, B. 2014. Emerging Arctic Security Challenges. Washington, DC: Center of a New American Security.

Lakshman, C. 2013. Biculturalism and attributional complexity: Cross-cultural leadership effectiveness. Journal of International Business Studies, 44(9): 922-940.

Laszlo, C., Brown, J., Ehrenfeld, J., Gorham, M., Pose, I. B., Robson, L., Saillant, R., \& Sherman, D. 2014. Flourishing Enterprise: The New Spirit of Business. Stanford University Press.

Lax, D. A., \& Sebenius, J. K. 2003. 3-D negotiation: Playing the whole game. Harvard Business Review, 81(11).

Lax, D. A., \& Sebenius, J. K. 2006. 3D Negotiation. Boston, MA: Harvard Buisness School Press.

Lee, R. M., Draper, M., \& Lee, S. 2001. Social connectedness, dysfunctional interpersonal behaviors, and psychological distress: Testing a mediator model. Journal of Counseling Psychology, 48(3): 310-318.

Lewin, K. 1946. Action research and minority problems. Journal of Social Issues, 2(4): 3446.

Lindsey, R. 2013. 2013 Arctic Report Card: NOAA, https://www.climate.gov.

Luhtanen, R., \& Crocker, J. 1992. A collective self-esteem scale: Self-evaluation of one's social identity. Personality and Social Psychology Bulletin, 18(3): 302-318.

Luken, R., \& Grof, T. 2006. The Montreal Protocol's multilateral fund and sustainable development. Ecological Economics, 56(2): 241-255.

Luria, G., Cnaan, R. A., \& Boehm, A. 2014. National culture and prosocial behaviors results from 66 countries. Nonprofit and Voluntary Sector Quarterly, 44(5): 1041-1065.

Maccormack, A., Murray, F., \& Wagner, E. 2013. Spurring Innovation Through Competitions. MIT Sloan Management Review, 55(1): 26-32.

Marquardt, M. J., \& Horvath, L. 2014. Global teams: How top multinationals span boundaries and cultures with high-speed teamwork. Nicholas Brealey Publishing.

Martinez de Velasco Aguirre, E. 2012. Global Innovation Bridges: A new policy instrument to support global entrepreneurship in peripheral regions. University of California, Berkeley.

Matveev, A. V., \& Nelson, P. E. 2004. Cross cultural communication competence and multicultural team performance perceptions of American and Russian managers. International Journal of Cross Cultural Management, 4(2): 253-270. 
Mayer, R. C., \& Davis, J. H. 1999. The effect of the performance appraisal system on trust for management: A field quasi-experiment. Journal of Applied Psychology, 84(1): 123-136.

Mayer, R. C., Davis, J. H., \& Schoorman, F. D. 1995. An integrative model of organizational trust. Academy of Management Review, 20(3): 709-734.

Mehan, H. 1979. Learning lessons: Social organization in the classroom. Cambridge, MA: Harvard University Press.

Meyer, E. 2015. Getting to Sí, Ja, Oui, Hai, and Da. Harvard Business Review, 93(12): 7480.

Mitroff, I. I., \& Denton, E. A. 1999. A study of spirituality in the workplace. MIT Sloan Management Review, 40(4): 83.

Montzka, S., Butler, J., Elkins, J., Thompson, T., Clarke, A., \& Lock, L. 1999. Present and future trends in the atmospheric burden of ozone-depleting halogens. Nature, 398(6729): 690-694.

Nansen, F. 1914. Through Siberia, the land of the future. London: Cambridge University Press.

Nansen, F. 1923. Russia and peace. London: Routledge.

Ng, E. S., \& Tung, R. L. 1998. Ethno-cultural diversity and organizational effectiveness: A field study. International Journal of Human Resource Management, 9(6): 980-995.

NSIDC. 2014: National Snow and Ice Data Center, http://nsidc.org/.

Ochieng, E. G., \& Price, A. D. 2009. Framework for managing multicultural project teams. Engineering, Construction and Architectural Management, 16(6): 527-543.

Oswald, S. L., Mossholder, K. W., \& Harris, S. G. 1994. Vision salience and strategic involvement: Implications for psychological attachment to organization and job. Strategic Management Journal, 15(6): 477-489.

Podsakoff, P. M., MacKenzie, S. B., Lee, J.-Y., \& Podsakoff, N. P. 2003. Common method biases in behavioral research: a critical review of the literature and recommended remedies. Journal of Applied Psychology, 88(5): 879-903.

Prins, S. 2010. From competition to collaboration: Critical challenges and dynamics in multiparty collaboration. Journal of Appiced Behavioral Science, 46(3): 281-312.

Prins, S., \& Bouwen, R. 2003. Distributed leadership in multiparty collaboration: Opportunities and challenges for leadership in the space-in-between organizations, Holland. 
Ramalingam, B., Jones, H., Reba, T., \& Young, J. 2008. Exploring the science of complexity: Ideas and implications for development and humanitarian efforts (2nd ed.). London: Overseas Development Institute

Ramarajan, L. 2014. Past, present and future research on multiple identities: Toward an intrapersonal network approach. The Academy of Management Annals, 8(1): 589659.

Rapoport, R. N. 1970. Three dilemmas in action research: with special reference to the Tavistock experience. Human Relations, 23(6): 499-513.

Reus, T. H. 2012. Culture's consequences for emotional attending during cross-border acquisition implementation. Journal of World Business, 47(3): 342-351.

Reynolds, C. R., \& Paget, K. D. 1983. National normative and reliability data for the revised Children's Manifest Anxiety Scale. School Psychology Review, 12: 324-336.

Ronen, S., \& Shenkar, O. 2013. Mapping world cultures: Cluster formation, sources and implications. Journal of International Business Studies, 44(9): 867-897.

Ruben, B. D. 1976. Assessing communication competency for intercultural adaptation. Group \& Organization Management, 1(3): 334-354.

Sachau, D. A. 2007. Resurrecting the motivation-hygiene theory: Herzberg and the positive psychology movement. Human Resource Development Review, 6(4): 377-393.

Schadewitz, N. 2009. Design patterns for cross-cultural collaboration. International Journal of Design, 3(3): 37-53.

Schön, D. A. 1983. The reflective practitioner: How professionals think in action. New York, NY: Basic Books.

Schouten, E. M., \& Remmé, J. 2006. Making sense of corporate social responsibility in international business: Experiences from Shell. Business Ethics: A European Review, 15(4): 365-379.

Sebenius, J. K. 2002. Hidden challenge of cross-border negotiations. Harvard Business Review, 80(3): 76-85.

Silverman, D. 1993. Qualitative research. London; Thousand Oaks, CA: Sage Publications.

Silverman, D. 2014. Interpreting qualitative data (5th ed.). Thousand Oaks, CA: Sage Publications, Inc.

Strauss, A., \& Corbin, J. (Eds.). 1998. Basics of qualitative research: Procedures and techniques for developing grounded theory. Thousand Oaks, CA: Sage. 
Subbarao, S., \& Lloyd, B. 2011. Can the Clean Development Mechanism (CDM) deliver? Energy Policy, 39: 1600-1611.

Sunstein, C. R. 2006. Montreal versus Kyoto: A tale of two protocols: University of Chicago Public Law \& Legal Theory Working Paper No. 136. Available from http://chicagounbound.uchicago.edu/cgi/viewcontent.cgi?article=1194\&context=publ ic_law_and_legal_theory.

Susman, G. I., \& Evered, R. D. 1978. An assessment of the scientific merits of action research. Administrative Science Quarterly, 23(4): 582-603.

Swann, J., William B, Jetten, J., Gómez, A., Whitehouse, H., \& Bastian, B. 2012. When group membership gets personal: A theory of identity fusion. Psychological Review, 119(3): 441.

Tajfel, H., \& Turner, J. C. 1979. An integrative theory of intergroup conflict. In W. G. Austin, \& S. Worchel (Eds.), The social psychology of intergroup relations: 33-47. Monterey, CA: Brooks-Cole.

Teddlie, C., \& Tashakkori, A. 2009. Foundations of mixed methods research: Integrating quantitative and qualitative approaches in the social and behavioral sciences. Thousand Oaks, CA: Sage Publications, Inc.

Trompenaars, F., \& Hampden-Turner, C. 1998. Riding the waves of culture (second ed.). New York, NY: McGraw-Hill.

Tsai, W., \& Ghoshal, S. 1998. Social capital and value creation: The role of intrafirm networks. Academy of Management Journal, 41(4): 464-476.

United States Coast Guard. 2013. United States Coast Guard Arctic strategy: Department of Homeland Security - U.S. Government.

Van Der Zee, K. I., \& Van Oudenhoven, J. P. 2000. The Multicultural Personality Questionnaire: A multidimensional instrument of multicultural effectiveness. European Journal of Personality, 14(4): 291-309.

Van Dyne, L., Ang, S., Ng, K. Y., Rockstuhl, T., Tan, M. L., \& Koh, C. 2012. Subdimensions of the four factor model of cultural intelligence: Expanding the conceptualization and measurement of cultural intelligence. Social and Personality Psychology Compass, 6(4): 295-313.

Van Oosten, E. B. 2006. Intentional change theory at the organizational level: a case study. Journal of Management Development, 25(7): 707-717.

Weick, K. E. 1995. Sensemaking in organizations. Thousand Oaks, CA: Sage. 
Weick, K. E., Sutcliffe, K. M., \& Obstfeld, D. 2005. Organizing and the process of sensemaking. Organization Science, 16(4): 409-421.

Wiseman, R. L., \& Shuter, R. 1994. Communicating in multinational organizations. Sage.

Wittgenstein, L. 1999. Tractatus Logico-Philosophicus (C. Ogden, Trans.). Dover Publications, Inc. Original work published in 1922.

Zwikael, O., Shimizu, K., \& Globerson, S. 2005. Cultural differences in project management capabilities: A field study. International Journal of Project Management, 23(6): 454-462. 


\title{
TRANSNATIONAL MULTIPARTY COLLABORATION: DETERMINING SUCCESS FACTORS
}

\author{
By
}

\section{James R. Hemsath}

\section{Submitted in Partial Fulfillment of the Requirements for the Quantitative Research Report in the Doctor of Management Program \\ at the Weatherhead School of Management}

Advisors:

Chris Laszlo, Ph.D.

Kathleen Buse, Ph.D.

Yunmei Wang, Ph.D.

\section{CASE WESTERN RESERVE UNIVERSITY}

January 2017 


\title{
TRANSNATIONAL MULTIPARTY COLLABORATION: DETERMINING SUCCESS FACTORS
}

\begin{abstract}
The complexities of global business and the need for rapid, effective responses to problems that cross borders and span cultures demand an understanding of transnational multiparty collaboration success factors. At the core of this work is 1) understanding the role that culture and identity play in creating a meta-identity built on the strengths of individual and organization identities; 2) the development of strong connectedness between the parties; and 3) the creation of a shared vision of what is trying to be achieved. This paper introduces a hypothesized model of transnational multiparty collaboration in order to examine how identity, culture, shared vision, empathy, and trust interact to influence successful collaboration. The survey gathered information from over 300 participants that represent eleven national/cultural sectors, 63\% representing as Anglo, 12\% Nordic European and 7.5\% Indigenous. Our findings are that aspects of culture, while important, can be seen as a dissatisfier, and once addressed, has little role in influencing collaboration. Empathy and Trust as representatives of interconnectedness have strong impacts on both shared vision and collaboration. Additionally, while role identity was a strong influence on shared vision, it had a negative influence on collaboration. In a like manner, individual identity had a negative influence on shared vision but a strong influence on collaboration. This suggests a need to balance role and individual identity to take advantage of differing perspectives, and in order to develop trust and empathy for roles including cultural roles, the project design must include incubation time.
\end{abstract}

Keywords: collaboration; multiparty; identity; culture; transnational; interconnectedness; empathy; trust; shared vision 


\section{INTRODUCTION}

The world is an increasingly complex place. Treaties such as the Trans-Pacific Partnership (TPP signed in February 2016), or the United Nation Convention on the Law of the Seas (UNCLOS, $\mathrm{Ku}, 2016$ ) are under debate as to their applicability as well as presenting the need for groups to work more efficiently across borders. The signing of the treaty on climate change in Paris in December 2015 will necessitate cross-border cooperation and collaboration between multiple parties and nations. In the Arctic, climate change is opening up new shipping lanes while at the same time increased winter storms and subsequent erosion are threatening communities (Alaska Sea Grant Marine Advisory Program, n.d.). With a quarter of the world's oil and gas reserves (Bird et al., 2008) and the ability to shorten the shipping distances by half (Greenert, 2014) from Europe to Asia and the United States, the Arctic is poised to be the next significant global development arena. To support this development, significant investments in infrastructure (Allianz Global Corporate \& Specialty SE, 2014) will be necessary in amounts that may exceed any one locale or region's ability to provide. In order to answer these challenges, it is necessary to find a way to work with different groups across borders and cultures.

Multiparty collaboration must consider both technical complexities of the collaboration as well as the social issues that will require the collaboration of a wide variety

of public and private authorities, technical experts, and social interest groups, all as interested stakeholders (Prins \& Bouwen, 2003). "Participation is not merely an instrument, but a complex system of structure and processes" (Bouwen \& Taillieu, 2004: 138). Understanding the motivations, drivers, intergroup characteristics, and inter-organizational dynamics is critical towards understanding multiparty collaboration (Prins, 2010). 
In companies that work to expand globally, team performance becomes vulnerable to cross-cultural interaction problems (Congden et al., 2009; Matveev \& Nelson, 2004). Managing cultural diversity, cultural differences, and cross-cultural conflicts have surfaced as frequent challenges for cross-cultural teams (Congden et al., 2009; Marquardt \& Horvath, 2014). However, the literature does not discuss cross-cultural collaboration. Much of the discussion centers on innovation of technical issues or the creation of areas where innovation could take place or what they termed as "districts" (Katz \& Wagner, 2014) within the context of constant change. References to "transnational" in articles related to innovation are focused on the need of a diverse team to foster innovation rather than innovation across borders (Bouncken \& Winkler, 2010; Edmondson, 2012a).

What is not clearly understood in the literature is how the combination of transnational and cross-cultural projects would complicate collaboration. Additionally, understanding that culture on its own can only contribute to dissatisfaction (Hemsath, 2015), what then promotes the working together of multiple parties that come from different places and cultures? The purpose of this study is to determine what factors might lead to or facilitate collaboration on projects or programs that are made up of multiple parties (entities) each with specific motivations and where those parties are from different nationalities and cultures. Ultimately our goal is to understand, under the umbrella of multiparty projects, how the variety of aspects such as culture, identity, interconnectedness, trust, empathy, shared vision come together to facilitate collaboration. These questions have guided the development of the following central research questions (RQ):

RQ1: What factors help explain successful transnational, cross-cultural multiparty collaboration? 
RQ2: What role does culture, cultural intelligence and identity and role identity play

in the facilitation of multiple parties working across borders and cultures?

RQ3: What are the relationships between empathy, trust and shared vision as they relate to collaboration?

\section{THEORY AND HYPOTHESES}

Previous qualitative research and the related emergent findings are used initially to develop the hypothesized quantitative study model. Hemsath (2015) found that differences in cultures must be acknowledged, but have less impact on project completion; Group and individual identity emerged as perhaps more important than national identity (culture); interconnectedness between parties has an impact on project success; and finally, shared vision is a critical component to reaching successful project goals. It is these emergent findings that motivate this research and to further understand translational multiparty collaboration.

A hypothesized model articulating what areas would influence successful collaboration across borders and cultures is shown in Figure 1. The model addresses the major concepts of identity (individual and role); empathy and trust; and shared vision. The role of culture intelligence is acknowledged as influencing both shared vision and subsequently collaboration. Our constructs are defined as follows:

- Cultural Intelligence (CQ): The capability of an individual to function effectively in culturally diverse settings (Van Dyne et al., 2012) and is based on four factors-Metacognitive CQ (mental ability to evaluate one's cultural knowledge), Motivational CQ (self-motivation to perform in cross-cultural situations) and Behavioral CQ (ability to adapt to different cultures).

- Individual Identity: The level or strength of an individual's identity and ability to share that identity will have a direct relationship with their ability to connect with another and not lose their own aspect of self-identity, at the same time the degree that they are willing to fuse their identity (Swann et al., 2012). 
- Group Identity (Role): Social Identity, or how much one identifies with their group, will have an impact on a multiparty collaboration and the willingness of that representative to be part of a shared vision.

- Empathy: The inherent ability of an individual to empathize with another will have an impact both on the degree to which they will be able to have a shared vision as well as be open to the constraints their role or group identity, which in turn will allow them to be open to collaboration.

- Trust: Defined as the willingness of a party to be vulnerable to the actions of another party based on the expectation that the other will perform a particular action important to the trustor, irrespective of the ability to monitor or control that other party (Mayer et al., 1995).

- Shared Vision: A common mental model of what the future will look like, it represents the capacity of sharing of that mental model, implied in this definition is a commitment by the group.

- Collaboration: The process of two or more people or organizations working together to realize shared goals. Inherent in this process is that the whole is greater than the sum.

FIGURE 5

\section{Hypothesized Model}

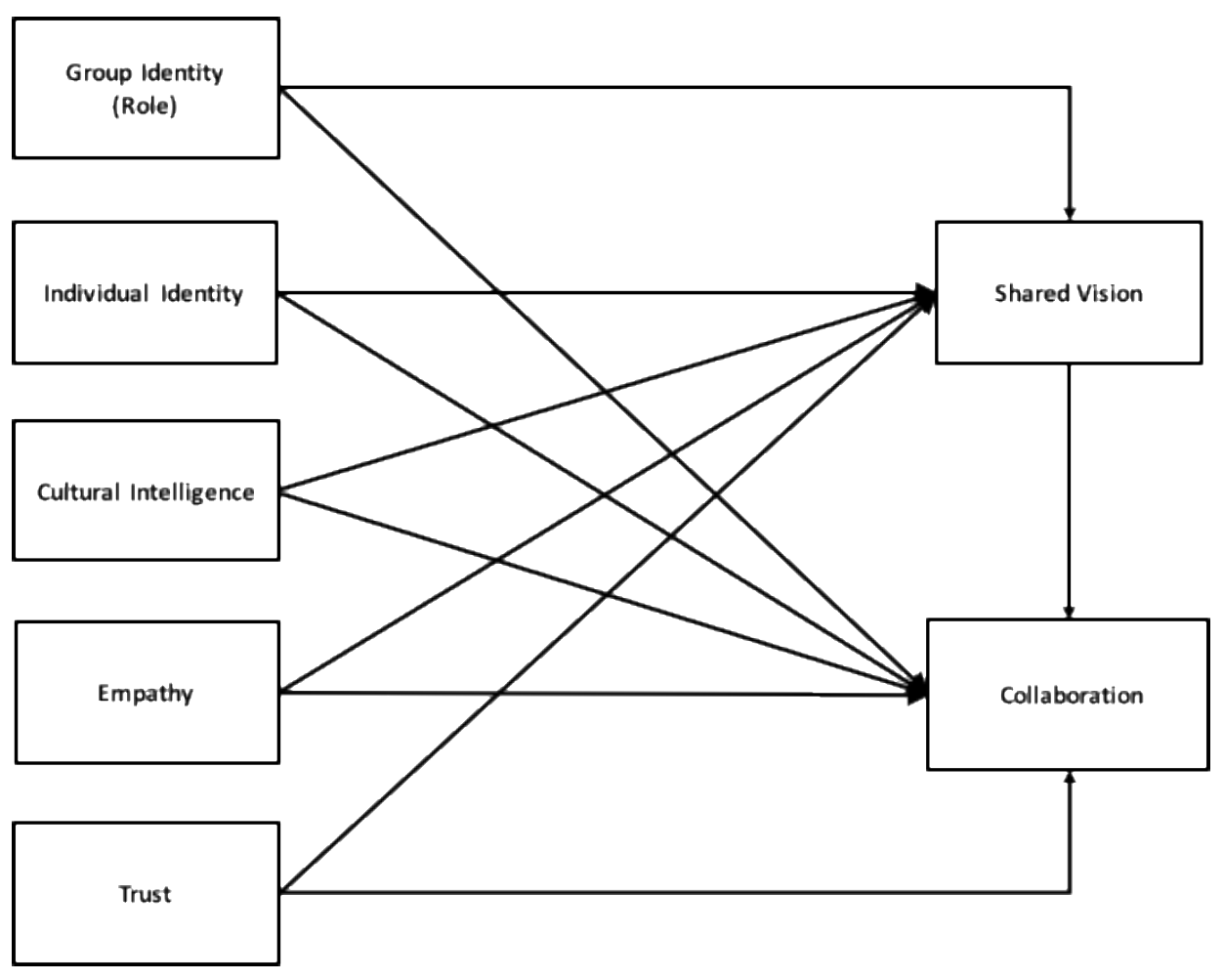


The expectation was that there would be significant discussion on the role of culture, especially in light of the work that has been done by Hofstede (1997b), Trompenaars and Hampden-Turner (1998), Project Globe (House, Javidan, Hanges, \& Dorfman, 2002) and others where culture is defined in specific ways of communicating, authority and managing conflict. These ideas are not entirely supported (Hemsath, 2015). There were no discussions of processes, structure or "mapping" of key cultural components. Rather, terms such as respect, traditions and discipline were used were used to describe factors relating to different cultures and how to address those cultures (Hemsath, 2015). A much more relaxed approach to problems as they came along was more the norm. Differences in cultures need to be acknowledged, respected and managed but once that is accommodated, it has no additional direct impact on collaboration and completion of the project/work. "The lack of institutional management of cross-cultural differences means that the leader explicitly or implicitly relies on tolerance and self-control to surmount differences" (Chevrier, 2003: 145). Finally, it is important to point out that individuals interviewed did not suggest that culture differences could be ignored. The act of collaboration and the creating of a shared vision are similar in that they are about individuals working together; logic dictates that cultural intelligence will play a role in these actions. As such, we propose the following hypotheses related to culture and its impact on both Shared Vision and Collaboration

Hypothesis 1a. Cultural Intelligence has a positive effect on Shared Vision. Hypothesis 1b. Cultural Intelligence has a positive effect on Collaboration. Strongly related to culture is identity. Identity can be defined as a person or individual's perception of who they are and what they represent (self-identity) as well as those groups or organizations they might be associated with (role). Identity can be cultural, 
national, organizational or professional. While associated and potentially derived from culture, it is broader in its development, and most importantly, it can evolve, change or be built on, but like culture, identity is something that is not given up lightly, this feeling is particularly strong in indigenous populations. Chevrier (2003) refers to the ability to create a project culture, while identity is a better word; the sentiment of being able to build on the strengths of individual identities and create a meta-identity is valid. "If the leaders of international project teams cannot draw upon shared national cultures, they may resort to other international cultures such as professional or corporate cultures to federate participants" (Chevrier, 2003: 147).

In a set of recent interviews (Hemsath, 2015), participants, all (with the exception of Americans) identified themselves first by their national identity (Norwegian, Singaporean, Finnish, Canadian, etc.) then by profession, degree or university. Interviewees representing indigenous groups tended to identify by tribal affiliation, then profession. Connor (1993) argues that "statesmen and scholars" tend to underestimate the "capacity" that "non-rational well springs of ethnonationalism" have on "influencing group behaviour."

Social Identity refers to a person's knowledge that they belong to a certain social group that has significance and meaning to them. Theoretical principles of the theory include: 1) people work to achieve and maintain a positive social identity; 2) positive social identity is based on favorable comparisons made among groups to which a person belongs; and 3) if social identity is unsatisfactory, then people strive to leave their current groups for one more favorable (Tajfel \& Turner, 1979). Data suggests that transnationally individuals will identify with a group that may not simply be driven by borders. Arctic indigenous groupsmembership cross borders and often individuals from Iceland, Norway, Sweden, Denmark or 
Finland —refer to themselves as Nordic. In establishing a shared vision individual identities must be acknowledged and incorporated, in a multipart event group identity must also be part of the shared vision

\section{Hypothesis 2a. Group Identity has a positive effect on Shared Vision.}

Hypothesis 2b. Individual Identity has a positive effect on Shared Vision.

Transnational multiparty teams have two identities that they have to work with. The first is the identity (role) of the organization (multiparty) they represent and the second is their individual identity. Both of these identities need to be accommodated. The former defined in terms of mission and objectives, while the second is one that can be more easily built on and would be open to, a form of alignment known as Identity Fusion. Identity fusion is a relatively "unexplored form of alignment that entails a visceral feeling oneness with the group." This feeling of oneness is associated with "increased permeability of the boundary between the personal and social self," which can lead to increased likelihood that "individual identity will influence group identity and vice versa" (Swann et al., 2012). This alignment would be extremely powerful in multiparty transnational collaborations as discussed in looking at the four principles of identity fusion. The first is "Agentic-personal-self" where when an individual "fuses" with a group they do not give up their self-identity, but rather they take on the group identity. This increases the probability for collaboration within the team. Second is "Identity Synergy," where the group identity is greater than the sum of the individual identity. Third is "Relational Ties," those with highly fused identities recognize the same in the other group members strengthening the relational ties they have (the interconnectedness) making the group stronger. The last principle is "Irrevocability"; this is different from other teams where individuals remain tied to the group as long as the reason 
for the group fits their needs, because of the strong relational ties that were created. This creates a strong identity, that while it may supersede or take precedence over individual identity, it does supplant it. The theory behind fused identity is one where influence flows in both directions to the group and to the individual, that personal self remains viable at the same time as the group identity. "Highly fused leaders may remain highly committed to the group while exercising their individual agency to steer the group in new directions" (Swann et al., 2012: 11), which could be considered an alternate definition of collaboration. However an overemphasis on group identity could hamper the ability to find a collaborative approach that addresses all parties needs in the same way that group think encourages unrealistic unanimity versus team think (Hayes, 1997: 136).

Hypothesis 2c. Individual Identity has a positive effect on Collaboration. Hypothesis 2d. Group Identity has a negative effect on Collaboration.

The concept of fused identity has at its core relational ties, where identities are recognized in others creating stronger bonds between group members - on both an individual basis and on organization basis. In our field research, this attribute was categorized as "interconnectedness" that action of connecting with each other on personal level creating a degree of interconnectedness where trust is established and a degree of becoming embedded in an organizational structure (Edmondson \& Nembhard, 2009). This happens over time, and it was often referred to in the context of getting things done. The expression "in the margin of the meeting" was used to represent that it was not an organizational process that accomplished things rather it was the relationships. Not all good emerges from individual minds but from the relational process, and it is out of collaborative action that the individual mind comes into existence. "Conversations are invited for example, about times in which 
relations have been productive, from these conversations are drawn positive images of what is possible, and during this process, a form of relationship emerges in which all are engaged in productive coordination" (Gergen, 2007: 376). He was referring to the process of Appreciative Inquiry, as it relates to developing relations and a sense of interconnectedness. Supporting and trusting relationships are the fulcrum that allows change to take place (Van Oosten, 2006). In the Intentional Change Theory, relationships actually facilitate the movement through each discovery that brings about purposeful change (Boyatzis \& Akrivou, 2006).

If a single word best captures the meaning of spirituality and the vital role it plays in people's lives, that word is interconnectedness (Hemsath, 2015). Those associated with organizations they perceived as "more spiritual" also saw their organizations as "more profitable" (Mitroff \& Denton, 1999). Spirituality should not be confused with religion but should be considered the emotions that are at the core of an individual's belief system, something that an individual or group can rally around. While interconnectedness can provide a conceptual model of the mechanism, there is little in the literature that would lead us to constructs that would allow us to measures this phenomenon. Therefore, we will look towards two potential antecedents that are integral to interconnectedness - trust and empathy. Empathy and Trust are necessary components of the process we are calling transnational multiparty collaboration. The ability of an individual to be able to empathize with another person's role identity or other structural constraints on their ability to participate in a certain will allow both parties to find alternate solutions a key aspect of collaboration. Empathy can be defined as the "reactions of one individual to the observed experiences of another" (Davis, 1983). Ruben (1976) defines cultural empathy as "the capacity to clearly project an interest 
in others, as well as to obtain and to reflect a reasonably complete and accurate sense of another's thoughts, feelings, and/or experiences." The ability to empathize with other team members is a necessity to come to an agreement on a shared vision and to be open to collaboration.

Hypothesis 3a. Empathy has a positive effect on Shared Vision. Hypothesis 3b. Empathy has a positive effect on Collaboration.

All negotiations can break down over the ability of one party to trust another. It is, therefore, reasonable to want to understand the role that trust plays in multiparty transnational collaboration. Instinctively we appreciate that the greater the degree of trust, or in other words, the greater the willingness of one party to trust another will have an impact on multiparty transnational collaboration. Trust is defined as the willingness of a party to be vulnerable to the actions of another party based on the expectation that the other will perform a particular action important to the trustor, irrespective of the ability to monitor or control that other party (Mayer et al., 1995).

Hypothesis 3c. Trust has a positive effect on Collaboration. Hypothesis 3d. Trust has a positive effect on Shared Vision. Hemsath's (2015) finding that successful transnational multiparty projects combine the characteristics of a shared vision that includes agreement on a set of common goals and an appreciation of a greater purpose. The definition of collaboration is the coming together of individuals to realize shared goals or shared visions. The two constructs are intertwined strongly suggesting that shared vision plays a role in collaboration.

Hypothesis 4. Shared vision has a positive effect on Collaboration. 
The intentional change theory (ICT) establishes that positive, energizing relationships are not only critical in supporting change but a sense of group identity is an important element in the construct of shared vision (Boyatzis \& Akrivou, 2006). Which brings us to the final component of our model where Shared Vision acts as an aggregator of not just those aspects of a greater purpose or an aspect of spirituality as discussed above, but as an aggregator of all those factors, identity, empathy and trust to allow parties to collaborate. "For many years practitioners and academics alike have argued that the creation of a vision, be it at an individual, team or organizational level, motivates people to action and inspires them to reach beyond their current state" (Boyatzis et al., 2015: 1). In a world of continuous and rapid change, the capacity to sense and actualize emergent realities, that is perceiving the most attractive and compelling version of the future at the very moment it emerges and acting on it instantly and appropriately is considered the most critical source of future competitive environment (Kaiser et al., 2013). Given the importance of having a shared vision, we would expect that once a shared vision is created the individual components of identity, empathy, and trust to be amplified. The following hypotheses articulate that relationship between shared vision and identity (group and individual), empathy, and trust in the development of a collaborative environment.

Hypothesis 5a. Shared vision partially mediates the effect of group identity on collaboration.

Hypothesis 5b. Shared vision partially mediates the effect of individual identity on collaboration.

Hypothesis 5c. Shared vision partially mediates the effect of empathy on collaboration. 
Hypothesis 5d. Shared vision partially mediates the effect of trust on successful collaboration.

\section{MEASURES}

For each construct, participants were asked to rate items on a 1 (strongly disagree) to 5 (strongly agree) response scale that best describes the individual as they really are to collect information on the three independent variables (individual and group identity, interconnectedness, one mediator (shared vision), one moderator (culture) and one dependent variable (successful collaboration). This survey was sent via email to 2,000 participants located in or working in the Arctic who are also working internationally. This is a broadbased survey and information was collected on Nationality, Age, Gender, Current Occupation (experience), Education and Sector (public, private, academic and NGO). A discussion on the model constructs follows describing the sources of scales for measure and sources of those measures.

\section{Cultural Intelligence}

A 10-item Cultural Intelligence Scale adapted from CQS (Ang \& Van Dyne, 2008), a five-point scale that has gone through extensive validation where the different Cronbach's Alphas exceed 0.70. In our hypothesis, it is suggested that the higher the CQ, the better, and an individual should be able to connect in a multiparty team. CQ has been used both in studies on transformational leadership (Bass, 1985) and organizational innovation (Elenkov \& Manev, 2009).

\section{Individual Identity}

The Aspects of Identity Questionnaire (AIQ-IV) as developed by Cheek, Smith, and Tropp (2002) was adapted resulting in nine key items to be measured on a five-point Likert scale. This is a highly reliable scale as shown with a Cronbach's Alpha of 0.92 . 


\section{Group or Role Identity}

Luhtanen and Crocker (1992) have devised a 16-point Collective Self-Esteem Scale that was adapted to include 11 relevant questions to determine how much of an individual's self-esteem is related to their social or group identity. The Collective Self-Esteem Scale has an Alpha $=0.92$.

\section{Interconnectedness}

The degree that individuals connect has a direct relationship to being able to create shared value. The degree of interconnectedness will be measured utilizing a scale devised to measure social connectedness (Lee, Draper, \& Lee, 2001). A seven-item scale was adapted from this work. This scale had an Alpha $=0.86-0.89$. While not part of our hypothesis we will collect data for this construct for later use.

\section{Empathy}

The eight-question survey used was adapted from the Multicultural Personality Questionnaire by Van Der Zee and Van Oudenhoven (2000). This scale has an Alpha = 0.78.

\section{Shared Vision}

Our model hypothesizes that that stronger the degree of Shared Vision the higher the likelihood of having a successful collaboration. The degree of Shared Vision will be measured using a scale devised by Gutiérrez Gutiérrez, Lloréns-Montes, and Bustinza Sánchez (2009) in paper measuring the effect that a six-sigma intervention had on shared vision. The scale used for measuring shared vision is composed of six items taken from work by Garcia-Morales, Llorens-Montes, and Verdú-Jover (2006), Oswald, Mossholder, and Harris (1994) and Tsai and Ghoshal (1998). This scale was a six question, Likert Scale that included whether the members of the organization have goals and an image of the future in 
common and share ambitions. Both the scale's unidimensionality, through the explanatory factor analysis and its internal consistency $($ alpha $=0.910)$ were confirmed (Gutiérrez Gutiérrez et al., 2009).

\section{Trust}

Trust will have a direct relationship on all parties' ability to come together and collaborate on a successful project. The greater the trust, the greater the likelihood of successful collaboration. A twelve-item scale was adapted from Colquitt, Scott, and LePine (2007) and Mayer and Davis (1999) that examines three areas where trust is manifested: Ability, Benevolence, and Integrity. These scales have a reliability factor (Alpha) of 0.85 to 0.88 (Ability), 0.87 to 0.89 (Benevolence) and 0.82 to 0.88 (Integrity).

\section{Collaboration}

Ultimately, what must be measured in our model is the degree of success in the collaboration. A six-item survey was adapted to measure the success of interdisciplinary and transdisciplinary collaboration (Hall et al., 2008). The reliability of this scale is alpha $=0.74$.

All constructs and scales are summarized in the Appendix.

\section{METHODOLOGY AND PROCEDURE}

The purpose of this study was to understand what factors are likely to significantly influence multiparty collaboration on projects that cross borders and cultures. In order to understand and discern what these factors might be, a survey was conducted using the constructs suggested above in order to provide quantitative and statistical verification of causality of these facilitating factors for this special case of collaboration. The sample population, consistent with the research context, consisted of a cascading random sample of individuals with work experience in the Arctic and made up of the eight arctic nations. 
Individuals were given the option to forward on the survey to others who would be interested in participating. The survey was sent to approximately 2,000 participants located in or working in the Arctic. It was posted on the Interagency Arctic Research Policy (IARPC) Committee's website, the Arctic Research Consortium of the United States (ARCUS) list serve. In addition, the North Star Group sent, via email, the survey to its subscription list for their Arctic report (approximately 600). The survey was submitted to the Case Western Reserve University IRB for approval and was given exempt status with no reporting requirements. This is a broad-based online survey and information was administered by Qualtrics.

From this data, a series of analyses including an Exploratory Factor Analysis (EFA), a Confirmatory Factor Analysis (CFA), Common Latent Factor analysis to determine method bias and a Structural Equation Model were conducted.

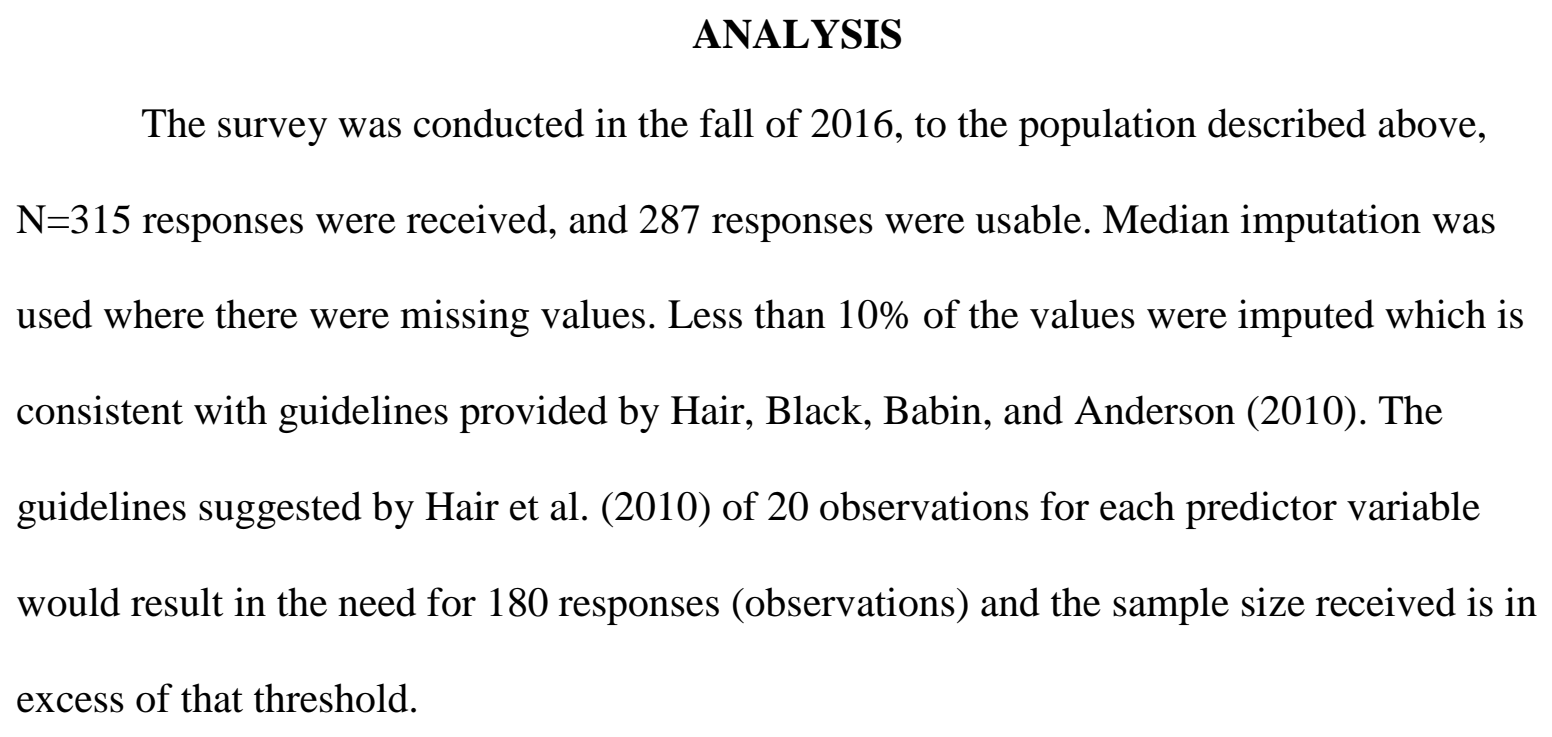

The survey was conducted in the fall of 2016, to the population described above, $\mathrm{N}=315$ responses were received, and 287 responses were usable. Median imputation was used where there were missing values. Less than $10 \%$ of the values were imputed which is consistent with guidelines provided by Hair, Black, Babin, and Anderson (2010). The guidelines suggested by Hair et al. (2010) of 20 observations for each predictor variable would result in the need for 180 responses (observations) and the sample size received is in excess of that threshold.

The variables that were measured on Likert Scales (Ordinal scales) with five intervals (choices) showed no extreme outliers; it appeared in examining the data that all responded were engaged in the survey. Demographic data was reasonable. In order to confirm data 
normality Skewness and Kurtosis statistics were calculated for each variable and, all absolute values were less than the threshold of 2.58 as recommended by (Hair et al., 2010).

In examining the demographics of our data; $56 \%$ of our respondents were male, $46 \%$ female; nearly two-thirds had graduate degrees; the majority of participants had 20 years or more experience; and the work sector they identified with was a third private, a third public and a third NGO or academic. These are further detailed in Table 1.

TABLE 1

Respondent Demographics

\begin{tabular}{|c|c|c|c|}
\hline Gender & & Age (years) & \\
\hline Male & $56.13 \%$ & $21-24$ & $0.38 \%$ \\
\hline Female & $43.87 \%$ & $25-34$ & $12.12 \%$ \\
\hline Experience (years) & & $35-44$ & $15.53 \%$ \\
\hline Less than 10 & $12.64 \%$ & $45-54$ & $23.11 \%$ \\
\hline 11 to 15 & $9.58 \%$ & $55-64$ & $31.44 \%$ \\
\hline $16-20$ & $10.34 \%$ & $65-74$ & $14.77 \%$ \\
\hline $21-25$ & $8.43 \%$ & $75-84$ & $1.89 \%$ \\
\hline Over 25 & $59.00 \%$ & 85 or older & $0.76 \%$ \\
\hline Education & & Industry Sector & \\
\hline High School & $3.82 \%$ & Private Sector & $35.11 \%$ \\
\hline University & $33.21 \%$ & Public Sector & $30.53 \%$ \\
\hline Graduate School & $62.98 \%$ & Non-Government Organization & $14.50 \%$ \\
\hline & & Academic & $19.85 \%$ \\
\hline
\end{tabular}

Information was also collected on nationality; respondents were asked to self-identify into ten national subcategories as suggested by Project Globe with the addition of a category from indigenous peoples. Not surprising since the survey was administered from North America that the majority of respondents were classified as Anglo (representing the U.S., Canada, and the U.K.). The responses are detailed in Table 2. 
TABLE 2

Respondent Nationalities

\begin{tabular}{|r|r|}
\hline Nationality (sub-sectors suggested by Project Globe) \\
\hline Anglo & $62.60 \%$ \\
\hline Arab & $1.18 \%$ \\
\hline Confucian Asian & $1.57 \%$ \\
\hline Eastern European & $2.76 \%$ \\
\hline Germanic European & $6.69 \%$ \\
\hline Nordic European & $11.81 \%$ \\
\hline Latin American & $1.18 \%$ \\
\hline Latin European & $1.57 \%$ \\
\hline Southern Asia & $2.36 \%$ \\
\hline Sub-Saharan Africa & $0.79 \%$ \\
\hline Indigenous & $7.48 \%$ \\
\hline
\end{tabular}

An EFA was conducted on this corrected database in order to determine if the observed variables load together as expected, to verify that the variables are correlated and that they meet expected criteria for reliability and validity. Maximum likelihood with Promax rotation was chosen as the estimation approach. Eight factors were modeled consistent with the hypothesized model and included social identity, which will be used in the determination of method bias.

The KMO and Bartlett's test for sampling adequacy (.826) were both adequate and significant. Communalities for each variable were sufficiently high (all above 0.300 and most above 0.500 ) indicating that the variables chosen were adequately correlated for a factor analysis. The Cronbach's alphas for the extracted factors are shown in Table 3. All alphas were well above 0.700 with the group collectively averaging 0.847 indicating very high reliability that the variables will load on those factors. The factors are all reflective because their indicators are highly correlated and are largely interchangeable (Jarvis, MacKenzie, \& Podsakoff, 2003). 
Discriminate validity refers to the extent to which factors are distinct and uncorrelated; that is it is important that the variables relate to their own factor rather than to another. Cross-loading between factors should be avoided if possible, in our EFA crossloadings were eliminated through the trimming of variables in the dataset, as shown in Table 3. The factors demonstrate sufficient convergent validity with all loadings well above the recommended minimum threshold (Hair et al., 2010) of .350 for sample sizes of 300 . This eight-factor model had a total variance explained of $53.1 \%$, with all extracted factors having Eigenvalues greater than 1.0.

TABLE 3

Reliability Statistics

\begin{tabular}{|c|c|c|c|c|}
\hline Construct & $\begin{array}{l}\text { Cronbach's } \\
\text { Alpha }\end{array}$ & $\begin{array}{c}\text { \# of } \\
\text { variables }\end{array}$ & Items & Loadings \\
\hline Trust & 0.947 & 9 & $\begin{array}{l}\text { Q22_4, 5, 6, 7, 8, } \\
9,10,11,12,\end{array}$ & $\begin{array}{l}0.743,0.739,0.697,0.828, \\
0.818,0.837,0.873,0.879 \\
0.908\end{array}$ \\
\hline Shared Vision & 0.913 & 6 & Q19_1, 2, 3, 4, 5, 6 & $\begin{array}{l}0.875,0.897,0.878,0.785 \\
0.660,0.709\end{array}$ \\
\hline Empathy & 0.836 & 8 & $\begin{array}{l}\text { Q21_1, 2, 3, 4, 5, } \\
6,7,8,\end{array}$ & $\begin{array}{l}0.556,0.602,0.584,0.812 \\
0.655,0.606,0.592,0.525\end{array}$ \\
\hline Cultural Intelligence & 0.804 & 7 & $\begin{array}{l}\text { Q15_3, 4, 6, 7, 8, } \\
9,10\end{array}$ & $\begin{array}{l}0.611,0.722,0.537,0.576 \\
0.560,0.639,0.606\end{array}$ \\
\hline Role Identity & 0.867 & 5 & Q17_1, 2,3,4,5 & $\begin{array}{l}0.716,0.964,0.898,0.551, \\
0.464\end{array}$ \\
\hline Individual Identity & 0.779 & 6 & Q16_2,3,4,5,6,7 & $\begin{array}{l}0.542,0.614,0.709,0.599 \\
0.719,0.528\end{array}$ \\
\hline Collaboration & 0.791 & 4 & Q20_3, 4, 5, 6 & $0.535,0.560,0.794,0.829$ \\
\hline Social Identity & 0.836 & 4 & Q23_1, 2, 3, 4 & $0.861,0.523,0.887,0.697$ \\
\hline
\end{tabular}

A Confirmatory Factor Analysis (CFA) was conducted using the AMOS software was used in order to confirm that the data collected and factors derived actually represent what is occurring. We examined the model to determine if it is plausible and statistically valid using a variety of indices. Initial analysis indicated a non-optimal fit. Subsequent covarying of error terms and the removal of six items after examination of the questions they 
represented to see if there was an overlap in the questions. Table 4 shows that the goodness of fit for our measurement model, as observed, is sufficient.

To test for convergent validity, we calculated the Average Variance Extracted (AVE) as well as the Maximum Shared Variance (MSV) for all factors, which were compared to the recommended minimum of 0.50 (Hair et al., 2010). Composite reliability (CR) was also calculated, and all scores for all factors were above the minimum of 0.700 (Hair et al., 2010) demonstrating that the model is both valid and will converge reliably. We note that there are two factors whose AVE is truly less than 0.5 . Those factors are not significantly low, and in conjunction with the CR testing, it is reasonable to assume that there is convergent reliability. To test for discriminant validity, we calculated the square root of the AVE and compared it to all the inter-factor correlations as calculated in the AMOS model. All factors demonstrated discriminant validity as the correlations were less than the square root of the AVE.

As the data for our model was collected from a survey (a single instrument), not dissimilar to data screening for unengaged responses, we examined, statistically, for method bias. Method bias, which is variance that is attributable to the measurement method rather than the constructs the measures represent (Podsakoff, MacKenzie, Lee, \& Podsakoff, 2003) could result in significant error in our model. In order to test for this, we used the "unmeasured latent factor" method as recommended by Podsakoff et al. (2003: 891) augmented with the utilization of a marker variable, in our case we used Social Desirability was included as an additional latent variable. To accomplish this, a common latent factor was created in order to test for shared variance amongst all the constructs to determine if that shared variance is significant using a chi-squared difference test between the unconstrained model and the constrained model where all the paths are constrained to zero. The difference 
test indicates that the groups are different at the model level $(\mathrm{p}=0.000)$ indicating that method bias exists. The CLF was retained for our structural model by imputing composite values for the Latent Factors. Both models had good fit as shown in Table 4, as well as model validity for the final CFA (Table 5), although empathy and identity continue to have weaker AVE scores.

TABLE 4

\section{Final Model Fit}

\begin{tabular}{|l|c|r|r|r|}
\hline \multicolumn{1}{|c|}{ Test } & & & \multicolumn{2}{c|}{ Method Bias with Marker } \\
\hline Chi Square/Degrees of Freedom & Measure* & Observed & Unconstrained & \multicolumn{1}{|c|}{ Constrained } \\
\hline RMSEA & $<3.0$ & 1.545 & 1.435 & 1.543 \\
\hline P-close & $<.05$ & 0.044 & 0.039 & 0.044 \\
\hline CFI & $>.50$ & 0.977 & 1.000 & 0.984 \\
\hline SRMR & $>.95$ & 0.940 & 0.954 & 0.939 \\
\hline Chi-square & $<.090$ & 0.050 & 0.042 & 0.0497 \\
\hline DF & & 990.5 & 960.000 & 1093.7 \\
\hline *Hu and Bentler (1999) & & 641 & 669 & 709 \\
\hline
\end{tabular}

TABLE 5

Final CFA Model Validity

\begin{tabular}{|c|c|c|c|c|c|c|c|c|c|c|}
\hline & CR & AVE & MSV & TRUST & $\begin{array}{c}\text { S. } \\
\text { VISION }\end{array}$ & EMPATHY & ROLE & CULTURE & IDENTITY & COLLAB \\
\hline TRUST & 0.920 & 0.595 & 0.059 & 0.771 & & & & & & \\
\hline S.VISION & 0.911 & 0.633 & 0.122 & 0.235 & 0.795 & & & & & \\
\hline EMPATHY & 0.779 & 0.374 & 0.097 & 0.128 & 0.232 & 0.612 & & & & \\
\hline ROLE & 0.849 & 0.543 & 0.075 & 0.243 & 0.349 & 0.242 & 0.737 & & & \\
\hline INTEL & 0.802 & 0.577 & 0.023 & 0.056 & -0.008 & 0.232 & 0.028 & 0.760 & & \\
\hline IDENTITY & 0.753 & 0.434 & 0.053 & 0.123 & 0.066 & 0.276 & 0.274 & 0.129 & 0.659 & \\
\hline COLLAB & 0.786 & 0.487 & 0.000 & 0.133 & 0.128 & 0.311 & 0.042 & 0.150 & 0.230 & 0.698 \\
\hline \multicolumn{6}{|c|}{$\begin{array}{l}\text { For Convergent validity: } \\
\text { AVE }>.5 \\
\text { CR }>\text { AVE } \\
\text { CR }>.7\end{array}$} & \multicolumn{5}{|c|}{$\begin{array}{l}\text { For Discriminant Validity: } \\
\text { MSV < AVE } \\
\text { Correlations < SQRT of AVE }\end{array}$} \\
\hline
\end{tabular}

Composite variables were created using the factor scores from the AMOS CLF analysis to accommodate the method bias that is inferred from the shared variance. A 
structural model was created from these latent factors in order to test the hypothetical model in Figure 1. Experience of the participants was used as the control variable and was accommodated by including it in the model as exogenous variable and then regressing them to the two endogenous variables: Shared Vision and Collaboration. Experience did not regress with any significance to Shared Vision and was included only for Collaboration. The model was tested to look for shared variance amongst all the constructs to determine if that shared variance is significant using a chi-squared difference test between an unconstrained model and a constrained model for the gender. The model was run with the groups in a constrained and unconstrained condition and examined for model fit and significance. A Chisquared difference test was calculated for these two states that showed that the two groups are invariant, that is there is no significant difference in the model between the two groups. Table 6 compares the model fit for the SEM model without accounting for groups and the model accounting for groups (unconstrained and constrained). In all cases, the model demonstrates adequate fit.

\section{TABLE 6 SEM Model Fit}

\begin{tabular}{|l|c|c|c|c|}
\hline \multicolumn{1}{|c|}{ Test } & Measure* & Observed & Unconstrained & Constrained \\
\hline Chi Square/Degrees of Freedom & $<3.0$ & 1.376 & 1.066 & 0.927 \\
\hline RMSEA & $<.05$ & 0.036 & 0.015 & 0.000 \\
\hline P-close & $>.50$ & 0.473 & 0.676 & 0.938 \\
\hline CFI & $>.95$ & 0.997 & 0.999 & 1.000 \\
\hline SRMR & $<.090$ & 0.015 & 0.0254 & 0.0319 \\
\hline Chi-square & & 2.751 & 4.264 & 13.902 \\
\hline DF & & 2 & 4 & 15 \\
\hline *Hu and Bentler (1999) & & & & \\
\hline
\end{tabular}




\section{RESULTS}

In this study, we sought to determine which factors suggested by previous findings (Hemsath, 2015) help explain successful transnational multiparty collaboration. We wanted to explore the relationship between culture and both self and role identity and the role they play in the facilitation of multiple parties working across borders. Finally, we wanted to understand the relationships between empathy, trust and shared vision as they relate to collaboration.

A key concept we wished to investigate was the impact that cultural intelligence has on shared vision and collaboration. As an independent variable, the regression path to Shared Vision and to Collaboration was not significant $(-0.069 ; \mathrm{p}=0.212$ and $0.059 ; \mathrm{p}=0.280)$. With culture not showing significance as an independent variable on an ad hoc basis we examined whether Cultural Intelligence could have a moderating effect on both individual and role identity and there was no significant moderation. Additionally, the regression path from Shared Vision to Collaboration was not significant and provided no mediation; the final model has Shared Vision as a Dependent Variable. Cultural Intelligence was not statistically significant as an influence on Shared Vision or Collaboration, but the regressions were maintained in the model as they were part of our theory. In a like manner, Individual Identity had no effect on Shared Vision. As a control and treating it as an exogenous variable, experience also was a significant influence on Collaboration. As shown in Figure 2, the final model explains $20 \%$ of the variation in Shared Vision $\left(\mathrm{R}^{2}=.0 .20\right)$ with Group Identity $\left(0.311^{* * *}\right)$ and Empathy $\left(0.200^{* * *}\right)$ being the largest influencers. The model also explains $21 \%$ of the variation in Collaboration $\left(\mathrm{R}^{2}=0.21\right)$, with Empathy $(0.284 * * *)$ and Trust $\left(0.110^{*}\right)$ having the largest influence. 
FIGURE 6

Final Structural Equation Model (SEM)

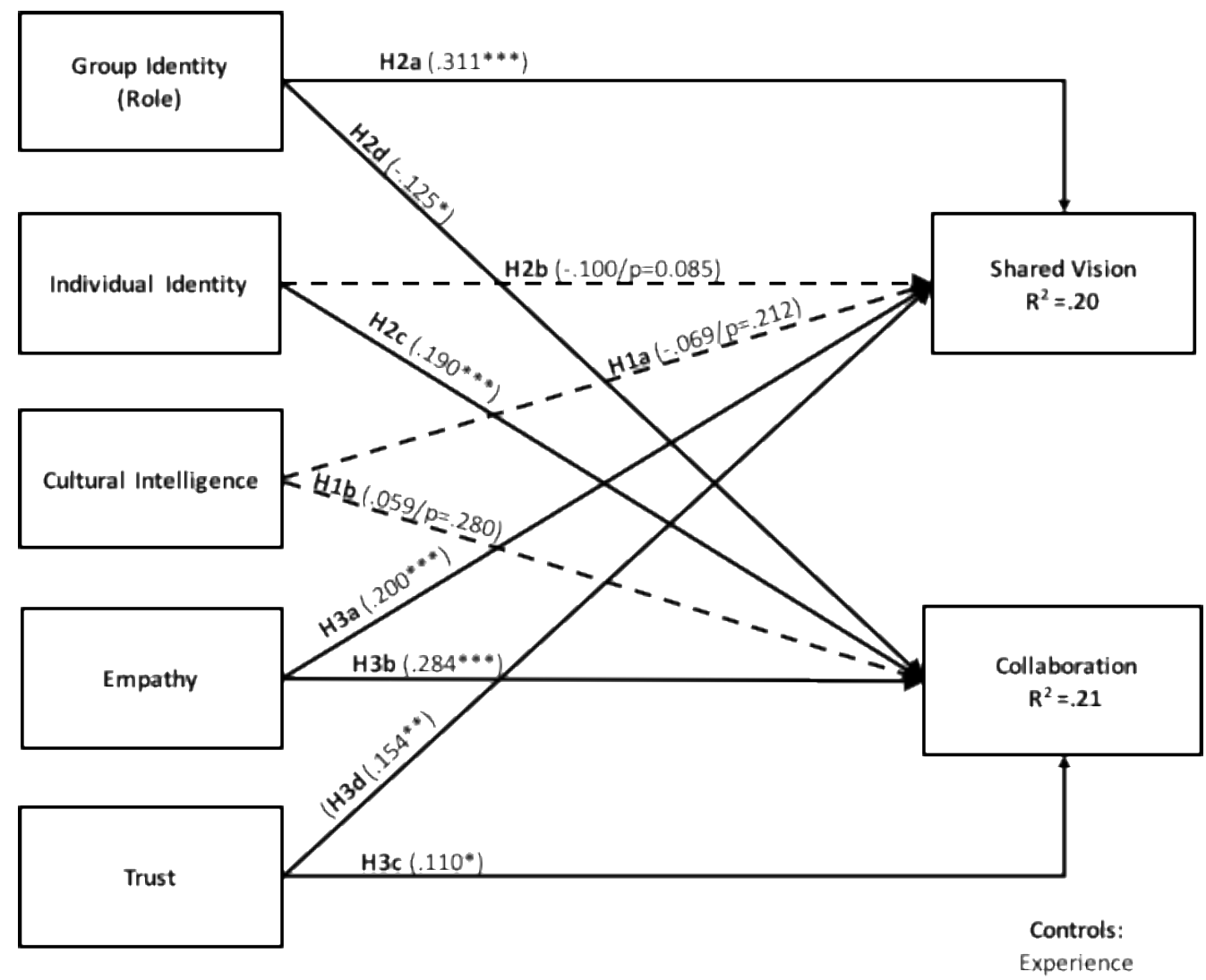

TABLE 7

Standardized Regression Weights and Associated P-Values

\begin{tabular}{|l|c|l|c|c|}
\hline & & & Estimate & P-value \\
\hline Shared Vision & $\leftarrow$ & Group Identity (Role) & 0.311 & $* * *$ \\
\hline Shared Vision & $\leftarrow$ & Empathy & 0.200 & $* * *$ \\
\hline Shared Vision & $\leftarrow$ & Individual Identity & -0.100 & 0.085 \\
\hline Shared Vision & $\leftarrow$ & Cultural Intelligence & -0.069 & 0.212 \\
\hline Shared Vision & $\leftarrow$ & Trust & 0.154 & 0.005 \\
\hline Collaboration & $\leftarrow$ & Experience (Control) & 0.174 & $* * *$ \\
\hline Collaboration & $\leftarrow$ & Group Identity (Role) & -0.125 & 0.030 \\
\hline Collaboration & $\leftarrow$ & Empathy & 0.284 & $* * *$ \\
\hline Collaboration & $\leftarrow$ & Individual Identity & 0.190 & 0.001 \\
\hline Collaboration & $\leftarrow$ & Trust & 0.110 & 0.043 \\
\hline Collaboration & $\leftarrow$ & Cultural Intelligence & 0.059 & 0.280 \\
\hline
\end{tabular}


The exploratory analysis of our survey data provided insights as to what factors would help explain transnational multiparty collaboration. We were able to develop strongly loaded and convergent and reliable constructs that related to our dependent variable collaboration. In conducting this analysis, we had included interconnectedness as a survey item and that data converged with empathy and was eliminated from our analysis. This suggests two things; the first is that empathy could be considered a strong antecedent to interconnectedness, and secondly, we need to research in greater detail what the antecedents to interconnectedness might be. The survey instrument used, was not distinct enough from empathy. It would be worthwhile to consider developing a scale specifically designed for measuring connectedness in a business or project environment to further out understanding. However, we were able to discern four key variables that could help explain our form of collaboration — empathy, trust, individual identity and role identity. Empathy and Trust as representatives of interconnectedness had strong impacts on both shared vision and collaboration.

It is important to remember that this was an exploratory effort, based on theory and results from a previous study we were motivated to examine a variety of factors that could explain transnational multiparty collaboration. Fifteen factors were promulgated through hypotheses; seven were supported. Table 8 provides a summary of our work related to identifying those factors as does Figure 2. 
TABLE 8

Hypothesis Summary Table

\begin{tabular}{|c|c|c|}
\hline Direct & Evidence & Supported? \\
\hline $\begin{array}{l}\text { H1a: Cultural Intelligence is positively associated with } \\
\text { Shared Vision. }\end{array}$ & Direct: $-0.069(\mathrm{p}=0.212)$ & No \\
\hline $\begin{array}{l}\text { H1b: Cultural Intelligence is positively associated with } \\
\text { Collaboration }\end{array}$ & $\mathrm{p}=0.280$, not significant & No \\
\hline $\begin{array}{l}\text { H2a: Group Identity is positively associated with } \\
\text { Shared Vision }\end{array}$ & Direct: $0.311^{* * *}$ & Yes \\
\hline $\begin{array}{l}\text { H2b: Individual Identity is positively associated with } \\
\text { Shared Vision. }\end{array}$ & $\begin{array}{l}\text { Direct: }-0.100(\mathrm{p} \text {-value }- \\
.085)\end{array}$ & No \\
\hline $\begin{array}{l}\text { H2c: Individual Identity is positively associated with } \\
\text { Collaboration }\end{array}$ & Direct: $0.190^{* * *}$ & Yes \\
\hline $\begin{array}{l}\text { H2d: Group Identity is negatively associated with } \\
\text { Collaboration. }\end{array}$ & Direct: $-0.125^{*}$ & Yes \\
\hline $\begin{array}{l}\text { H3a: Empathy is positively associated with Shared } \\
\text { Vision. }\end{array}$ & Direct: $0.200^{* * *}$ & Yes \\
\hline $\begin{array}{l}\text { H3b: Empathy is positively associated with } \\
\text { Collaboration. }\end{array}$ & Direct: $0.284^{* * *}$ & Yes \\
\hline H3c: Trust is positively associated with Collaboration & Direct: $0.110^{*}$ & Yes \\
\hline H3d: Trust is positively associated Shared Vision. & Direct: $0.154^{* *}$ & Yes \\
\hline $\begin{array}{l}\text { H4: Shared vision is positively associated with } \\
\text { Collaboration. }\end{array}$ & $\begin{array}{l}\text { Regression path from shared } \\
\text { vision to collaboration was } \\
\text { not significant }\end{array}$ & No \\
\hline Mediation & Evidence & Supported? \\
\hline $\begin{array}{l}\text { H5a: Shared vision partially mediates the relationship } \\
\text { between group identity and collaboration. }\end{array}$ & $\begin{array}{l}\mathrm{p}=0.130 ; \text { Std. regression } \\
\text { weight }=0.088\end{array}$ & No \\
\hline $\begin{array}{l}\text { H5b: Shared vision partially mediates the relationship } \\
\text { between individual identity and collaboration. }\end{array}$ & $\begin{array}{l}\mathrm{p}=0.130 ; \text { Std. regression } \\
\text { weight }=0.088\end{array}$ & No \\
\hline $\begin{array}{l}\text { H5c: Shared vision partially mediates the relationship } \\
\text { between empathy and collaboration. }\end{array}$ & $\begin{array}{l}\mathrm{p}=0.130 ; \text { Std. regression } \\
\text { weight }=0.088\end{array}$ & No \\
\hline $\begin{array}{l}\text { H5d: Shared vision partially mediates the relationship } \\
\text { between trust and successful collaboration. }\end{array}$ & $\begin{array}{l}\mathrm{p}=0.130 ; \text { Std. regression } \\
\text { weight }=0.088\end{array}$ & No \\
\hline
\end{tabular}

Surprisingly, shared vision did not have a strong impact on collaboration as expected and did not mediate those factors that were antecedent to shared vision as it relates to collaboration. This is unusual as it is reasonable to expect that as a multiparty team comes together and creates a shared vision supporting their project, the stronger the vision, the more 
likely it would be that they would be able to collaborate and develop collaborative solutions to the project at hand. This was not born out in the data that was collected and from our model perspective we carried shared vision as a dependent variable. It is interesting to note that the $\mathrm{R}^{2}$ for shared vision $\left(\mathrm{R}^{2}=0.20\right.$ and collaboration $\left(\mathrm{R}^{2}=0.21\right)$ mirrored each other. An explanation for this result may lie in the questions asked about collaboration. The survey instrument tended to measure an individual's propensity to collaborate rather than the degree they collaborated. A survey may not be the proper instrument to measure degree of collaboration as that will be project specific. Shared vision, as measured, was about the degree of unity and the very act of creating this unity may be the antithesis to collaboration.

The intent of collaborative solutions is to find a way to incorporate differences to create something new — a bigger pie rather than agreeing on the size of a piece of pie. Interestingly, in the positive factors supporting shared vision, role or group identity had the largest role $(.331 ; \mathrm{p}<0.001)$ while individual identity was negative $(-0.100 ; \mathrm{p}=0.085)$ which indicated weak significance. With collaboration, individual identity was strongly significant while group identity was negative. One observation of this effect is that in a multiparty project in order to create conditions for collaboration two things need to occurthe first is that is important to encourage individuality in the team in order to be aware of differences and uniqueness's that provide the spark to find an innovative solution. Secondly, as it relates to the different parties, it is important that they maintain their individuality as well so that the motivation is to develop a collaborative approach that addresses all the needs. Experience was used as a control and was only significant $(\mathrm{p}<0.001)$ as it related to collaboration, not shared vision. This is reasonable as the more experienced an individual is, the more likely they will have gained the skill sets that will allow them to collaborate. 
Finally, as our intent was to understand how transnational multiparty teams collaborate we need to understand the impact that culture has. We used a very strong indicator-Cultural Intelligence as our survey instrument; yet in spite of this culture was not statistically significant for either shared vision or collaboration and the regression weights were weak as well suggesting small influence. This is counter-intuitive; we know that the better we are as individuals in understanding and working in different cultures the better our performance should be in working in a transnational environment. However, Hemsath (2015) suggested that culture can only be a dissatisfier; that is, if we don't acknowledge cultural differences it is unlikely that we will be successful on a cross-border project. But, once addressed have it will have little role in impacting collaboration. The results from our survey would indicate that this may be the case.

\section{DISCUSSION}

The need to understand the factors that result in successful multiparty collaborations that take place across borders and cultures is critical to successful infrastructure projects that need to take place in the Arctic regime, which is characterized by harsh climates, long distances from supplies and a variety of national interests and the interests of the indigenous peoples of the North. It is a highly complex problem where the key factors are "imbedded" in the practitioners in this realm. A sequential exploratory mixed method approach was constructed to examine this complex system (and potentially wicked problem). Utilizing one on one interviews in order to solicit those factors that the practitioners themselves felt were critical to success; we have conducted a large N survey in order to quantify these factors and their relations with each other, so that we might understand what might facilitate greater project success. In particular, the results of this quantitative study led us to unexpected 
findings that might change the thinking about how multiparty projects can be managed, in order to find collaborative solutions to the complex problems that exist in these projects, made further complex with the addition of differing cultures.

It was expected that shared vision would be linked to collaboration, it is well understood that having a common vision focus allows people to work together in a more effective manner. "That the creation of a vision, be it at an individual, team or organizational level, motivates people to action and inspires them to reach beyond their current state" (Boyatzis et al., 2015: 1). However, this was not the case from this study. Shared Vision and Collaboration are distinct and separate variables that may, in fact, run counter to each other, where the greater the shared vision on a project the less likely that there will be collaboration. It is important to note that when using collaboration, we are suggesting that this is distinct from cooperation. That shared vision results in the submerging of individual identity to a group identity. This is supported by the study in which Group Identity is strongly supportive of Shared Vision, while Individual Identity is not and conversely Individual Identity strongly supports Collaboration while Group Identity has a negative impact on Collaboration. The conclusion should not be drawn, however, that shared vision and collaboration are not supportive of each other. It is the author's suggestion that there is a balance that has to be established where team members and parties have a common vision of what the goal is, but that should not submerge the tensions that individuality (personal and as a role) brings to the team that provides an environment where collaboration can exist. This is extremely contextual, and the use of a large sample size $(\mathrm{N}=287)$ survey may not be the appropriate vehicle to discern what this balance should be. It is also important to note that the $\mathrm{R}^{2}$ for both of these dependents were the same, and tended to be the same in different components of the 
structural equation modeling. From a management perspective, this supports the need for having a shared vision to allow for agreement on what the goals are while understanding that having a collaborative environment is necessary for successful projects in the highly complex environment of transnational multiparty projects.

In a transnational multiparty environment, identity—both the group or role identity that is the individual parties and the individual identity of the participants—must be accommodated. We were interested in whether there would be some form of identity fusion that would be indicated as it relates to shared vision and collaboration where identity fusion represents an alignment of the needs for both kinds of identity. The theory was this alignment would lead to increased likelihood that "individual identity will influence group identity and vice versa" (Swann et al., 2012). As discussed above, the two forms of identity were not in alignment. This may be from the style and type of questions in the survey; the survey was measuring how well someone relates to the "group" and how well someone relates to the "self." An individual that strongly relates to the group will also strongly relate to a shared vision, another group aspect. Our collaboration scale was on one's propensity to be willing to be open to collaborative effort, which from this study relates to the strength of an individual's sense of self. The theory of fused identity is very much related to collaboration, where individual and group identity become part of the discussion rather than one or another. Again, in a similar way, it is the balancing of these components that will be key to collaborative success.

Interconnectedness was anticipated to be a key component in transnational multiparty collaboration. That the more a group or team are connected with each other the greater the likelihood an individual could "remain highly committed to the group while exercising their 
individual agency to steer the group in new directions" (Swann et al., 2012: 11), which in part is a component of collaboration. Empathy and trust were used as indicator variables for the concept of interconnectedness and each of these variables impacted significantly shared vision and collaboration. This would suggest that interconnectedness can play a significant role in finding the balance between shared vision and collaboration that allows for successful projects. Further research related to determining the antecedents of interconnectedness, especially in conjunction with fused identity is recommended.

The results of this study strongly support the concept that Culture or Cultural Intelligence is a gateway that must be passed but has no influence on aspects of collaboration or shared vision. That differing cultures were something to be acknowledged, and then you move on getting the work done (Hemsath, 2015). Still, it was felt that cultural intelligence would play a role in this model. We are able to conclude that it does not. However, we still recommend that having members on the team that have high cultural intelligence will assure that one does not have to spend time managing culture rather than managing the project.

\section{LIMITATIONS}

It is important to note that the findings, conclusions, and recommendations from this study need to be limited to the population that the data was taken from. The problem of practice and context of this study are directed at work in the Arctic, the author's location and network tend to be arctic in nature and, therefore, the conclusion derived apply to work done in the Arctic as opposed (for example) to Africa. This does not mean to imply that the conclusion could not be used in another context, but it is important to note the limitation. It is also important to note that this information was collected from a broad-based survey reaching out to over 2000 individuals with both the request to participate but to forward it on to others. 
While the population, in general, was taken from those doing business in the Arctic and presumably across borders, there is no way to determine levels of expertise. The survey is contextual; it is about relations and experiences and as such there can also be variations in the responses. No numerical response will truly represent the thought behind it - this is a limitation to a quantitative study that simply needs to be acknowledged.

\section{CONCLUSION}

This study was conducted as an exploratory study, looking for confirmation of previous findings and to identify areas where future research is necessary. We suggest that further research be conducted on the relationship or more accurately the balance between shared vision and collaboration. Intuitively, we understand that there is a connection, but as this survey pointed out that is not necessarily the case. From our perspective, we are concerned about the success of multiparty transnational work, which by its very nature is complex and involves context and meaning all complicated by different cultures and languages. We would suggest that the next phase of research address the tension between shared vision represents and collaboration in conjunction with understanding more about fused identities. We further suggest that an Action Research technique in conjunction with a focused survey be conducted. Again, in the context of the problem of practice and work conducted in the Arctic, a group formed from the Arctic Economic Council and the Arctic Circle Task Force on infrastructure be the desired population. Additionally, as noted above, we also suggest that additional research be conducted to further understand the antecedents of interconnectedness and their relationship with identity.

The intent of research based on the problem of practice - in our case, to understand, under the umbrella of multiparty projects, how the variety of factors such as culture, identity, 
interconnectedness, shared vision, trust, and empathy come together to facilitate the emergence of a transnational multiparty collaborative success - is to provide suggestions that can be applied to practice. The following are those important implications for practice.

4. In the development of a team or project vision or mission statement, it is important that it not be used to submerge differing perspectives and approachesto allow for the development of collaborative solutions.

5. Time must be spent in order to allow all parties the opportunity to develop trust in the relations and more importantly to develop a sense of empathy for the differing roles that are being played on the project, including cultural roles.

6. The success of a cross-border project is not only dependent on understanding cultural needs and perspectives. It is important to do so, but the success of the project is dependent on other actions.

Fridtjof Nansen was an Arctic Explorer and recipient of the 1922 Nobel Peace Prize.

Early on he identified the value of Arctic transportation as a way to shorten distances and costs of moving goods and services. Something that just now is coming to fruition. He also suggested that in the context of international trade that the North could act as a model of cooperation as it provided a push for the advancement of human knowledge (Emmerson, 2010). That aspect of collaboration, working across borders in transnational teams in order to provide a better life for the people of the North, is at the heart of this research. 


\section{APPENDIX \\ Construct Table}

\begin{tabular}{|c|c|c|c|}
\hline Construct & Definition & Survey Items (Scale) & Citations \\
\hline Cultural Intelligence & $\begin{array}{l}\text { Cultural Intelligence (CQ) } \\
\text { is defined as the capability } \\
\text { of an individual to function } \\
\text { effectively in culturally } \\
\text { diverse settings (Van Dyne } \\
\text { et al, 2012) and is based on } \\
\text { four factors - } \\
\text { Metacognitive CQ (mental } \\
\text { ability to evaluate one's } \\
\text { cultural knowledge) } \\
\text { Cognitive CQ (general } \\
\text { knowledge about cultures } \\
\text { and cultural differences) } \\
\text { Motivational CQ (self- } \\
\text { motivation to perform in } \\
\text { cross-cultural situations) }\end{array}$ & $\begin{array}{l}\text { The Cultural Intelligence Scale (CQS) - Cultural Intelligence } \\
\text { Center, } 2005 \\
\text { Read each statement and select the response that best describes } \\
\text { your capabilities. } \\
\text { Select the answer that BEST describes you AS YOU REALLY } \\
\text { ARE (1 = strongly disagree; } 5 \text { = strongly agree). } \\
\text { Metacognitive CQ } \\
\text { 1. I am conscious of the cultural knowledge I use when } \\
\text { interacting with people with different cultural backgrounds. } \\
\text { 2. I adjust my cultural knowledge as I interact with people from } \\
\text { a culture that is unfamiliar to me. } \\
\text { Cognitive CQ } \\
\text { 1. I know the cultural values and religious beliefs of other } \\
\text { cultures. } \\
\text { 2. I know the rules for expressing nonverbal behaviors in other } \\
\text { cultures. } \\
\text { Behavioral CQ } \\
\text { Motivational CQ I change my verbal behavior (e.g., accent, tone) when a } \\
\text { 1. I enjoy interacting with people from different cultures. } \\
\text { 2. I am confident that I can socialize with locals in a culture that } \\
\text { is unfamiliar to me. } \\
\text { 3. I am sure I can deal with the stresses of adjusting to a culture } \\
\text { that is new to me. } \\
\text { cross-cultural interaction requires it. } \\
\text { (. }\end{array}$ & $\begin{array}{l}\text { Ang et al. (2007) } \\
\text { Composite Reliabilities } \\
\text { exceeded } 0.70 \text { (metacognitive } \\
\text { CQ }=0.72 \text {, motivational CQ = } \\
0.76 \text { and behavioral CQ = } \\
0.83 \text { : (Fornell \& Larcker, } \\
\text { 1981)). }\end{array}$ \\
\hline
\end{tabular}




\begin{tabular}{|c|c|c|c|}
\hline Construct & Definition & Survey Items (Scale) & Citations \\
\hline & & $\begin{array}{l}\text { 2. I use pause and silence differently to suit different cross- } \\
\text { cultural situations. } \\
\text { 3. I vary the rate of my speaking when a cross-cultural situation } \\
\text { requires it. }\end{array}$ & \\
\hline Individual Identity & $\begin{array}{l}\text { The level or strength of an } \\
\text { individual's identity and } \\
\text { ability to share that identity. }\end{array}$ & $\begin{array}{l}\text { Read each statement and select the response that best describes } \\
\text { your capabilities. } \\
\text { Select the answer that BEST describes you AS YOU REALLY } \\
\text { ARE ( } 1 \text { = strongly disagree; } 5 \text { = strongly agree). } \\
\text { 1. My personal values and moral standards are important to my } \\
\text { sense of who I am } \\
\text { 2. My dreams and imagination are important to my sense of } \\
\text { who I am } \\
\text { 3. My personal goals and hopes for the future are important to } \\
\text { my sense of who I am } \\
\text { 4. My emotions and feelings are important to my sense of who I } \\
\text { am } \\
\text { 5. My thoughts and ideas are important to my sense of who I } \\
\text { am } \\
\text { 6. The ways I deal with my fears and anxieties are important to } \\
\text { my sense of who I am } \\
\text { 7. My feeling of being a unique person, being distinct from } \\
\text { others is important to my sense of who I am } \\
\text { 8. Knowing that I continue to be essentially the same inside } \\
\text { even though life involves many external changes are } \\
\text { important to my sense of who I am } \\
\text { 9. My self-knowledge, my ideas about what kind of person I } \\
\text { really am are important to my sense of who I am }\end{array}$ & $\begin{array}{l}\text { Cheek et al. (2002) } \\
\text { Alpha }=.92\end{array}$ \\
\hline
\end{tabular}




\begin{tabular}{|c|c|c|c|}
\hline Construct & Definition & Survey Items (Scale) & Citations \\
\hline $\begin{array}{l}\text { Group or Role } \\
\text { Identity }\end{array}$ & $\begin{array}{l}\text { Social Identity or how } \\
\text { much one identifies with } \\
\text { their group. }\end{array}$ & $\begin{array}{l}\text { Read each statement and select the response that best describes } \\
\text { your capabilities. } \\
\text { Select the answer that BEST describes you AS YOU REALLY } \\
\text { ARE ( } 1 \text { = strongly disagree; } 5 \text { = strongly agree). } \\
\text { 1. I am a worthy member of the social groups I belong to } \\
\text { 2. I am a cooperative participant in the social group I belong to } \\
\text { 3. I often feel I'm a useless member of my social group } \\
\text { 4. In general, I am glad to be a member of the social group I } \\
\text { belong to } \\
\text { 5. I feel good about the social group I belong to } \\
\text { 6. Overall others consider my group good } \\
\text { 7. In general, others respect the social groups I am a member of } \\
\text { 8. Overall my group membership has very little to do with how } \\
\text { 9. Thel gbout myself } \\
\text { 10. The group I belong to is an important reflection of who I am } \\
\text { kind of person I am to is unimportant to my sense of what } \\
\text { 11. In general belonging to this group is an important part of my } \\
\text { self-image. }\end{array}$ & $\begin{array}{l}\text { Luhtanen and Crocker }(1992) \\
\text { Alpha }=0.92\end{array}$ \\
\hline Interconnectedness & $\begin{array}{l}\text { The degree that individuals } \\
\text { connect. }\end{array}$ & $\begin{array}{l}\text { Read each statement and select the response that best describes } \\
\text { your capabilities. } \\
\text { Select the answer that BEST describes you AS YOU REALLY } \\
\text { ARE ( } 1 \text { = strongly disagree; } 5=\text { strongly agree). } \\
\text { 1. I catch myself losing a sense of connectedness with society. } \\
\text { 2. I am able to connect with other people. I see people as } \\
\text { friendly and approachable } \\
\text { 3. My associates feel like family. } \\
\text { 4. I find myself actively involved in people's lives } \\
\text { 5. Even among my friends, there is no sense of } \\
\text { brother/sisterhood. } \\
\text { 6. I am in tune with the world. } \\
\text { 7. I feel comfortable in the presence of strangers }\end{array}$ & $\begin{array}{l}\text { Lee et al. }(2001) \\
\text { Alpha }=.86-.89 \text { for the total } \\
\text { scale }\end{array}$ \\
\hline
\end{tabular}




\begin{tabular}{|c|c|c|c|}
\hline Construct & Definition & Survey Items (Scale) & Citations \\
\hline Shared Vision & $\begin{array}{l}\text { A common mental model of } \\
\text { what the future will look } \\
\text { like. }\end{array}$ & $\begin{array}{l}\text { Read each statement and select the response that best describes } \\
\text { your capabilities. } \\
\text { Select the answer that BEST describes you AS YOU REALLY } \\
\text { ARE ( } 1=\text { strongly disagree; } 5=\text { strongly agree). } \\
\text { 1. In the organization, there is a clear vision guiding the } \\
\text { strategic goals and missions } \\
\text { 2. The leadership of the company shares a common vision of } \\
\text { the organization's future } \\
\text { 3. The shared vision guiding change, in the organization, is } \\
\text { appropriate } \\
\text { 4. We agree on what is important for our organization } \\
\text { 5. Our unit shares the same ambitions and vision with other } \\
\text { 6. People on our unit are enthusiastic about pursuing the } \\
\text { collective goals and missions of the whole organization }\end{array}$ & $\begin{array}{l}\text { Gutiérrez Gutiérrez et al. } \\
(2009) \\
\text { Alpha }=0.910\end{array}$ \\
\hline Collaboration & $\begin{array}{l}\text { Collaboration is the process } \\
\text { of two or more people or } \\
\text { organizations working } \\
\text { together to realize shared } \\
\text { goals. Inherent in this } \\
\text { process is that the whole is } \\
\text { greater than the sum }\end{array}$ & $\begin{array}{l}\text { Read each statement and select the response that best describes } \\
\text { your capabilities. } \\
\text { Select the answer that BEST describes you AS YOU REALLY } \\
\text { ARE (1 = strongly disagree; 5 = strongly agree). } \\
\text { 1. I tend to be more productive working on my own projects } \\
\text { than working as a member of a collaborative team. } \\
\text { 2. The questions I am often interested in generally do not } \\
\text { warrant collaboration from other disciplines. } \\
\text { 3. While working on a project within my discipline, I } \\
\text { sometimes feel it is important to seek the perspective of } \\
\text { other disciplines when trying to answer particular parts of } \\
\text { my question. } \\
\text { I believe the benefits of collaboration from different } \\
\text { disciplines usually outweigh the inconveniences and costs of } \\
\text { such work. } \\
\text { In my own work, I typically incorporate perspectives from } \\
\text { disciplinary orientations that are different from my own. }\end{array}$ & $\begin{array}{l}\text { Adapted from Hall et al. } \\
\text { (2008) } \\
\text { Alpha }=0.74\end{array}$ \\
\hline
\end{tabular}




\begin{tabular}{|c|c|c|c|}
\hline Construct & Definition & Survey Items (Scale) & Citations \\
\hline & & $\begin{array}{l}\text { 6. In my collaborations with others, I integrate theories and } \\
\text { models from different disciplines. }\end{array}$ & \\
\hline Empathy & $\begin{array}{l}\text { Empathy can be defined as } \\
\text { the "reactions of one } \\
\text { individual to the observed } \\
\text { experiences of another } \\
\text { (Davis, 1983)." } \\
\text { Ruben (1976) } \\
\text { defines cultural empathy as } \\
\text { "the capacity to clearly } \\
\text { project an interest in others, } \\
\text { as well as to obtain and to } \\
\text { reflect a reasonably } \\
\text { complete and accurate } \\
\text { sense of another's thoughts, } \\
\text { feelings, and/or } \\
\text { experiences". }\end{array}$ & $\begin{array}{l}\text { Read each statement and select the response that best describes } \\
\text { your capabilities. } \\
\text { Select the answer that BEST describes you AS YOU REALLY } \\
\text { ARE ( } 1 \text { = strongly disagree; } 5=\text { strongly agree). } \\
\text { 1. I sympathize with others } \\
\text { 2. I set others at ease } \\
\text { 3. I enjoy other people's stories } \\
\text { 4. I pay attention to the emotions of others } \\
5 . \quad \text { I am a good listener } \\
\text { 6. I enjoy getting to know others profoundly } \\
\text { 7. I notice when someone is in trouble } \\
\text { 8. I sense when others get irritated }\end{array}$ & $\begin{array}{l}\text { Adapted from Multicultural } \\
\text { Personality Questionnaire } \\
\text { (Van Der Zee \& Van } \\
\text { Oudenhoven, 2000) } \\
\text { Alpha }=0.78\end{array}$ \\
\hline Trust & $\begin{array}{l}\text { Trust is defined as the } \\
\text { willingness of a party to be } \\
\text { vulnerable to the actions of } \\
\text { another party based on the } \\
\text { expectation that the other } \\
\text { will perform a particular } \\
\text { action important to the } \\
\text { trustor, irrespective of the } \\
\text { ability to monitor or control } \\
\text { that other party (Mayer et } \\
\text { al. 1995) }\end{array}$ & $\begin{array}{l}\text { Read each statement and select the response that best describes } \\
\text { your capabilities. } \\
\text { Select the answer that BEST describes you AS YOU REALLY } \\
\text { ARE ( } 1 \text { = strongly disagree; } 5=\text { strongly agree). } \\
\text { The trustee is whom you are working with } \\
\text { Ability } \\
\text { 1. [The Trustee] is very capable of performing their job. } \\
\text { 2. [The Trustee] is known to be successful at the thing they } \\
\text { try to do. } \\
\text { 3. [The Trustee] has much knowledge about the work that } \\
\text { needs to be done. } \\
\text { 4. I feel very confident about [The Trustee] 's skills. } \\
\text { Benevolence } \\
\text { 1. [The Trustee] is very concerned about my welfare. }\end{array}$ & $\begin{array}{l}\text { Adapted from } \\
\text { Colquitt et al. (2007); } \\
\text { Mayer and Davis (1999) } \\
\text { Alpha }=.85 \text { to } .88 \text { (Ability) } \\
\text { Alpha }=.87 \text { to } .89 \\
\text { (Benevolence) } \\
\text { Alpha }=.82 \text { to } .88 \text { (Integrity) }\end{array}$ \\
\hline
\end{tabular}




\begin{tabular}{|c|c|c|c|}
\hline Construct & Definition & Survey Items (Scale) & Citations \\
\hline & & 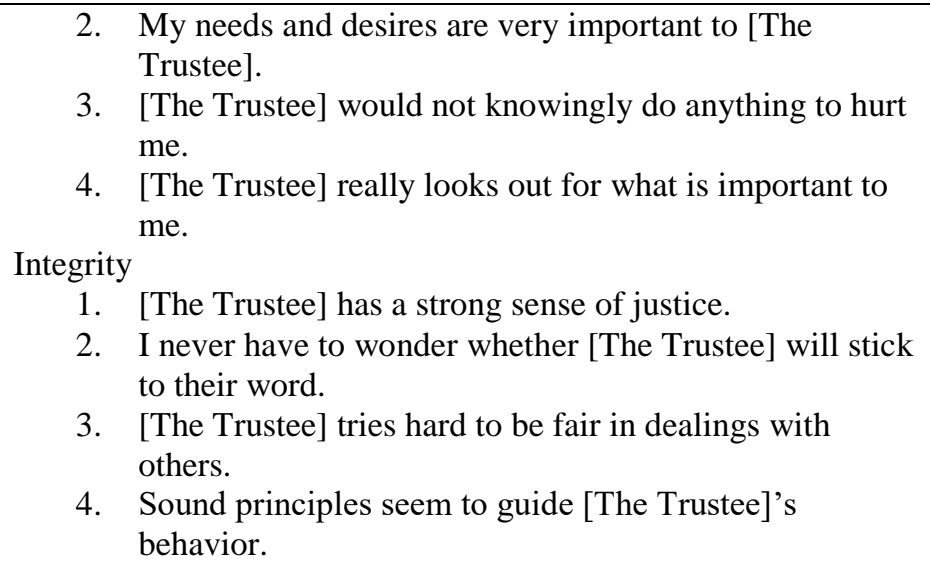 & \\
\hline Social Desirability & $\begin{array}{l}\text { Whether the participant } \\
\text { feels that socially desirable } \\
\text { characteristics are always } \\
\text { true of them. }\end{array}$ & $\begin{array}{ll}\text { 1. I never lie } \\
2 . & \text { I never get angry } \\
3 . & \text { I tell the truth every single time } \\
4 . & \text { I am always good }\end{array}$ & $\begin{array}{l}\text { Reynolds and Paget (1983), } \\
\text { "National normative and } \\
\text { reliability data for the Revised } \\
\text { Children's Manifest Anxiety } \\
\text { Scale." }\end{array}$ \\
\hline $\begin{array}{l}\text { Demographic } \\
\text { Information }\end{array}$ & \multicolumn{3}{|c|}{$\begin{array}{ll}\text { 1. } & \text { Gender: Male/Female } \\
\text { 2. Years' Experience: } \\
\text { 3. Nationality (Project Globe classifications) } \\
\text { 4. Age: } \\
\text { 5. Education: High School, University, Graduate School } \\
\text { 6. Sector: Academic, Private Sector, Public Sector and Non-Government Organizations (NGO) }\end{array}$} \\
\hline
\end{tabular}




\section{REFERENCES}

Alaska Sea Grant Marine Advisory Program. n.d. Sea level rise and storm surge: Available from https://seagrant.uaf.edu/map/climate/docs/sea-level.php.

Allianz Global Corporate \& Specialty SE. 2014. Allianz Safety and Shipping Review: 26.

Ang, S., \& Van Dyne, L. 2008. Conceptualization of cultural intelligence: Definition, distinctiveness, and nomological network. In S. Ang, \& L. Van Dyne (Eds.),

Handbook of cultural intelligence: Theory, measurement, and applications: 3-15. New York: M.E. Sharpe.

Ang, S., Van Dyne, L., Koh, C., Ng, K. Y., Templer, K. J., Tay, C., \& Chandrasekar, N. A. 2007. Cultural intelligence: Its measurement and effects on cultural judgment and decision making, cultural adaptation and task performance. Management and Organization Review, 3(3): 335-371.

Bass, B. M. 1985. Leadership and performance beyond expectations. Free Press; Collier Macmillan.

Bird, K. J., Charpentier, R. R., Gautier, D. L., Houseknecht, D. W., Klett, T. R., Pitman, J. K., Moore, T. E., Schenk, C. J., Tennyson, M. E., \& Wandrey, C. R. 2008. CircumArctic resource appraisal: Estimates of undiscovered oil and gas north of the Arctic Circle: United States Geological Survey (USGS).

Bouncken, R. B., \& Winkler, V. A. 2010. National and cultural diversity in transnational innovation teams. Technology Analysis \& Strategic Managment, 22(2): 133-151.

Bouwen, R., \& Taillieu, T. 2004. Multi-party collaboration as social learning for interdependence: Developing relational knowing for sustainable natural resource management. Journal of Community \& Applied Social Psychology, 14(3): 137-153.

Boyatzis, R. E., \& Akrivou, K. 2006. The ideal self as the driver of intentional change. Journal of Management Development, 25(7): 624-642.

Boyatzis, R. E., Rochford, K., \& Taylor, S. N. 2015. The role of the positive emotional attractor in vision and shared vision: Toward effective leadership, relationships, and engagement. Frontiers in Psychology, 6: 670.

Cheek, J. M., Smith, S., \& Tropp, L. R. 2002. Relational identity orientation: A fourth scale for the AIQ Paper presented at the meeting of the Society for Personality and Social Psychology, Savannah, GA.

Chevrier, S. 2003. Cross-cultural management in multinational project groups. Journal of World Business, 38(2): 141-149. 
Colquitt, J. A., Scott, B. A., \& LePine, J. A. 2007. Trust, trustworthiness, and trust propensity: A meta-analytic test of their unique relationships with risk taking and job performance. Journal of Applied Psychology, 92(4): 909-927.

Congden, S. W., Matveev, A. V., \& Desplaces, D. E. 2009. Cross-cultural communication and multicultural team performance: A German and American comparison. Journal of Comparative International Management, 12(2): 73-89.

Connor, W. 1993. Beyond reason: The nature of the ethnonational bond. Ethnic and Racial Studies, 16(3): 373-389.

Davis, M. H. 1983. Measuring individual differences in empathy: Evidence for a multidimensional approach. Journal of Personality and Social Psychology, 44(1): 113-126.

Edmondson, A. C. 2012. Teaming: How organizations learn, innovate, and compete in the knowledge economy. San Francisco, CA: Jossey-Bass.

Edmondson, A. C., \& Nembhard, I. M. 2009. Product development and learning in project teams: the challenges are the benefits*. Journal of Product Innovation Management, 26(2): 123-138.

Elenkov, D. S., \& Manev, I. M. 2009. Senior expatriate leadership's effects on innovation and the role of cultural intelligence. Journal of World Business, 44(4): 357-369.

Emmerson, C. 2010. The Future History of the Arctic. New York, NY: Public Affairs.

Fornell, C., \& Larcker, D. F. 1981. Evaluating structural equation models with unobservable variables and measurement error. Journal of Marketing Research, 18(1): 39-50.

Garcia-Morales, V. J., Llorens-Montes, F. J., \& Verdú-Jover, A. J. 2006. Antecedents and consequences of organizational innovation and organizational learning in entrepreneurship. Industrial Management \& Data Systems, 106(1): 21-42.

Gergen, K. J. 2007. Relativism, religion, and relational being. Common Knowledge, 13(2): 362-378.

Greenert, J. W. 2014. The United States Navy Arctic Roadmap for 2014 to 2030: Office of the Chief of Naval Operations. Washington DC, Dtic Document.

Gutiérrez Gutiérrez, L. J., Lloréns-Montes, F. J., \& Bustinza Sánchez, Ó. F. 2009. Six sigma: From a goal-theoretic perspective to shared-vision development. International Journal of Operations \& Production Management, 29(2): 151-169.

Hair, J. F., Black, W. C., Babin, B. J., \& Anderson, R. E. 2010. Multivariate data analysis (7th ed.). Upper Saddle River, NJ: Pearson Prentice Hall 
Hall, K. L., Stokols, D., Moser, R. P., Taylor, B. K., Thornquist, M. D., Nebeling, L. C., Ehret, C. C., Barnett, M. J., McTiernan, A., \& Berger, N. A. 2008. The collaboration readiness of transdisciplinary research teams and centers: Findings from the National Cancer Institute's TREC year-one evaluation study. American Journal of Preventive Medicine, 35(2): S161-S172.

Hayes, N. 1997. Successful team management. Thomson Learning.

Hemsath, J. R. 2015. Looking beyond culture: Building successful multiparty collaboration. Unpublished Qualitative Research Report. Case Western Reserve University, Cleveland, $\mathrm{OH}$.

Hofstede, G. 1997. Cultures and organzations: Software of the mind. New York, NY: McGraw-Hill.

House, R., Javidan, M., Hanges, P., \& Dorfman, P. 2002. Understanding cultures and implicit leadership theories across the globe: an introduction to project GLOBE. Journal of World Business, 37(1): 3-10.

Hu, L. t., \& Bentler, P. M. 1999. Cutoff criteria for fit indexes in covariance structure analysis: Conventional criteria versus new alternatives. Structural Equation Modeling: A Multidisciplinary Journal, 6(1): 1-55.

Jarvis, C. B., MacKenzie, S. B., \& Podsakoff, P. M. 2003. A critical review of construct indicators and measurement model misspecification in marketing and consumer research. Journal of Consumer Research, 30(2): 199-218.

Kaiser, A., Feldhusen, B., \& Fordinal, B. 2013. Vision development as a knowledge creating process Paper presented at the 2013 46th Hawaii International Conference on System Sciences (HICSS). 3593-3602.

Katz, B., \& Wagner, J. 2014. The rise of innovation districts: A new geography of innovation in america. Brookings Institution.

Lee, R. M., Draper, M., \& Lee, S. 2001. Social connectedness, dysfunctional interpersonal behaviors, and psychological distress: Testing a mediator model. Journal of Counseling Psychology, 48(3): 310-318.

Luhtanen, R., \& Crocker, J. 1992. A collective self-esteem scale: Self-evaluation of one's social identity. Personality and Social Psychology Bulletin, 18(3): 302-318.

Marquardt, M. J., \& Horvath, L. 2014. Global teams: How top multinationals span boundaries and cultures with high-speed teamwork. Nicholas Brealey Publishing.

Matveev, A. V., \& Nelson, P. E. 2004. Cross cultural communication competence and multicultural team performance perceptions of American and Russian managers. International Journal of Cross Cultural Management, 4(2): 253-270. 
Mayer, R. C., \& Davis, J. H. 1999. The effect of the performance appraisal system on trust for management: A field quasi-experiment. Journal of Applied Psychology, 84(1): 123-136.

Mayer, R. C., Davis, J. H., \& Schoorman, F. D. 1995. An integrative model of organizational trust. Academy of Management Review, 20(3): 709-734.

Mitroff, I. I., \& Denton, E. A. 1999. A study of spirituality in the workplace. MIT Sloan Management Review, 40(4): 83.

Oswald, S. L., Mossholder, K. W., \& Harris, S. G. 1994. Vision salience and strategic involvement: Implications for psychological attachment to organization and job. Strategic Management Journal, 15(6): 477-489.

Podsakoff, P. M., MacKenzie, S. B., Lee, J.-Y., \& Podsakoff, N. P. 2003. Common method biases in behavioral research: a critical review of the literature and recommended remedies. Journal of Applied Psychology, 88(5): 879-903.

Prins, S. 2010. From competition to collaboration: Critical challenges and dynamics in multiparty collaboration. Journal of Appiced Behavioral Science, 46(3): 281-312.

Prins, S., \& Bouwen, R. 2003. Distributed leadership in multiparty collaboration: Opportunities and challenges for leadership in the space-in-between organizations, Holland.

Reynolds, C. R., \& Paget, K. D. 1983. National normative and reliability data for the revised Children's Manifest Anxiety Scale. School Psychology Review, 12: 324-336.

Ruben, B. D. 1976. Assessing communication competency for intercultural adaptation. Group \& Organization Management, 1(3): 334-354.

Swann, J., William B, Jetten, J., Gómez, A., Whitehouse, H., \& Bastian, B. 2012. When group membership gets personal: A theory of identity fusion. Psychological Review, 119(3): 441.

Tajfel, H., \& Turner, J. C. 1979. An integrative theory of intergroup conflict. In W. G. Austin, \& S. Worchel (Eds.), The social psychology of intergroup relations: 33-47. Monterey, CA: Brooks-Cole.

Trompenaars, F., \& Hampden-Turner, C. 1998. Riding the waves of culture (second ed.). New York, NY: McGraw-Hill.

Tsai, W., \& Ghoshal, S. 1998. Social capital and value creation: The role of intrafirm networks. Academy of Management Journal, 41(4): 464-476. 
Van Der Zee, K. I., \& Van Oudenhoven, J. P. 2000. The Multicultural Personality Questionnaire: A multidimensional instrument of multicultural effectiveness. European Journal of Personality, 14(4): 291-309.

Van Dyne, L., Ang, S., Ng, K. Y., Rockstuhl, T., Tan, M. L., \& Koh, C. 2012. Subdimensions of the four factor model of cultural intelligence: Expanding the conceptualization and measurement of cultural intelligence. Social and Personality Psychology Compass, 6(4): 295-313.

Van Oosten, E. B. 2006. Intentional change theory at the organizational level: a case study. Journal of Management Development, 25(7): 707-717. 